\title{
Annual Report for NERI Proposal \#2000- 0109 on Forewarning of Failure in Critical Equipment at Next-Generation Nuclear Power Plants
}

September 2001

\author{
L. M. Hively \\ V. A. Protopopescu \\ M. Maghraoui \\ J. W. Spencer
}




\title{
DOCUMENT AVAILABILITY
}

Reports produced after January 1, 1996, are generally available free via the U.S. Department of Energy (DOE) Information Bridge:

Web site: http://www.osti.gov/bridge

Reports produced before January 1, 1996, may be purchased by members of the public from the following source:

\author{
National Technical Information Service \\ 5285 Port Royal Road \\ Springfield, VA 22161 \\ Telephone: 703-605-6000 (1-800-553-6847) \\ TDD: 703-487-4639 \\ Fax: 703-605-6900 \\ E-mail: info@ntis.fedworld.gov \\ Web site: http://www.ntis.gov/support/ordernowabout.htm
}

Reports are available to DOE employees, DOE contractors, Energy Technology Data Exchange (ETDE) representatives, and International Nuclear Information System (INIS) representatives from the following source:

Office of Scientific and Technical Information

P.O. Box 62

Oak Ridge, TN 37831

Telephone: $865-576-8401$

Fax: 865-576-5728

E-mail: reports@adonis.osti.gov

Web site: http://www.osti.gov/contact.html

This report was prepared as an account of work sponsored by an agency of the United States Government. Neither the United States government nor any agency thereof, nor any of their employees, makes any warranty, express or implied, or assumes any legal liability or responsibility for the accuracy, completeness, or usefulness of any information, apparatus, product, or process disclosed, or represents that its use would not infringe privately owned rights. Reference herein to any specific commercial product, process, or service by trade name, trademark, manufacturer, or otherwise, does not necessarily constitute or imply its endorsement, recommendation, or favoring by the United States Government or any agency thereof. The views and opinions of authors expressed herein do not necessarily state or reflect those of the United States Government or any agency thereof. 
ORNL/TM-2001/195

\title{
ANNUAL REPORT FOR NERI PROPOSAL \#2000-0109 ON FOREWARNING OF FAILURE IN CRITICAL EQUIPMENT AT NEXT-GENERATION NUCLEAR POWER PLANTS
}

\author{
L. M. Hively \\ V. A. Protopopescu \\ Oak Ridge National Laboratory \\ P.O. Box 2009 \\ Oak Ridge, Tennessee 37831-6355 \\ M. Maghraoui \\ J. W. Spencer \\ Duke Engineering and Services, Inc. \\ P.O. Box 65415 \\ Charlotte, North Carolina 28265-0415
}

September 2001

\author{
Prepared by \\ OAK RIDGE NATIONAL LABORATORY \\ P. O. Box 2008 \\ Oak Ridge, Tennessee 37831-6285 \\ managed by \\ UT-Battelle, LLC \\ for the
}

U. S. DEPARTMENT OF ENERGY

under contract DE-AC05-00OR22725 



\section{CONTENTS}

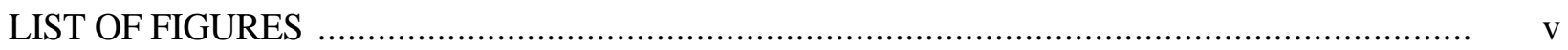

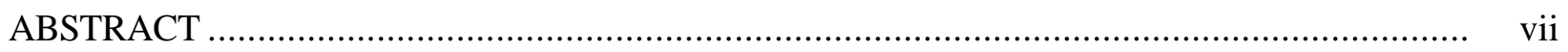

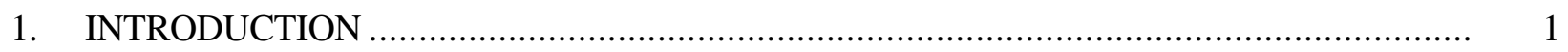

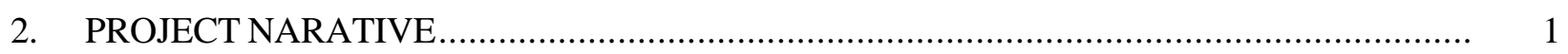

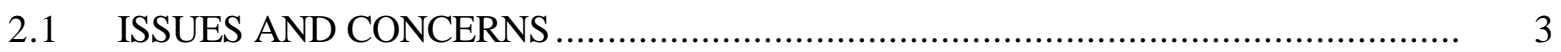

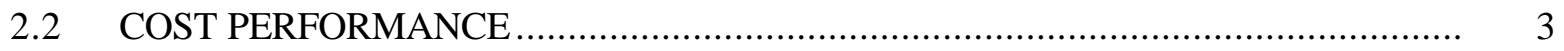

2.3 STATUS SUMMARY FOR FIRST PROJECT YEAR.............................................. 4

3. TECHNICAL APPROACH AND RESULTS ..................................................... 5

$3.1 \quad$ BACKGROUND.................................................................................. 5

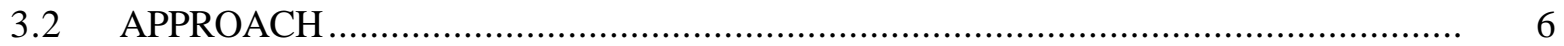

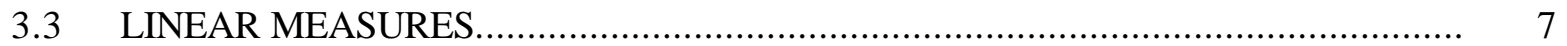

3.4 TRADITIONAL NONLINEAR MEASURES …............................................. 8

3.5 PHASE-SPACE DISSIMILARITY MEASURES ................................................. 11

3.6 VALIDATION OF PHASE-SPACE DISSIMILARITY OF MODEL DATA .............. 14

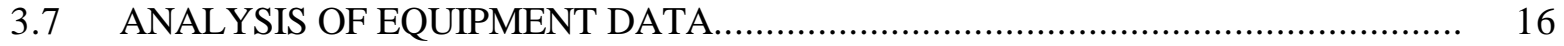

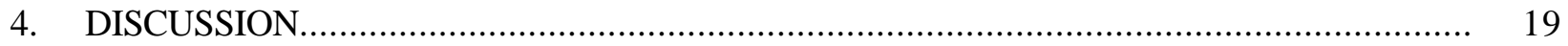

ACKNOWLEDGMENTS ................................................................................... 20

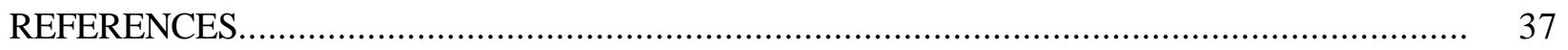

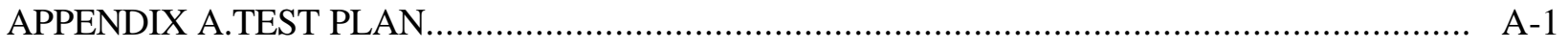





\section{LIST OF FIGURES}

Figure $\quad$ Page

1 Phase-space plots for the Lorenz system.................................................................. 21

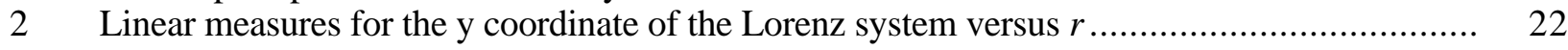

3 Renormalized nonlinear measures versus $r$ for the y coordinate of the Lorenz system............. 23

4 Renormalized nonlinear measures versus $r$ for the y coordinate of the Lorenz system with

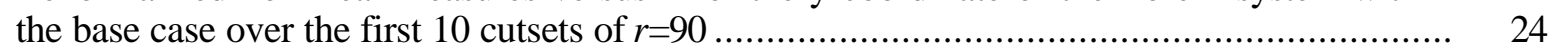

5 Renormalized nonlinear measures versus $r$ for the y coordinate of the Lorenz system............ 25

6 Important features of the test equipment (5HP motor-driven pump) at the DE\&S testing facility in Mount Holly, North Carolina............................................................................. 26

7 Use of the zero-phase quadratic filter for removal of high-frequency noise from typical power data from the base line unbalance test ................................................................ 27

8 Various linear measures of the unbalance power data as a function of the dataset number....... 28

9 Traditional nonlinear measures of the unbalance power data as a function of the dataset number

10 Correlation of phase-space dissimilarity measures of vibration levels as a function of the

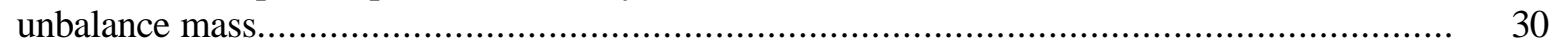

11 Illustration of misalignment between motor and pump ......................................... 31

12 Various linear measures of the misalignment power data as a function of the dataset number

13 Traditional nonlinear measures of the misalignment power data as a function of the dataset number

14 Correlation of phase-space dissimilarity measures and vibration levels as a function of the unbalance mass. 



\begin{abstract}
This annual report describes the first year's accomplishments under the NERI2000-109 project. We present a model-independent approach to quantify changes in the nonlinear dynamics underlying timeserial data. From time-windowed data sets, we construct discrete distribution functions on the phase space. Condition change between base case and test case distribution functions is assessed by dissimilarity measures via $L_{1}$-distance and $\chi^{2}$ statistic. The discriminating power of these measures is first tested on noiseless model data, and then applied for detecting dynamical change in power from a motorpump system. We compare the phase-space dissimilarities with traditional linear and nonlinear measures used in the analysis of chaotic systems. We also assess the potential usefulness of the new measures for robust, accurate, and timely forewarning of equipment failure.
\end{abstract}





\section{INTRODUCTION}

This NERI Project began in August 2000. The project has three tasks. The first (current) project year involves only Task 1, namely development of nonlinear prognostication for failures in critical equipment at nuclear power facilities. Examples of such equipment include blowers, compressors, fans, vacuum pumps, cooling units, generators, invertors, motor generators, governors, couplings, gearboxes, motors (electric, hydraulic, pneumatic), pumps, valve operators, and turbines. This annual report describes the work status for the first year of the project, spanning August 2000 through August 2001. Tasks 2-3 span the second (FY 2002) and third (FY 2003) project years, and will not be discussed in this annual report. Section 2 describes the status of the tasks, issues/concerns for each task, cost performance, and status summary of tasks. Section 3 discusses the detailed technical aspects of the work, including the technical background, traditional linear and nonlinear analysis, phase-space dissimilarity analysis, validation of the dissimilarity measures for model data, and analysis of equipment data. Section 4 presents the conclusions of this year's work and summarizes the expectations for the second year's work.

\section{PROJECT NARRATIVE}

This narrative begins by explaining the project subtasks from the NERI2000-109 proposal for the first project year. These subtasks are listed in the same order as in the proposal, for easy reference.

Task 1.1 of our proposal is as follows. A database of diagnostic data sets will be assembled from historical or newly acquired data. We will first locate occurrences of the most significant failures, and then assemble the associated diagnostic data. This data will begin with the failure occurrence, and extend backward in time to the baseline period. The data sets will then be analyzed via linear measures for obvious trends.

Under Task 1.1, time and funding constraints for the first project year did not allow long-term failure monitoring of nuclear power plant equipment. Instead, we acquired new data via accelerated failure tests by seeding specific faults in test equipment. In consultation with the Oak Ridge National Laboratory (ORNL), DE\&S constructed a test plan, which includes a summary of important-to-safety equipment in nuclear power pants; the choice of two test modes (unbalance and misalignment); the DE\&S testing

facility; detailed specifications of the equipment to be tested; the test protocol; and specifications of the data acquisition equipment. Appendix A contains the full test plan, which was completed in the third project quarter. DE\&S provided sample test data to ORNL for preliminary analysis. ORNL analyzed this data and found a rich set of nonlinear features. The sampling rate was adequate $(12.5 \mathrm{KHz})$, but the number of data points was too small (16,384 points). ORNL needed voltages and currents from all three phases of the three-phase electric motor, for conversion to instantaneous power. ORNL also needed longer datasets. These requirements necessitated an upgrade to the data acquisition system (Emax by PdMA Corporation), causing some delay while PdMA modified their software. DE\&S subsequently received the upgrades and provided the test data for the two test sequences. Total payments to DE\&S were $\$ 49,906.40$ under the subcontract (versus an allocated cost of $\$ 50 \mathrm{~K}$ ), as follows: $\$ 5,536.00$ on December 7, 2000, for preliminary test data; $\$ 6,529.20$ on January 4, 2001, for testing options; $\$ 11,139.28$ on February 12, 2001, for the test plan; $\$ 14,436.32$ on March 16, 2001, for equipment specifications; $\$ 12,265.60$ on June 6, 2001, for test data.

Task 1.2 of our proposal is as follow. The diagnostic data from Task 1.1 will be analyzed for the adequacy of data quality for subsequent nonlinear analysis. ORNL experience indicates that inadequate data quality produces inferior or unusable results. This analysis will evaluate the data-sampling rate, 
digitization precision, number of points per dataset, frequency response of the sensors, and related elements. Adequate quality data typically has $\geq 20,000$ data points, sampled at $\geq 10$ times the fundamental rotational frequency over $\geq 1$ second at $\geq 6$ bits of digitization precision. If the existing historical diagnostic data is determined to be of insufficient quality, changes in the data acquisition methods will be instituted to produce data that is capable of being analyzed by the nonlinear methods. This task will be performed by ORNL.

Under Task 1.2, ORNL performed quality checks of the test data. The table below summarizes the data quality checks that we performed. ORNL identified three misalignment datasets with ranges of instantaneous power that far exceeded the others. DE\&S confirmed these findings, and determined that the problem was due to a memory limitation in the Emax system for more than two sequential datasets. DE\&S corrected the problem by rebooting the Emax system. DE\&S provided replacement datasets of adequate data quality to ORNL.

Brief description of the data quality check for each dataset For good quality data, result should be

- proper number of data points 500,000

- any intervals(s) with unchanged signal amplitude

no

- adequate sampling rate

no

- excessive periodic content

no

- excessive noise

no

- saturation at high/low limits (indicator of improper amplification) no

- consistent signal amplitude across multiple datasets in the test yes

Task 1.3 of the proposal is as follows. Each set of adequate-quality diagnostic data from Task 1.2 will be analyzed with the nonlinear paradigm to determine the presence of a statistically significant condition change indication. This analysis will also determine the characteristics of the PS-DF associated with each specific failure type. This task will be performed by ORNL.

Task 1.4 of the proposal is as follows. A library of PS-DF types and their correlated failure types will be developed for subsequent correlation to unknown failures by means of the nonlinear characteristics. This task will be performed by ORNL.

Task 1.5 of the proposal is as follows. The extent of PS-DF changes, via the measures of dissimilarity, will be associated with the time remaining until observed failure for the observed failure events. This correlation will be used subsequently to indicate the assessment of remaining condition of the equipment. This task will be performed by ORNL.

ORNL used a research-class FORTRAN code that performs Tasks 1.3-1.5 as an integrated sequence of algorithmic operations on both the misalignment data and the imbalance data from DE\&S. The analysis converts time-serial, process-indicative data into a discretized phase-space (PS) representation. The resulting distribution function (DF) captures the location and occurrence frequency for the nonlinear process dynamics. Dissimilarity measures indicate departure of the test case DF from the baseline DF as an underlying system parameter changes. Forewarning of failure corresponds to a statistically significant rise in dissimilarity, as to the desired outcome of Task 1.3. The library under Task 1.4 is formed by the sequence of PS-DFs for the misalignment and unbalance tests. Correlation of the dissimilarity measures with the failures was performed by reference to the ISO standards 2372 and 3945, as the desired outcome for Task 1.5. Sections 3.2 and 3.4 of this report describe this analysis in detail.

Task 1.6 of the proposal follows. This task will involve the robust implementation of the nonlinear analysis algorithms for near-real-time analysis of equipment data. Specifically, ORNL will implement the nonlinear paradigm on a desktop computer, which will be placed at an appropriate DE\&S site for use by 
the reactor operators there. This mode of on-site data acquisition and diagnosis will be similar to the mode of operation for equipment prognostication at an advanced nuclear reactor. This task will focus on algorithm changes that minimize the memory requirements and maximize computational speed.

ORNL procured and set up a Win2000 1.3GHz Athlon PC with 1.5GB of memory and two 81 GB hard drives. The PC also has Ethernet capability, keyboard, mouse, video board, read-only CD-ROM, and data archival capability (100MB Zip drive and re-writable CD-ROM). An existing 15" monitor at ORNL was used to display the results. A new Compaq FORTRAN compiler was procured for this computer. Procurement costs totaled $\$ 3,026$. Sample analyses for Sec. 3.6 from an existing $500 \mathrm{MHz}$ Pentium II computer were reproduced exactly on the new machine, demonstrating the robustness of the FORTRAN algorithm in moving across processors (Pentium II to Athlon) and different operating systems (WinNT to Win2000). The new PC is 2.42 times faster than the older machine, consistent with the proportionately faster processor speed $(1.3 \mathrm{GHz} / 500 \mathrm{MHz}=2.6)$. The new $\mathrm{PC}$ has not been transferred to DE\&S because on-site data acquisition of operational data is not anticipated for the second project year. This new computer will significantly enhance ORNL's analysis capability for this project.

\subsection{ISSUES AND CONCERNS}

Analysis of preliminary test data identified a need for longer datasets and more data channels, as explained in the narrative for Task 1.1. ORNL requested that DE\&S obtain an upgrade the Emax software from PdMA Corporation to meet these requirements, causing a delay in the test plan and diagnostic data acquisition, as described above. Project spending has not risen linearly, also due to this delay in data acquisition. Consequently, we anticipate that \$30-40K of FY 2001 funds will not be spent in the first project year. We have requested that Phil Wong (Oakland Operations Office) authorize carryover of these funds into FY 2002. We expect to use this carry-over funding for more detailed nonlinear analysis of the test data.

\subsection{COST PERFORMANCE}

We received $\$ 157,000$ for the first project year on August 18, 2000. Total costs through the fourth fiscal quarter of the first project year (August 2000 through August 2001) are \$97,725. We anticipate that spending through the end of FY 2001 will leave \$30-40K of carry-over into FY 2002, as shown in the plot of project costs versus time below. The dashed (- -) curve from months 12-15 shows subsequent expected costs, versus nominal linear spending versus time in the solid curve $(-)$. 


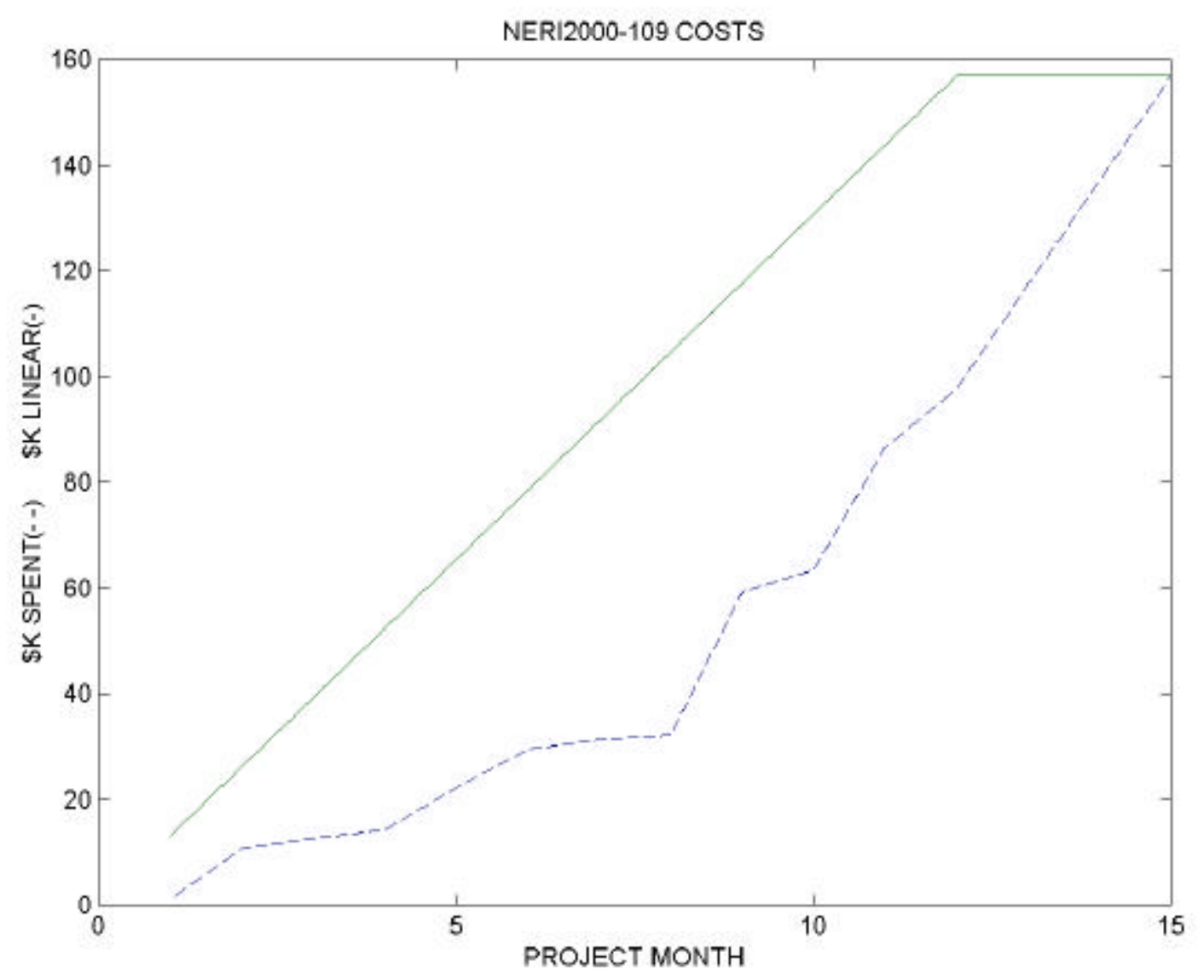

\subsection{STATUS SUMMARY FOR FIRST PROJECT YEAR}

\begin{tabular}{|c|c|c|}
\hline Milestone/task description & $\begin{array}{c}\text { Planned } \\
\text { completion } \\
\text { date }\end{array}$ & $\begin{array}{c}\text { Actual } \\
\text { completion } \\
\text { date }\end{array}$ \\
\hline Task 1.1: ORNL set subcontract in place for DE\&S & $09 / 00$ & $10 / 00$ \\
DE\&S provide preliminary test data to ORNL & $09 / 00$ & $02 / 01$ \\
DE\&S construct test plan for accelerated testing & $11 / 00$ & $04 / 01$ \\
DE\&S provide datasets to ORNL & $01 / 01$ & $06 / 01$ \\
\hline Task 1.2: ORNL analyze quality of DE\&S test data & $02 / 01$ & $06 / 01$ \\
DE\&S provide replacement datasets for any found inadequate & $02 / 01$ & $06 / 01$ \\
\hline Task 1.3: ORNL perform condition change analysis on data & $08 / 01$ & $08 / 01$ \\
\hline Task 1.4: ORNL construct library of nonlinear condition change signatures & $08 / 01$ & $08 / 01$ \\
\hline Task 1.5: ORNL correlate condition change to approaching failure & $08 / 01$ & $08 / 01$ \\
\hline Task 1.6: ORNL procure new computer & $08 / 01$ & $05 / 01$ \\
ORNL implement nonlinear analysis software on new PC & $08 / 01$ & $06 / 01$ \\
\hline
\end{tabular}




\section{TECHNICAL APPROACH AND RESULTS}

\subsection{BACKGROUND}

The Advanced Technology Program (ATP) of the National Institute of Standards and Technology (NIST) held a workshop on Condition-Based Maintenance (CBM) during its November 17-18, 1998 fall meeting in Atlanta, Georgia [NIST, 1998]. Workshop participants identified three technical barriers to widespread CBM: (i) the inability to predict the remaining useful life of a machine accurately and reliably; (ii) a lack of continuous machine monitoring; and (iii) the need for decision systems to learn impending failures, and to recommend what action to take. These barriers could potentially be addressed through innovations in three technical areas: (i) prognostication capabilities, (ii) cost effective sensor and monitoring systems, and (ii) reasoning or expert systems. Decision models should accommodate changes in mission compliance, operational environment, economic rules, priority assessments, and functional requirements. The need for decision infrastructure is being addressed by a separate NERI project [Harmon, et al., 2001] that includes DE\&S, which is also collaborating on this NERI project.

This NERI2000-109 project addresses the first need for technical innovation (prognostication) via nonlinear analysis of equipment operational data. The NIST/ATP workshop [NIST, 1998] identified high quality diagnostics and sensor information as essential for prognostication. Indeed, data is needed not only for prognostication, but also for training and validating the decision methodology. Workshop participants placed a very high priority on quality and completeness of data sets. The barriers to achieving these goals include: (a) incomplete understanding of the evolution of faults and how they effect equipment; (b) non-robust state-based modeling techniques to develop understanding of physics of failures (reduced order modeling); (c) and lack of predictive methodologies for unsteady signatures that are indicative of physics-based failure modes; (d) ignorance about controlling parameters, which hampers development of accurate models; and (e) unavailability of test facilities, especially replication of the real operating environment. Our NERI2000-109 project addresses items (a)-(c) by quantifying the (nonstationary) condition change in test equipment as a sequence of robust nonlinear statistical signatures for progression of a (seeded) fault in specific test equipment. This project addresses item (d) by associating the change in the controlling parameter (seeded fault) with the equipment response. This project addresses (e) by tests of nuclear-grade equipment at the DE\&S facilities, which are very similar to real plant conditions. We use hypothesis testing to demonstrate these capabilities, as discussed in detail below.

We expect that regulatory criteria from the U.S. Nuclear Regulatory Commission (NRC) will continue to govern operation and safety in next generation Nuclear Power Plant (NPP). The NRC identifies three strategic areas for the reactor oversight process [NRC, 2000]: reactor safety, radiation safety (including occupational and public safety) and safeguards (physical protection). Reactor safety relies on mitigating systems, barrier integrity, and emergency preparedness to respond to initiating events (unplanned reactor shutdowns, loss of normal reactor cooling after an unplanned shutdown, and unplanned events that result in significant changes in reactor power). Failure prognostication is intended primarily to forecast initiating events in operational equipment, and secondarily to forewarn of failures in mitigating (safety) systems.

Plant processes evolve from normal to abnormal conditions with an accompanying display of rich dynamics, including multiple time scales, quasi-periodicity, nonlinearity, and chaos. Usually, such systems: have many components with hierarchical structure, are driven by various competing forces, and interact strongly with noisy and/or nonstationary environments. Quantitative analysis of the corresponding time serial data has been a difficult and frustrating problem for diagnosis of the degradation, fault, or failure. Key issues include: (i) lack of a proper (physical) model, forcing the analyst 
to view signals as generated by a black box whose internal mechanism is either poorly understood, or not understood at all; (ii) non-stationary signals, i.e., with statistical properties that change significantly over the observation period with changes not known a priori and not explicitly advertised; (iii) nonlinear structure of various component dynamics and their complex, intricate interconnection, rich in feedbacks and hysteresis; (iv) rarely functioning at steady state, and more typically occurring far from equilibrium via continuous feedback-control loop(s) to adjust to changing conditions.

\subsection{APPROACH}

One of the most important problems encountered in nonlinear time-series analysis is the appropriate characterization of features and events in nonlinear systems' dynamics. Often these features are either described by several different quantities or do not have a precise definition at all. The former category includes: (content of) information, (relative) entropy, and synchrony. Examples of the latter group are: coherence, patterns, or complexity. These features may have various origins, such as nonstationarity, nonlinearity, nonequilibrium, and intertwining of length- and time-scales. The presence of any one of these factors frequently introduces erratic fluctuations, patchiness, lack of obvious structure, or other irregularities. Previously, these irregularities have been neglected as noise without much structure and meaning. Recent advances in nonlinear science have facilitated the interpretation of intermediate and small-scale details as bona fide structure, with significant information about the underlying dynamics. Analysis of this structure enables a deeper understanding of basic dynamical features of system, and results in more efficient assessment, prediction, prevention, control, and repair of their malfunctions.

We address the forewarning problem within a purely pragmatic approach geared at designing, testing, and implementing such measures. We base this approach on a set of nested assumptions that we retain or discard by: (a) the Occam's razor (i.e. start with a simple explanation before resorting to a complicated one); (b) consideration of falsifiable hypotheses only; and (c) acceptance of operationally realizable tests only. In a more or less decreasing order of generality, the assumptions underlying our approach are:

(i) For a broad range of circumstances, the motor-pump system behaves as a finite-dimensional nonlinear, possibly chaotic dynamical system. This assumption underlies all efforts of modeling such systems by a system of coupled nonlinear evolution equations, for which relevant dynamics occur on a bounded, finite dimensional region of the phase space (PS), called an attractor. Moreover, under assumption (i), we do not attempt to answer questions about nonstationarity or nonequilibrium. Indeed, statistical tests for stationarity produce a binary result, namely, they indicate whether a change occurred, but provide no information about the extent of departure from one state to another. Stationarity tests also have limited value for inherently nonstationary processes that undergo changes in dynamics. For such nonstationary processes, a measure of dissimilarity that quantifies the "distance" between attractors turns out to be more useful [Schreiber, 1997; Moeckel and Murray, 1997; Schreiber, 1999]. This approach is closely related to testing hypotheses of chaotic fluctuations by comparing the "spatial distance" in phase space between observed time series and theoretical attractors [Bjernstad and Grenfell, 2001; Cushing et al. 1998]. Such phase-space comparisons also provide a robust criterion for estimating model parameters [Bjernstad and Grenfell 2001; Ellner and Seifu, in press].

(ii) Time-serial power data captures the main features of nonlinear equipment dynamics. Recent studies show that different observables do not capture the same amount and/or quality of information [Letellier et al., 1998]. Obviously, this result has momentous implications for forewarning analysis. In the absence of a model, the "correct" choice among apparently equivalent channels can be assessed only a posteriori. 
(iii) The first two assumptions are easy to understand and are well documented in the literature, allowing the use of nonlinear dynamical methods for time-series analysis. Global aspects of the equipment dynamics can be adeptly captured, characterized, and discriminated by nonlinear descriptors such as Lyapunov exponents, Kolmogorov entropy, correlation dimension, etc. [Qu et al., 1993]. Straightforward methods exist [Eckmann and Ruelle, 1985; Abarbanel, 1996; Cover et al., 1997] for discriminating between regular and chaotic motion, or for detecting the transition between these regimes. However, distinguishing different chaotic regimes can be very difficult, especially when data are limited and noisy.

(iv) The PS parameters can be adequately chosen for equipment failure forewarning. In addition to implicitly relying on the validity of (i)-(iii), this assumption constrains the length and quality of the data.

(v) No significant correlation exists between the base case and the failure event, and thus no time relationship between the physical state of the base case and event. This assumption simply implies that the characteristic time of the underlying equipment dynamics is much shorter than the time interval between the "normal" (base case) regime and the onset of the abnormal behavior. We shall see in Sec. 3.6 the effect of violating this assumption on model data.

(vi) A fixed threshold value for all the data sets is sufficient for robust and reliable forewarning. On the one hand, the threshold is easy to understand and modify operationally, but is very difficult to justify by general principles since the very notion of threshold is "in the eye of the beholder". On the other hand, the results of the analysis depend heavily on the threshold value. Continuing test input and adjustment is necessary for successful practical implementation.

(vii) Forewarning of an event is indicated by several successive occurrences above threshold within the forewarning window. The same caveats apply to this assumption as in (vi). Here we choose the number of crossings by striking a balance between timeliness and accuracy of forewarning. Within the scope of this study, this judiciousness of this balance is evaluated a posteriori.

We systematically tested the validity of the assumptions (iv) and (vii), including various checks in the algorithm development. In particular, we tested these hypotheses one by one, starting with the simplest ones via appropriate analysis of the data, while keeping the others unchanged. If an assumption was found to be false, it was rejected and replaced by a more valid assumption. A conclusive test of assumption (iv) requires statistically significant amounts of standard length data of verified quality for all types of equipment failures. Such a test is beyond the scope of the present project. The results of such an analysis would allow a test of more "universal" values for the parameters under assumptions (v) through (vii).

This section is organized as follows. Sections 3.3-3.4 discuss typical traditional linear and nonlinear measures for time series analysis. Section 3.5 explains the phase-space analysis, and Sec. 3.6 presents results of our analysis on model data. Section 3.7 describes the analysis of machine data.

\subsection{LINEAR MEASURES}

Analysis of time serial data begins with the collection of a process-indicative scalar signal, $x$, from a dynamical system whose dimensionality, structure, parameters, and regime are usually unknown. This signal is sampled at equal time intervals, $\tau$, starting at the initial time, $t_{0}$, and yields a sequence of $N$ points, $x_{i}=x\left(t_{0}+i \tau\right)$. Several linear measures are useful for characterizing the gross features of this data. The first is the mean, $\underline{\mathrm{x}}$, or average over the $N$ data points: 


$$
\underline{x}=\sum_{i=1}^{N} x_{i}
$$

The second is the sample standard deviation $(\sigma)$, which follows from Eq. (3.1):

$$
\sigma^{2}=\sum_{i=1}^{N}\left(x_{i}-\underline{x}\right)^{2} /(N-1) \text {. }
$$

Equation (3.2) is the second moment about the mean, implying that higher moments are available. Thus, a third linear measure is the third moment about the mean, called skewness, $s$ :

$$
s=\sum_{i=1}^{N}\left(x_{i}-\underline{x}\right)^{3} / N \sigma^{3} .
$$

A fourth linear measure is the fourth moment about the mean, called kurtosis, $k$ :

$$
k=\sum_{i=1}^{N}\left(x_{i}-\underline{x}\right)^{4} / N \sigma^{4}-3 .
$$

Typical process data have significant values for skewness and kurtosis, but Gaussian random processes have values that are not significantly different from zero [Abramowitz and Stegun, 1965]. A large positive (negative) value of skewness corresponds to a longer, fatter tail of the data distribution about the mean to the right (left). Kurtosis measures the amount of flattening (negative $k$ ) or excess peakedness (positive $k$ ) about the mean. Another measure applies to both linear and nonlinear systems, and involves counting the number of times $\left(\mathrm{n}_{\mathrm{c}}\right)$ that the signal crosses the mean value. More specifically, one-half of a wave period is delimited by two successive mean crossings. For $n_{c}>1$, the average number of time steps per wave cycle $(\mathrm{m})$ as:

$$
\mathrm{m}=\mathrm{N} /\left[\mathrm{n}_{\mathrm{c}}-1 / 2\right]=2 \mathrm{~N} /\left(\mathrm{n}_{\mathrm{c}}-1\right) \approx 2 \mathrm{~N} / \mathrm{n}_{\mathrm{c}} .
$$

This last measure indicates the average periodicity in the signal, or the inverse of the average frequency. Analysis of typical data (below) shows that these measures provide little, if any, discrimination for detection of condition change. We include these measures for the sake of completeness and to show that linear measures are inadequate for prognostication.

\subsection{TRADITIONAL NONLINEAR MEASURES}

Nonlinear analysis uses the same sequence of time serial data $\left(x_{i}\right)$ to reconstruct the process dynamics. In particular, phase-space (PS) reconstruction [Eckmann and Ruelle, 1985] uses $d$-dimensional time-delay vectors, $y(i)=\left[x_{i}, x_{i+\lambda}, \ldots, x_{i+(d-1)}\right]$, for a system with $d$ active variables and time lag, $\lambda$. The choice of lag and embedding dimension, $d$, determines how well the PS reconstruction unfolds the underlying dynamics from a finite amount of noisy data. Takens found that, for a $d$-dimensional system, $2 d+1$ dimensions generally results in a smooth, nonintersecting reconstruction [Takens, 1981]. Sauer et al. (1991) showed that, using ideal data (i.e. no noise and infinite precision), the first integer greater than the correlation dimension is often sufficient to reconstruct the system dynamics; this result has been confirmed by computing the embedding dimension via the false nearest-neighbors method [Abarbanel and Kennel, 1993; Abarbanel et al., 1993; Cao 1997]. However, too high an embedding dimension could result in overfitting for real data with finite length and noise. We further note that different observables 
of a system contain unequal amounts of dynamical information [Letellier et al. 1998], implying that PS reconstruction could be easier from one variable, but more difficult or even next to impossible from another. As indicated in the discussion of assumptions (i)-(vii), our analysis seeks to balance these caveats within the constraints imposed by the finite length noisy data.

Various nonlinear measures have been defined to characterize process dynamics using the PS reconstruction. [Kantz and Schreiber, 1997; Rezek and Roberts, 1998]. We choose three of these nonlinear measures, against which we compare the dissimilarity indicators. In particular, we use: the first minimum in the mutual information function as a measure of decorrelation time, the correlation dimension as a measure of dynamic complexity, and the Kolmogorov entropy as a measure of predictability. For the reader's convenience, we briefly describe these three measures next.

The mutual information function (MIF) is a nonlinear version of the (linear) autocorrelation and crosscorrelation functions and was originally developed by Shannon and Weaver (1949) with subsequent application to time series analysis by Fraser and Swinney (1986). The MIF measures the average information (in bits) that can be inferred from one measurement about a second measurement and is a function of the time delay between the measurements. Univariate MIF measures predictability within the same data stream at different times. Bivariate MIF measures predictability of one data channel, based on measurements in a second signal at different times. For the present analysis, we use the first minimum in the univariate MIF, $M_{1}$, to indicate the average time lag that makes $x_{i}$ independent of $x_{j}$. The MIF, I( $\left.q, r\right)$, and system entropy, $H$, are defined by

$$
\begin{gathered}
I(q, r)=I(r, q)=H(q)+H(r)-H(r, q), \\
H(q)=-\sum_{i} P\left(q_{i}\right) \log \left[P\left(q_{i}\right)\right], \\
H(q, r)=-\sum_{i, j} P\left(q_{i}, r_{j}\right) \log \left[P\left(q_{i}, r_{j}\right)\right] .
\end{gathered}
$$

For a window of $N$ points, we denote the $Q$ set of data measurements by $q_{1}, q_{2}, \ldots, q_{N}$, with associated occurrence probabilities $P\left(q_{1}\right), P\left(q_{2}\right), \ldots, P\left(q_{N}\right)$. R denotes a second set of data measurements, $r_{1}, r_{2}, \ldots$ . , $r_{N}$, with a time delay relative to the $q_{i}$ values, having associated occurrence probabilities $P\left(r_{1}\right), P\left(r_{2}\right)$, . . -,$P\left(r_{N}\right)$. The function $P\left(q_{i}, r_{j}\right)$ denotes the joint probability of both states occurring simultaneously. $H$ and $I$ are expressed in units of bits if the logarithm is taken in base two.

The maximum-likelihood correlation dimension, $D$, is [Takens 1984; Schouten et al. 1994a]:

$$
D=\left\{(-1 / M) \sum_{i j} \ln \left[\left(\delta_{i j} / \delta_{0}-\delta_{n} / \delta_{0}\right) /\left(1-\delta_{n} / \delta_{0}\right)\right]\right\}^{-1}
$$

where $M$ is the number of randomly sampled point pairs; $\delta_{i j}$ is the maximum-norm distance between the (randomly chosen) $i-j$ point pairs, as defined in Eq. (3.11) below. The distance (scale length) $\delta_{n}$ is associated with noise as measured from the time serial data. Note that the distances are normalized with respect to a nominal scale length $\delta_{0}$, which is chosen as a balance between sensitivity to local dynamics (typically at $\delta_{0} \leq 5 a$ ) and avoidance of excessive noise (typically at $\delta_{0} a$ ). Here, the symbol $a$ denotes the absolute average deviation as a robust indicator of variability [Schouten et al. 1994a] in the data, 


$$
a=(1 / w) \sum_{i=1}^{w}\left|x_{i}-\underline{x}\right|
$$

where $\underline{x}$ is the mean of $x_{i}$ over the window of $N$ points. The distances $\delta_{i j}$ are defined by

$$
\delta_{i j}=\max _{0 \leq k \leq m-1}\left|x_{i+k}-x_{j+k}\right|,
$$

where $m$ is the average number of points per cycle, as determined by Eq. (3.5).

The Kolmogorov entropy, $K$, measures the rate of information loss per unit time, or (equivalently) the degree of predictability. A positive, finite entropy is generally considered a clear demonstration that the time series and its underlying dynamics are chaotic. A very large entropy indicates a stochastic (nondeterministic) and therefore totally unpredictable phenomenon. The K-entropy is estimated from the average divergence time for pairs of initially close orbits. More precisely, the entropy is obtained from the average time for two points on an attractor to go from an initial separation $\delta \leq \delta_{0}$ to a separation of more than a specific distance $\left(\delta>\delta_{0}\right)$. The maximum-likelihood Kentropy is calculated from the method by Schouten et al. (1994),

$$
\begin{gathered}
K=-f_{s} \log (1-1 / \underline{b}), \\
\underline{b}=(1 / M) \sum_{i=1}^{M} b_{i},
\end{gathered}
$$

with $b_{i}$ as the number of timesteps for two points, initially within $\delta \leq \delta_{0}$, to diverge to $\delta>\delta_{0}$. The symbol $f_{s}$ denotes the data-sampling rate.

There are several problems associated with the use of these measures for detection of dynamical change. The most serious is that these nonlinear measures are expressed as a sum or integral over (a region of) the PS, which averages out all dynamical details into a single number. Two (very) different dynamical regimes may lead to very close, or even equal measures. The situation is even murkier for noisy dynamics, in which case reliable determination of the nonlinear measures is next to impossible. The second difficulty arises from the definitions of K-entropy and correlation dimension in the limit of zero scale ength. However, all real data have noise and even noiseless model data is limited by the finite precision of computer arithmetic. Thus, we choose a finite scale length that is somewhat larger than the noise $\left(\delta_{0}=2 a\right)$, at which to report the values of $K$ and $D$, corresponding to finite-scale dynamic structure. Consequently, the calculated values of $K$ and $D$ have smaller values than expected for the zero-scalelength limit $\left(\delta_{0} \quad 0\right)$ and cannot capture dynamical complexity at length scales smaller than $\delta_{0}$. A third difficulty arises from the definition of these nonlinear measures as functionals of the distribution functions. Some of these functionals do not satisfy all the mathematical properties of a distance. In particular, for some of them, symmetry and the triangle inequality may be violated [Quin Quiroga et al., 2000]. Therefore, these measures cannot define a metric in the mathematical sense. They may indicate change, although only in a sense that has to be made precise for each situation.

In an attempt to improve the discrimination power, Thomasson et al. (2001) has recently proposed the "recurrence quantification" approach that does not require assumptions about stationarity, length, or noise. Their new measure quantifies the recurrence of sets of points of various lengths that "almost repeat themselves" during the dynamics. It can be viewed somewhat as a generalization of the Poincaré section concept and is designed to detect and characterize "real phenomena" present in the time serial data. Since 
we do not attempt to infer what "real phenomena" are, our approach has a much more modest goal, namely to detect condition change from the time-serial data, independent of specific assumptions about the underlying dynamics. As we have seen in Sec. 3.2, general assumptions are necessary, but - at this stage of the development of the field - we feel that they should be retained or eliminated on a minimalist and pragmatic basis alone.

\subsection{PHASE-SPACE DISSIMILARITY MEASURES}

The traditional nonlinear measures described in the previous section characterize global features of the dynamics, and can clearly distinguish between regular and chaotic dynamics. However, they do not reveal slight dissimilarities between dynamical states. The same is true for other global indicators, such as fractal dimension, Lyapunov exponents, etc. This lack of discrimination occurs because such traditional measures are based on averaged or integrated features of the dynamics over the attractor, which provide a global picture of long-term dynamical behavior.

Greater discrimination is possible by more detailed analysis of the reconstructed dynamics. The natural (or invariant) measure on the attractor provides a more refined representation of the reconstruction, describing the visitation frequency of the system dynamics over the PS. We obtain a useful discrete representation of the invariant measure from time serial data as follows. We first represent each signal value, $x_{i}$, as a symbolized form, $s_{i}$, that is, one of $S$ different integers, $0,1, \ldots, S-1$,

$$
0 \leq s_{i}=I N T\left[S\left(x_{i}-x_{\min }\right) /\left(x_{\max }-x_{\min }\right)\right] \leq S-1 .
$$

Here, the function (INT) converts a decimal number to the closest lower integer, and $x_{\min }$ and $x_{\max }$ denote the minimum and maximum values of $x_{i}$, respectively, over the base case (reference data). We previously used [Hively et al., 1999; Gailey et al., 1999; Hively et al., 2000] the minimum and maximum values over both the base case and test case (data to be tested for departure from the base case). However, in reat or near-real-time analyses, only base case extrema are actually known. We require that $s_{i}\left(x_{i}=x_{\max }\right)=S-1$ in order to maintain exactly $S$ distinct symbols. Consequently, Eq. (3.14) creates symbols that are uniformly distributed between the minimum and maximum in signal amplitude (uniform symbols).

An alternative is equiprobable symbols. These symbols are formed by ordering the base case time-serial data from the smallest to largest value. The first N/S of these ordered data values corresponds to the first symbol (0). Ordered data values (N/S)+1 through $2 \mathrm{~N} / \mathrm{S}$ correspond to the second symbol (1), and so on up to the last symbol (S-1). Consequently, equiprobable symbols have non-uniform partitions in the signal amplitude so that each symbol has the same occurrence frequency (N/S) of $\mathrm{x}$ values. Much structure is inherent in uniform symbols before beginning the PS reconstruction, but no PS structure arises from equiprobable symbols. Thus, a key advantage of equiprobable symbols is that dynamical structure arises only from the phase-space reconstruction, as described below. Large negative and large positive values of $x_{i}$ have little affect on equiprobable symbolization, but dramatically change the partitions for uniform symbols. Moreover, information theoretic measures of the PS-DF (e.g., mutual information function) are a smooth function of the reconstruction parameters for equiprobable symbols, but are noisy functions of these same parameters for uniform symbols. We find that equiprobable symbols provide better discrimination of condition change than uniform symbols.

The phase-space (PS) is partitioned into $S^{d}$ hypercubes or bins by the symbolization process. We then count the number of PS points occurring in each bin to obtain the distribution function (DF) as a discretized density on the attractor. We denote the population of the $i$ th bin of the distribution function, $Q_{i}$, for the base case, and $R_{i}$ for a test case, respectively. For infinitely precise data, this representation 
has been used in Grebogi et al. (1988). The choice of parameters $(S, N$, and $d)$ depends not only on the system, but also on the specific data under consideration. In the preliminary phase of the analysis, we systematically varied each parameter with the others fixed, to obtain optimum sensitivity of the measures to changes in system dynamics for each class of data. After achieving optimal sensitivity, the values of the parameters were kept fixed.

We use an embedding window, $M_{1}=(d-1) \lambda$, based on the first minimum in the mutual information function, $M_{1}$ [Fraser and Swinney, 1986]. This choice of time delay provides maximal information for the reconstruction of the phase space dynamics. Then, we set $\lambda=\operatorname{INT}\left[0.5+M_{1} /(\mathrm{d}-1)\right]$ to obtain an integer value for the reconstruction lag when $M_{1}$ is not evenly divisible by $d-1$. The reconstruction requires that $\lambda \quad d \quad 2 M_{1}+1$ from the above formula.

After reconstruction (unfolding) of the dynamics, the test case is compared to the base case. Diks et al. (1996) measured differences between delay vector distributions by the square of the distance between two DFs. Schreiber (1997 and 1999) measured dissimilarity via the Euclidean distance between points of the attractor. This measure of dissimilarity only accounts for the geometrical shape and location of the attractor. Manuca and Savit (1996 and 1998) described dissimilarity via ratios of the correlation integral over the DF. This is essentially the correlation dimension discussed in Sec. 3.4. Moreover, these papers discuss dissimilarity measures from the perspective of nonstationarity, while our focus is on condition change, as explained in the Introduction. We measure the difference between $Q_{i}$ with $R_{i}$ by the $\div^{2}$ statistics and $L_{1}$ distance,

$$
\begin{gathered}
\chi^{2}=\sum_{i}\left(Q_{i}-R_{i}\right)^{2} /\left(Q_{i}+R_{i}\right), \\
L=\sum_{i}\left|Q_{i}-R_{i}\right|,
\end{gathered}
$$

where the summations in both equations run over all of the populated PS cells. The choice of these measures is based on the following considerations. The $\div^{2}$ statistic is one of the most powerful, robust, and widely used statistical tests to measure discrepancies between observed and expected frequencies. The $\div^{2}$ statistic is obviously symmetric, but does not always satisfy the triangle inequality, so it does not define a distance in the mathematical sense. The $L_{1}$ distance is the natural metric for distribution functions since it is directly related to the total invariant measure on the attractor and does define a bona fide distance. Therefore, these measures account for changes in the geometry, shape, and visitation frequency of the attractor and can be viewed as somewhat complementary. Obviously, calculation of these measures in a consistent fashion, requires that the base case and test case contain the same number of points, identically sampled; otherwise the distribution functions have to be properly rescaled.

We extended the previous analysis in a manner that is naturally compatible with the underlying dynamics. By connecting successive PS points as prescribed by the dynamics, $y(i) \rightarrow y(i+1), i=1,2, \ldots$ we obtained a discrete representation of the process flow [Abarbanel, 1996]. The $2 d$-dimensional vector, $Y(i)=[y(i)$, $y(i+1)$ ], formed by adjoining two successive vectors from the $d$-dimensional reconstructed PS, lives in a $2 d$-dimensional space, that we call the connected phase space (CPS). As before, $Q$ and $R$ denote the CPS DFs for the base case and test case, respectively. We define the measures of dissimilarity between these two CPS DFs, as before, via the $L_{1}$-distance and $\div^{2}$ statistic, [Hively et al., 1999, 2000, 2000a; Protopopescu, et al., 2001 and references therein] 


$$
\begin{gathered}
x_{c}^{2}=\sum_{i j}\left(Q_{i j}-R_{i j}\right)^{2} /\left(Q_{i j}+R_{i j}\right) \\
L_{c}=\sum_{i j}\left|Q_{i j}-R_{i j}\right| .
\end{gathered}
$$

The subscript $c$ indicates the connected distribution function measure. We note that the value $\lambda=1$ results in $d-1$ components of $y(i+1)$ being redundant with those of $y(i)$, but we allow this redundancy to accommodate other data such as discrete points from two-dimensional maps. The CPS measures have a higher discriminating power than their non-connected counterparts. Indeed, we can prove that the measures defined in Eqs. (3.15)-(3.18) satisfy the following inequalities [Hively et al., 2000]: $\chi^{2} \leq L, \chi_{c}^{2} \leq L_{c}, L \leq L_{c}$, and $\chi^{2} \leq \chi_{c}^{2}$. Alternative forms are: $\chi^{2} \leq L \leq L_{c}$ and $\chi^{2} \leq \chi_{c}^{2} \leq L_{c}$.

The $\chi^{2}$ statistic requires statistical independence between various samples. However, the PS points depend on one another due to reconstruction from time delay vectors with dynamical structure [Diks $e t$ al., 1996]. The resulting statistical bias is avoidable by averaging contributions to Eqs. (3.15)-(3.18) over values of $y(j)$ or $Y(j)$ which satisfy $|i-j|<\Lambda$ [Diks et al., 1996], where $\Lambda$ is some largest typical correlation time lag. We tested the bias in typical data by sampling every $\Lambda$-th connected phase space point for $4 \quad \Lambda 23$, resulting in $\Lambda$ different samples for the base case $\left(Q_{i}\right)$ and for each cutset $\left(R_{i}\right)$. We then averaged the sampled $\chi^{2}$ values over the $\Lambda^{2}$ different combinations of distribution functions for the base case and test case cutsets. As expected, a decrease proportional to $1 / \Lambda$ occurs in the sampled $\chi^{2}$ values, because the number of data points contributing to $\chi^{2}$ decreases in the same proportion. The trend over time in sampled $\chi^{2}$ values is the same as in $\chi^{2}$ values without sampling, showing that no bias is present. Thus, we use unsampled $\chi^{2}$ values for the remainder of this work as a relative measure, rather than as an unbiased $\chi^{2}$ statistic for accepting or rejecting a null statistical hypothesis [Hively et al., 1999].

Use of the dissimilarity measures on finite length, noisy data requires a consistent statistical implementation and interpretation. Moreover, construction of the base case(s) also requires careful statistics to eliminate possible outliers and to ensure robust results. We use the first $B$ non-overlapping cutsets as base cases. However, a few of these base case cutsets may be very different from the typical regime, causing a severe bias in the detection of condition change. This is especially true for noisy data. We statistically test the base case cutsets for outliers as follows. Dissimilarity comparisons among the $B$ base case cutsets yields $B(B-1) / 2$ unique pairs, from which we obtain an average, $\underline{V}$, and sample standard deviation, $\sigma$ for each of the dissimilarity measures, $V=L, L_{c}, \chi^{2}$, and $\chi_{c}^{2}$. We calculate a $\chi^{2}$ statistic, $\Sigma\left(V_{i j}-\underline{V}\right)^{2} / \sigma$, for each of these four dissimilarity measures. The index $j$ is fixed, to test the $j$ th cutset against the other $B-1$ cutsets, thereby giving $B-1$ degrees of freedom in the $\chi^{2}$ statistic. The null statistical hypothesis allows a random outlier with a probability less than $2 / B(B-1)$, corresponding to less than one out of the $B(B-1) / 2$ unique pairs. In the latter case, we identify an outlier cutset as having the largest $\chi^{2}$ statistic greater than 19.38 over the four dissimilarity measures, which corresponds to a probability larger than $1 / 45$ for $B=10$. If this analysis does not identify any outlier, then the previous values of $V$ are used for subsequent renormalization, as described below. If this analysis identifies an outlier, we remove it. We then repeat this analysis for the remaining base case cutsets to identify any additional outliers when the largest chi-squared statistic exceeds the below threshold, corresponding to a random probability of greater than $2 / B(B-1)$, as interpolated from standard statistical tables for $B-1$ degrees of freedom [Abramowitz and Stegun, 1965]. Here, $B$ is the number of non-outlier base case cutsets. Thus, rejection of the null hypothesis corresponds to a $\chi^{2}$ statistic greater than 19.38, 17.24, $15.03,12.74$, and 10.33 , for $B=10,9,8,7$, and 6 , respectively. 
This approach dramatically improves the robustness of the condition change detection. If the analysis identifies five (or more) outliers, we would have to reject all ten base cases as unrepresentative, and acquire a new set of ten cutsets as base cases. However, the present analysis never finds more than four outliers. Subsequently, we compare the non-outlier base case cutsets to each non-overlapping test case cutset, and obtain average values for the dissimilarity measures for each test case.

The choice of $B$ should strike a judicious balance between a reasonably short base case period to capture quasi-stationary, "normal" dynamics and a sufficiently long period for statistical significance. We have chosen $B=5$ for the noiseless, model generated data for fixed dynamical conditions, where the variability arises only from the location in and the discrete sampling of the PS. On the other hand, we have chosen $B$ $=10$ for noisy machine data to provide a larger statistical sample.

The disparate range and variability of various nonlinear measures are difficult to interpret (especially for noisy data), so we need a consistent means of comparison. Thus, we renormalize the nonlinear measures [Hively et al., 1999 and 2000]. For each nonlinear measure, $V=\left\{D, K, M_{1}, L, L_{c}, \chi^{2}\right.$, and $\left.\chi_{c}{ }^{2}\right\}$, we define $V_{i}$ as the value of the nonlinear measure for the $i$ th cutset. As before, $\underline{V}$ is the mean value of that nonlinear measure over the non-outlier base cases, with a corresponding sample standard deviation $\sigma$, as described above. No averaging is needed for $D, K$, and $M_{1}$ since the calculation of these measures involves only one cutset at the time. The renormalized form is then $U(V)=\left|V_{i}-\underline{V}\right| / \sigma$, which measures the number of standard deviations that the test case deviates from the base case mean. Several successive occurrences above threshold provide a clear indication of condition change.

\subsection{VALIDATION OF PHASE-SPACE DISSIMILARITY ON MODEL DATA}

We show the discriminating power of the nonlinear measures by first testing them as well as some of the assumptions (i)-(vii) on noiseless modelgenerated time serial data. We use the well-known Lorenz model [Lorenz, 1963], a system of three coupled nonlinear differential equations:

$$
\frac{d x}{d t}=a(y-x), \frac{d y}{d t}=r x-y-x z, \frac{d z}{d t}=x y-b z
$$

with properties that have been well documented in the literature. We integrated the Lorenz system with timesteps $\delta t=0.03$ and used the variable $y$ to reconstruct the dynamics. We fixed parameters $a$ and $b$ at the values 10 and 8/3, respectively. Figure 1 shows the phase-space reconstruction for this model system, representing where the dynamics does (and does not) spend its time. Figure 1 (left) displays the phasespace by plotting the sequence of points in $(\mathrm{x}, \mathrm{y}, \mathrm{z})$ coordinates from the integration of Eq. (3.19). Figure 1 (right) illustrates the power of the time-delay reconstruction from the y coordinate only, as very similar to the phase space from all three coordinates. We used time-delay reconstruction for the dissimilarity analysis.

As the variable parameter $r$ increases from zero, the Lorenz system displays increased complexity and different stability properties. Transitions from one type of solution to another occur through bifurcations or transitions to chaos for which traditional nonlinear measures are good indicators, in general. However transitions between two chaotic regimes are not readily detected by these traditional measures, especially for small changes in the parameter $r$. Therefore, we concentrate on detecting dynamical change within a region where the Lorenz system behaves chaotically [Jackson, 1989 and 1990], namely for $45 \quad r$

We started with $r=45$ which was considered the base case and kept $r$ unchanged for 2,250,000 points (45 cutsets of 50,000 points). Then, we increased $r$ from 45 to 90 in one unit steps for each 50,000-point window. Finally, we maintained $r=90$ for another $2,250,000$ points (45 cutsets of 50,000 points). 
Figure 2 shows linear measures of he $y$-coordinate of the Lorenz model. The minimum $\left(y_{\min }\right)$ and maximum $\left(y_{\max }\right)$ values in each cutset are roughly constant for $r=45$, changing monotonically as $r$ increases from 45 to 90 because the attractor size increases, then remaining constant for $r=90$ (Fig. 2a). The absolute average deviation (a) and standard deviation $(\sigma)$ of y are likewise constant for $r=45$, rising linearly as $r$ increases from 45 to 90, then remaining constant for $r=90$ (Fig. 2b). Skewness (s) varies erratically over the entire range of $45 \leq r \leq 90$, while kurtosis $(k)$ remains roughly constant for $r<59$, varies erratically for $59 \leq r<90$, then rises abruptly to a new (roughly) constant for $r=90$ (Fig. 2c). The number of time steps per cycle $(m)$ is roughly constant at $m=50$ for $r=45$, decreasing erratically over the range of $45<r<90$, then remaining roughly constant at $m=27$ for $r=90$ (Fig. 2d). These correlations arise from the larger attractor size as $r$ increases in the Lorenz model.

Figure 3 shows the consistency and robustness of the resulting dissimilarity measures. Indeed, as long as the parameter $r$ is unchanged, the dynamical system remains in the same regime, and the dissimilarity measures remain consistently close to zero. When the parameter varies monotonically, the dissimilarity measures rise monotonically, in roughly linear fashion, and over a much broader range than the traditional nonlinear measures. The dissimilarity measures reach a clear plateau at $r=90$, illustrating their consistency. The base case consisted of the first ten adjacent windows for $r=45$. We obtained the traditional and (C)PS renormalized measures by comparing the distribution function for each 50,000point test case to each of the ten base cases, using Eq. (3.15)-(3.18). We note that the CPS measures (dashed curves in Fig. 3) lie below the non-connected measures (solid curves in Fig. 3). This does not contradict the rigorous inequalities for these measures [Hively et al., 2000], since the curves in Fig. 3 were obtained by averaging, to obtain renormalized measures. Only the MIF values are given in the unrenormalized form because the first minimum in the MIF is completely constant over the base case, resulting in $\sigma=0$. Of course, if the window length decreases, more variability appears and $\sigma$ would be different from zero. Figure 3 shows various nonlinear measures versus $r$. The correlation dimension (Fig. 3a) varies erratically between 0 and 0.2 , over the whole range. The renormalized Kolmogorov entropy (Fig. 3b) also varies erratically while gradually rising from 0 to 4 . Figure $3 \mathrm{c}$ shows the location of the first minimum in the mutual information function, $M_{1}$, with a single abrupt step at $r=60$. A smaller integration step $(\delta t=0.1)$ yields a series of finer steps (not shown here), thereby illustrating the limitation of a coarser sampling rate. In sharp contrast, the (connected) phase space measures (Figs. 3d and 3e) increase almost monotonically from zero to more than 500 as $r$ rises from 45 to 90 . The values of $L$ and $\chi^{2}$ essentially coincide over the whole range, because the measures are dominated by phase space bins that are populated only for the base case $\left(Q_{i}>0\right.$ for $\left.R_{i}=0\right)$ and only the test case $\left(R_{i}>0\right.$ for $\left.Q_{i}=0\right)$, for which the two measures become analytically equivalent. Figure 4 shows the dissimilarity measures for a different choice of the base case, namely over the first ten cutsets of $r=90$. These curves are roughly mirror images of those in Fig. 3: large and constant dissimilarity for $r=45$, a monotonic and roughly linear decrease during the transition $(45<r<90)$, and small dissimilarity in the base case region $(r=90)$. Figure 5 shows the dissimilarity measures for several cutset lengths $(\mathrm{N})$, varying from 5,000 to 25 points. As expected, the quality of the results degrades dramatically as the length of the window shortens. For a very short window, the long-range regularity of the dynamics is overcome by short-range variability, which depends strongly on the specific location in the PS. This result underscores the need for "sufficiently long data sets" in comparison to the characteristic times of the underlying dynamics, in order to provide "sufficiently good" statistics.

In addition to the Lorenz system, we previously assessed [Hively, et al., 2000] the discriminating power of the dissimilarity measures for the Bondarenko model [Bondarenko, 1997]. This infinite-dimensional model is described by a system of time-delayed ordinary differential equations, and is very different from the Lorenz system. As before, we found that correlation dimension, Kolmogorov entropy, and mutual 
information function varied erratically with the changing parameter. Our analysis also showed that the (C)PS measures rise almost monotonically as the parameter in the Bondarenko model increases.

Although the analysis of model data was not an explicit part of the NERI2000-109 proposal, an essential aspect of this work is validation of the methodology on well-characterized and carefully controlled data, as provided by model data. The results of this subsection do indeed show that the hypotheses underlying this nonlinear analysis are valid. Moreover, the methodology gives consistent and robust indication of change in the process dynamics as measured by the phase-space dissimilarity with a changing parameter. In sharp contrast, the traditional nonlinear measures (correlation dimension, Kolmogorov entropy, and mutual information) provide no such consistency or robustness.

\subsection{ANALYSIS OF EQUIPMENT DATA}

Having validated the nonlinear measures of condition change on model data (Sec. 3.6), we turn next to analysis of equipment data. Machine dynamics has a long history [King, 1985]. Qu et al. (1993) demonstrated the usefulness of several nonlinear measures for vibration data from rotating machinery (turbo-generator and compressor). Moreover, failure prognostication is one of the hardest problems to solve for nonlinear and chaotic systems [Casdagli, 1989; Sugihara and May, 1990; Essawy, 2001], due to process sensitivity to initial conditions [Farmer and Sidorowich, 1987].

We begin this phase of the work by summarizing important-to-safety equipment in nuclear power plants (NPP). Table A.1 of Appendix A provides examples of typical NPP equipment. Furthermore, the INPOEPIX database shows that motor failures directly impact NPP operations, including reactor trips (25\% of failures), unit off-line ( $40 \%$ of failures), and reduced power operation (35\% of failures); see Table A.2 of Appendix A. Such failures typically develop over many months, and sometimes years. Consequently, the time and funding for PY01 of this NERI project do not permit acquisition of real process data from such NPP equipment to obtain such failure sequences. Instead, we acquired new data by seeding specific faults in test equipment. Appendix A shows the complete test plan, including the choice of two representative failure modes (unbalance and misalignment). Figure 6 shows the important features of the test equipment (5HP motor-driven pump) at the DE\&S testing facility in Mount Holly, North Carolina. The test protocol involves acquisition of test data for a no-fault baseline, followed by datasets for successively larger faults.

DE\&S provided initial test data to ORNL for preliminary analysis, which revealed a rich set of nonlinear features. The sampling rate was adequate $(12 \mathrm{KHz})$, but the number of data points was too small $(16,384$ points). ORNL requested voltages, $V_{i}$, and currents, $I_{i}$, from all three phases of the three-phase electric motor. ORNL also requested longer datasets for robust conversion of the time-serial data to statistical distribution functions, as described in Sec. 2. These requirements necessitated an upgrade to the data acquisition system (Emax by PdMA Corporation), causing some delay while PdMA modified their software. DE\&S subsequently received the Emax upgrades and provided the power data for the two test sequences. The final data acquisition parameters for these six channels included a sampling rate of $12,288 \mathrm{~Hz}$ over $42.67 \mathrm{~s}(524,288$ points $)$ with a digitization accuracy better than $1 \%$. These data were converted to instantaneous power, $P=\Sigma_{\mathrm{i}} I_{i} V_{i}$, which we used for all subsequent analysis. The time-serial motor power data was saved to a separate ACSII file for each value of unbalance mass, and for each value of misalignment. These datasets were transferred from DE\&S to ORNL as an attachment (4.6MB for each dataset) to an e-mail message. Quality of the data was assured by Task 1.2 (data quality analysis), as described in Sec. 2. ORNL subsequently concatenated the sequence of datasets into a single long dataset for the unbalance test, and another long dataset for the misalignment test. The dissimilarity analysis used these long (concatenated) datasets, as discussed below. 
The machine power data include high frequency artifacts, typically treated as "noise." We remove essentially all of these artifacts with a novel zero-phase quadratic filter [Hively et al., 1995]. This filter uses a moving window of $2 n+1$ points of raw data, $e_{i}$, with the same number of data points, $n$, on either side of a central point. We fit the data to a quadratic equation, $F\left(t_{i}\right)=a_{1} T_{i}^{2}+a_{2} T_{i}+a_{3}$, with $T_{i}=t_{i}-t_{c}$, and $t_{c}$ the time at the central point of the moving window. We obtain the best fit to the data by minimizing the function, $\Psi=\Sigma_{\mathrm{i}}\left[F(t)-e_{i}\right]^{2}$, where the sum is over the $2 n+1$ points in the moving window. The minimum in $\Psi$ is found from the condition $\partial \Psi / \partial a_{k}=0$, which yields three linear equations in three unknowns. The window-averaged signal at the central point is the fitted value at the central point, $F\left(t_{c}=\right.$ $\left.t_{i}\right)=a_{3}$. We note that the sums over odd powers of $T_{i}$ are zero and that symmetric sums over even powers of $T_{i}$ (over $i$ from $-n$ to $n$ ) can be converted to sums from 1 to $n$, giving a window-averaged solution for the artifact signal,

$$
F\left(t=t_{c}\right)=\left[3\left(3 n^{2}+3 n-1\right)\left(\sum e_{i+c}\right)-15\left(\sum i^{2} e_{i+c}\right)\right] /\left(4 n^{2}+4 n-3\right)(2 n+1) .
$$

The sums in this last equation are over $i$ from $-n$ to $n$, with sums over even powers of $i$ explicitly evaluated with standard formulas for $\Sigma_{\mathrm{i}} i^{2}$ and $\Sigma_{\mathrm{i}} i^{4}$ (Gradshteyn and Ryzhik, 1965). The effort to evaluate Eq. (3.20) can be reduced further by computing the sums initially with $c=n+1$, and then using recursions thereafter for $c>n+1$ [Hively et al., 1995]. Application of this filter to the $N$-point set of raw data, $e_{i}$, yields $N-2 n$ points of low-frequency signal data, $f_{i}$. The residue, $g_{i}=e_{i}-f_{i}$, has essentially no low-frequency activity, and captures essentially all of the high-frequency "noise." The filter window width $(n=7)$ corresponds to optimal removal of this high-frequency "noise." Figure 7 illustrates this filtering process for typical power data from the baseline of unbalance test sequence. Subsequent analysis uses only the low-frequency-filtered machine power data.

DE\&S performed the unbalance test by attaching successively larger masses $(0-101.7$ grams $)$ to the motor-pump coupling, as illustrated in Fig. 6. Table 1 summarizes the test results, with the most relevant data shown in bold: unbalance mass (second column), peak vertical vibration (third column), and peak horizontal vibration (fourth column). Figure 8 shows various linear measures of the motor-pump power as a function of the dataset number in this unbalance test sequence. The top subplot of Fig. 8 shows the addition of successively larger amounts of unbalance mass to the motor-pump coupling. The second plot down in Fig. 8 depicts the overall variation in motor power level (2000-3500W), which is nearly constant for the first five datasets, rising abruptly to the largest values for intermediate unbalance masses, then decreasing gradually for datasets 9-13. The third plot down in Fig. 8 presents values of skewness (solid), which varies erratically between $0.2-0.5$ over the test sequence. This subplot also displays kurtosis (- -), which decreases erratically from 0.3 in the first dataset to -1.2 in the fourth dataset, rising to -1 in the fifth dataset, varying erratically around zero over datasets $6-12$, and finally decreasing to -0.5 for the last dataset. The bottom subplot of Fig. 8 illustrates the number of timesteps per power cycle, which rises from $\sim 15$ in the first dataset to $\sim 60$ in dataset 4 , then decreases to $\sim 35$ in dataset 5 , remains nearly constant over datasets 612 , and finally rises somewhat to $\sim 20$ in the last dataset. Figure 9 shows a similar set of plots for traditional nonlinear measures of the unbalance power versus the dataset number. The top subplot of Fig. 9 shows the monotonic rise in unbalance mass, as in Fig. 8. The second plot down in Fig. 9 depicts the very erratic variation between 1.4-2.3 in correlation dimension, $D$, versus dataset number. The third plot down in Fig. 9 presents the erratic variation in Kolmogorov entropy, $K$, between 0.001-0.018 versus dataset number. The bottom plot of Fig. 9 illustrates the variation in the first minimum in the mutual information function, $M_{1}$, which is between 15-16 for dataset 1, 10-14 for dataset 2, 14-20 for dataset 3, 10-20 for dataset 4, 10-11 over dataset 5, 14-16 for datasets 6-12, then down to 911 for the last dataset. Thus, the linear and traditional measures of motor power are uncorrelated to unbalance mass. 
In sharp contrast to Figs. 89, Fig. 10 shows a clear correlation between the phase-space dissimilarity measures (top) and the vibration levels (bottom) as functions of the unbalance mass. All four dissimilarity measures (Fig. 10 top) rise monotonically and in unison for $0 \leq$ (unbalance mass) $\leq 50 \mathrm{~g}$. The operational vibration levels (Fig. 10 bottom) rise monotonically (and almost linearly) with increasing unbalance mass. Table A.12 of Appendix A provides a correlation between the phase-space dissimilarity measures and the vibration levels, based on ISO 2372 and ISO 3945 standards. In particular, Table A.12 shows that the 5HP motor is in Class I (small machines to 20HP), for which the onsets of unsatisfactory and unacceptable vibration occur at $2.8 \mathrm{~mm} / \mathrm{s}$ and $7.1 \mathrm{~mm} / \mathrm{s}$, respectively. Figure 10 (bottom) shows these vibration limits as two horizontal lines with corresponding labels in the two bands (unsatisfactory for range of $2.8 \mathrm{~mm} / \mathrm{s}<\mathrm{v}<7.1$, and unacceptable for $\mathrm{v}>7.1 \mathrm{~mm} / \mathrm{s}$ ). Thus, the phase-space dissimilarity measures provide clear and consistent indications of condition change that correlate with unbalance mass.

DE\&S performed the second test by introducing successively larger amounts of misalignment, as illustrated in Fig. 11. Table 2 summarizes the test results, with the most relevant data shown in bold: vertical angular misalignment (fifth column), peak vertical vibration (seventh column), and peak horizontal vibration (eighth column). Figure 12 shows various linear measures of the motor-pump power as a function of the dataset number in this misalignment test sequence. The top subplot of Fig. 12 shows the vertical angular misalignment of the motor-pump system via insertion of shims in the motor-to-pump coupling and/or under the motor mount; note the non-monotonic change in the first two datasets. The second subplot down in Fig. 12 depicts the variation in motor power, which remains almost constant (2000-3000 W) for datasets 1-8, then rises slightly (2500-3500 W) for dataset 9, and is largest (and most variable) for the last dataset (4500-7000 W). The third subplot down in Fig. 12 displays skewness and kurtosis of the motor power, both of which vary erratically over the whole range of misalignment. The bottom subplot in Fig. 12 illustrates the number of timesteps per cycle, with mostly low values (15-25) for datasets $1-3,5$, and 7-9 interspaced with high plateau values (50-70) for datasets 4, 6, and 10. Figure 13 shows a similar set of plots for traditional nonlinear measures of the misalignment motor power versus the dataset number. The top subplot of Fig. 13 shows the monotonic rise in vertical offset, as in Fig. 12. The second plot down in Fig. 13 depicts the very erratic variation between 1.6-2.4 in correlation dimension, $D$, versus dataset number. The third plot down in Fig. 13 presents the erratic variation in Kolmogorov entropy, $K$, between 0.001-0.036 versus dataset number. Interestingly, the smallest values of correlation dimension, $D$, and Kolmogorov entropy, $K$, in Fig. 13 both occur in datasets 4, 6, and 10; these same datasets have the smallest values of kurtosis (dashed curve in the third subplot down in Fig. 12) and the largest values of timesteps per cycle (bottom subplot of Fig. 12). We conclude from the results in Figs. 12-13 that no correlation exists between the linear and traditional measures of motor power and the values of motor-pump misalignment, not unlike the results for the linear and nonlinear measures of pump-motor power for the unbalance test sequence.

In sharp contrast to Figs. 12-13, Fig. 14 shows correlation between the phase-space dissimilarity measures (top) and the vibration levels (bottom) as functions of the misalignment. All four dissimilarity measures (Fig. 14 top) rise in unison for $0.19 \leq$ misalignment $(\mathrm{mm}) \leq 1.1$. The operational vibration levels (Fig. 14 bottom) rise somewhat erratically with increasing misalignment. Referring again to Appendix A, Table A.12 provides a correlation between the phase-space dissimilarity measures and the vibration levels, based on ISO 2372 and ISO 3945 standards. In particular, Table A.12 shows that the 5HP motor is in Class I (small machines to 20HP), for which the onsets of unsatisfactory and unacceptable vibration occur at $2.8 \mathrm{~mm} / \mathrm{s}$ and $7.1 \mathrm{~mm} / \mathrm{s}$, respectively. As in Fig. 10 (bottom), Fig. 14 (bottom) shows these vibration limits as two horizontal lines with corresponding labels in the two bands (unsatisfactory for range of 2.8 $\mathrm{mm} / \mathrm{s}<\mathrm{v}<7.1$, and unacceptable for $\mathrm{v}>7.1 \mathrm{~mm} / \mathrm{s})$. The rise and subsequent fall in dissimilarity measures (Fig. 14 top) is accompanied by the same rise and fall in vibration levels (Fig. 14 bottom) for datasets $1-4$, and is probably due to the inconsistent introduction of misalignment by shims under the motor mount and in the motor-to-pump coupling. See Table 2. Thus, the phase-space dissimilarity measures also provide indication of condition change that correlates with misalignment. 


\section{DISCUSSION}

One of the most important problems encountered in nonlinear time-series analysis is the appropriate characterization of changes in the system's dynamics. More often than not, physical systems are complex, nonstationary, affected by noise, and difficult to fully quantify in ordinary physical or mathematical terms. Such systems usually have low-dimensional dynamics that varies between (quasi) periodic and completely irregular (chaotic). Thus, to a certain extent, global aspects of the dynamics may be legitimately quantified by traditional nonlinear descriptors such as Lyapunov exponents, Kolmogorov entropy, and correlation dimension. While these descriptors are adequate for discriminating between clear-cut regular and chaotic dynamics, they are not sufficiently sensitive to distinguish quasi-periodicity, intermittency, or slightly different chaotic regimes, especially when data are limited and/or noisy. Therefore, robust and timely forewarning of equipment failures has remained an outstanding challenge. We address this problem, by introducing four new measures of dissimilarity that capture more details about the dynamics and differences between various regimes and therefore are more sensitive than the traditional nonlinear measures. A change in these measures signifies that the system has departed from the base case and can be interpreted as a forewarning of an impending failure.

The PS indicators of condition change measure the difference between PS distribution functions for a base case and a test case, as $\chi^{2}$ statistics and $L_{1}$ distance. Thus, these indicators retain the differences between the process dynamics and avoid the inner cancellation effects due to averaging over many orbits (as one does, for instance, when calculating the correlation dimension and Kolmogorov entropy). Changes in the Lorenz and Bondarenko model dynamics are clearly detected by the dissimilarity measures and somewhat by Kolmogorov entropy. On the other hand, these changes are either undetected or poorly detected by the correlation dimension and mutual information measures. The new measures also provide forewarning of failure due to two seeded fault conditions, as described in Sec 3.7. These results show that the PS measures are superior to traditional nonlinear measures for detection of condition change.

We note that the PS indicators contain more information than we have systematically exploited so far. For instance, some datasets show a remarkably close similarity between the pairs $\left\{\chi^{2}, L\right\}$ and $\left\{L_{\mathrm{c}}, \chi_{c}{ }^{2}\right\}$, while other datasets show close similarities between $\left\{L, L_{c}\right\}$ and $\left\{\chi^{2}, \chi_{c}^{2}\right\}$. Other data sets show no similarities at all. The first situation may arise because the base case and test case distribution functions are not significantly different from zero on a common domain. The second situation can be interpreted as a sign of very slow dynamics (little change between the PS and CPS measures). The third case displays more variability in the dynamics.

We view these results as an encouraging validation of our method and its potential for event forewarning. There are a few caveats though: (i) the present data were obtained in a controlled laboratory setting, which is substantially different from the uncontrolled plant environment where a monitoring device might attempt forewarning; (ii) the PS-reconstruction parameters were adjusted to give the best indication of forewarning for these datasets. The algorithm may not be equally well tuned for other datasets. Thus, we are acutely aware that as long as the dynamics is unknown, it may reserve surprises.

On the other hand, the performance and robustness of our approach on model data and real machine data suggests that this methodology could allow convenient, non-intrusive sensor placement by a technician in a non-laboratory, plant setting and be used as a complementary quantitative method in conjunction with other diagnostic methods. The technology is model-independent and computationally fast, allowing removal of artifacts in the data that would otherwise obscure the underlying dynamics. Future use of this 
approach as a complementary and/or stand-alone method for equipment failure forewarning will require extensive analysis of several events for each machine and failure mode, and detailed determination of detection criteria. Future work will involve: (i) statistical evaluation of false positives and negatives, and of false positives during normal operation, (ii) detailed monitoring of each machine to determine optimal PS reconstruction parameters, which subsequently would be fixed for real-time monitoring, (iii) the specific nonlinear feature(s) for event forewarning of know failure modes.

In addition to the above technical accomplishments, the PY1 work produced several important lessonslearned. First, the use of two different shim types in the misalignment test (Sec. 3.7) points to a need for closer coordination between DE\&S and ORNL for experimental design and test implementation. These details will be governed by the PY2 test plan. Second, ORNL's experience with motor data suggests that the high frequency "noise" in the power data (e.g., bottom subplot of Fig. 7) is indicative of the equipment dynamics. However, ORNL analysis of that noise did not uncover any such indications, probably due to an inadequate sampling rate. ORNL has asked DE\&S to look into higher sampling rates, perhaps up to $50 \mathrm{KHz}$. Third, DE\&S transferred the multi-megabyte datasets to ORNL as attachments to e-mail messages rapidly and easily. We expect to expand the use of data transfer via the Internet in PY2.

The second phase of the proposed work begins in PY2, and involves compelling demonstration of the nonlinear prognostication, which entails the acquisition and analysis of much more data. We hope to obtain at least 20 test sequences that begin with nominal operation, and progress to a non-normal, degraded, faulted, or failure state as a specific parameter changes. We further hope to show this forewarning for different kinds of nuclear-grade equipment, as opposed to many different failure modes for one piece of equipment. The measures of success include false positives, false negatives, and the forewarning times. ORNL subsequently will improve the nonlinear paradigm in order to minimize the number of false positive and false negative indications of failure, while maximizing the forewarning time. ORNL received $\$ 481 \mathrm{~K}$ for PY2 on $8 / 15 / 01$, and has begun planning efforts with DE\&S to continue collaboration on the NERI2000-109 project during this second phase.

\section{Acknowledgments}

We gratefully acknowledge sponsorship of this work by the U.S. Department of Energy's Nuclear Energy Research Initiative, and the Office of Basic Energy Sciences. The Oak Ridge National Laboratory is managed for the United States Department of Energy by UT-Battelle, LLC, under Contract No. DEAC05-00OR22725. 

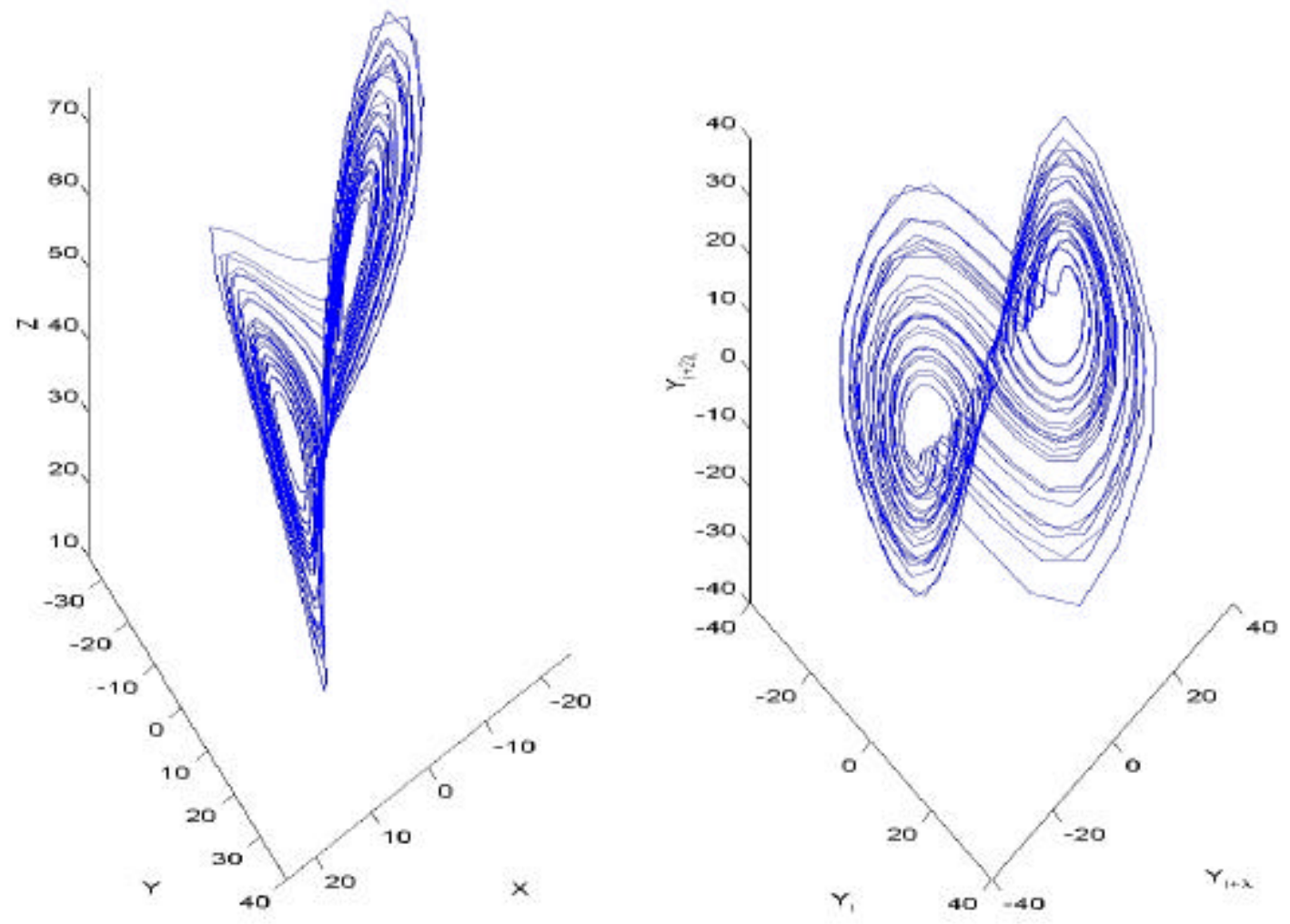

Fig. 1. Phase-space plots for the Lorenz system: (left) 1,000 points from the (x, y, z) coordinate sequence, as obtained from the integration Eq. (3.19) for $r=45, a=10$, and $b=8 / 3$; and (right) phasespace reconstruction for the same parameters as (left) but using three different time-delayed elements of the $y$-coordinate only to form the three-dimensional vector sequence $\left(y_{i}, y_{i+\lambda}, y_{i+2 \lambda}\right)$ for a time lag, $\lambda=3$. 

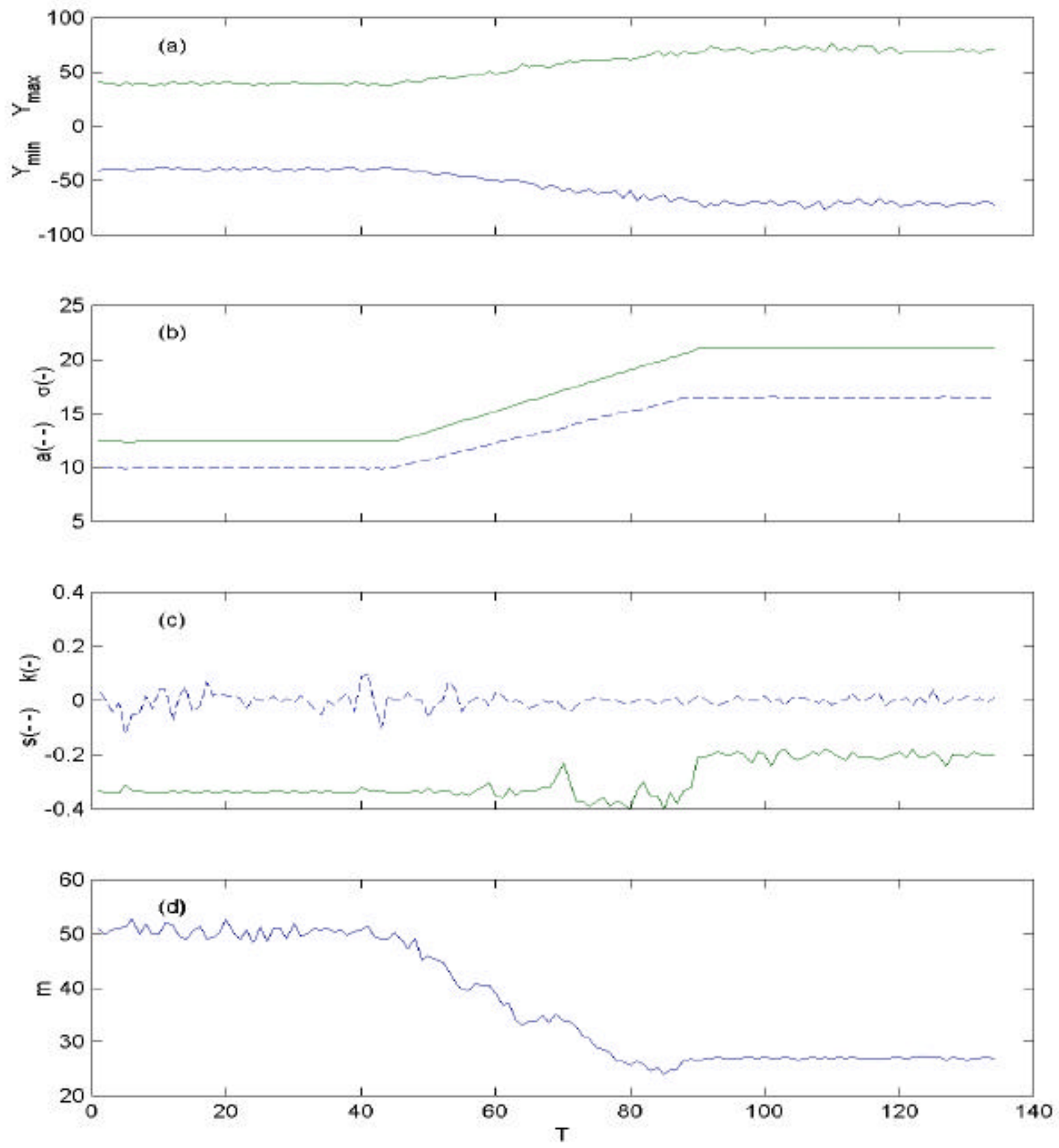

Fig. 2. Linear measures for the y-coordinate of the Lorenz system versus $r$ : (a) minimum $\left(\mathrm{Y}_{\min }\right)$ and maximum values $\left(\mathrm{Y}_{\max }\right)$, (b) absolute average deviation ( $a$, from Eq. 3.10) and standard deviation ( $\sigma$, from Eq. 3.2), (c) skewness ( $s$, from Eq. 3.3) and kurtosis $(k$, from Eq. 3.4), and (d) time steps per cycle ( $m$, from Eq. 3.5). As described in the text, the horizontal axis variable (T) is a surrogate for the value of $r$ is as follows: $r=45$ for $0 \leq \mathrm{T} \leq 45, r=\mathrm{T}$ for 46 $\leq \mathrm{T} \leq 89, r=90$ for $90 \leq \mathrm{T} \leq 134$. 

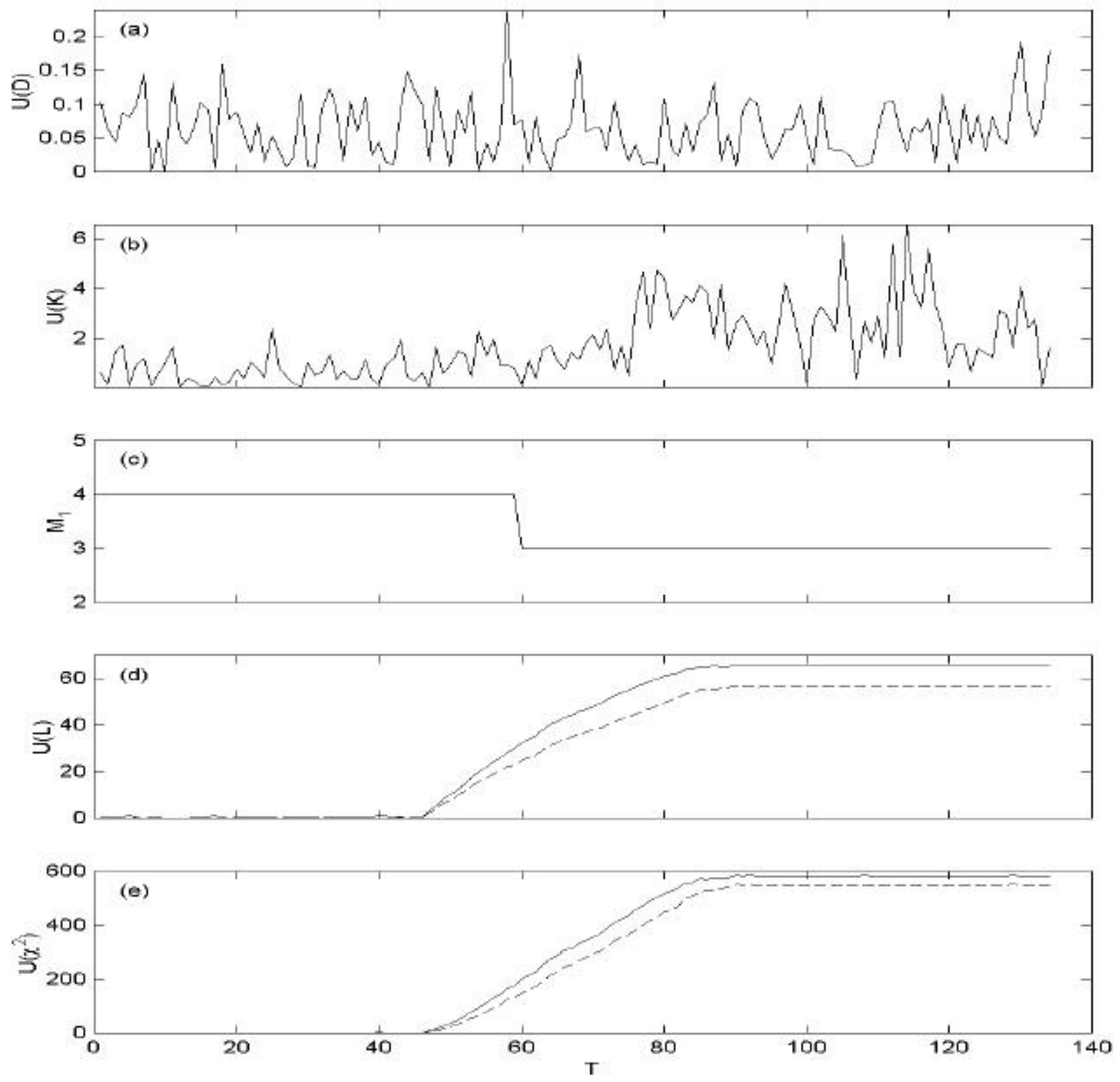

Fig. 3. Renormalized nonlinear measures versus $r$ for the y coordinate of the Lorenz system: (a) correlation dimension, (b) Kolmogorov entropy, (c) lag (in time steps) of the first minimum in the mutual information function, (d) non-connected (solid) and connected (--) $\mathrm{L}_{1}$ dissimilarity, and (e) non-connected (solid) and connected (--) $\chi^{2}$ dissimilarity. The phase-space reconstruction parameters are: $S=12, d=3$, $N=50000$, and $\lambda=2 . \mathrm{M}_{1}$ is constant for $r=45$, so subplot (c) is not renormalized. As described in detail in the text, the horizontal axis variable (T) is a surrogate for $r$ as follows: $r=45$ for $0 \leq \mathrm{T} \leq 45, r=\mathrm{T}$ for $46 \leq \mathrm{T} \leq 89, r=90$ for $90 \leq \mathrm{T} \leq 134$. 

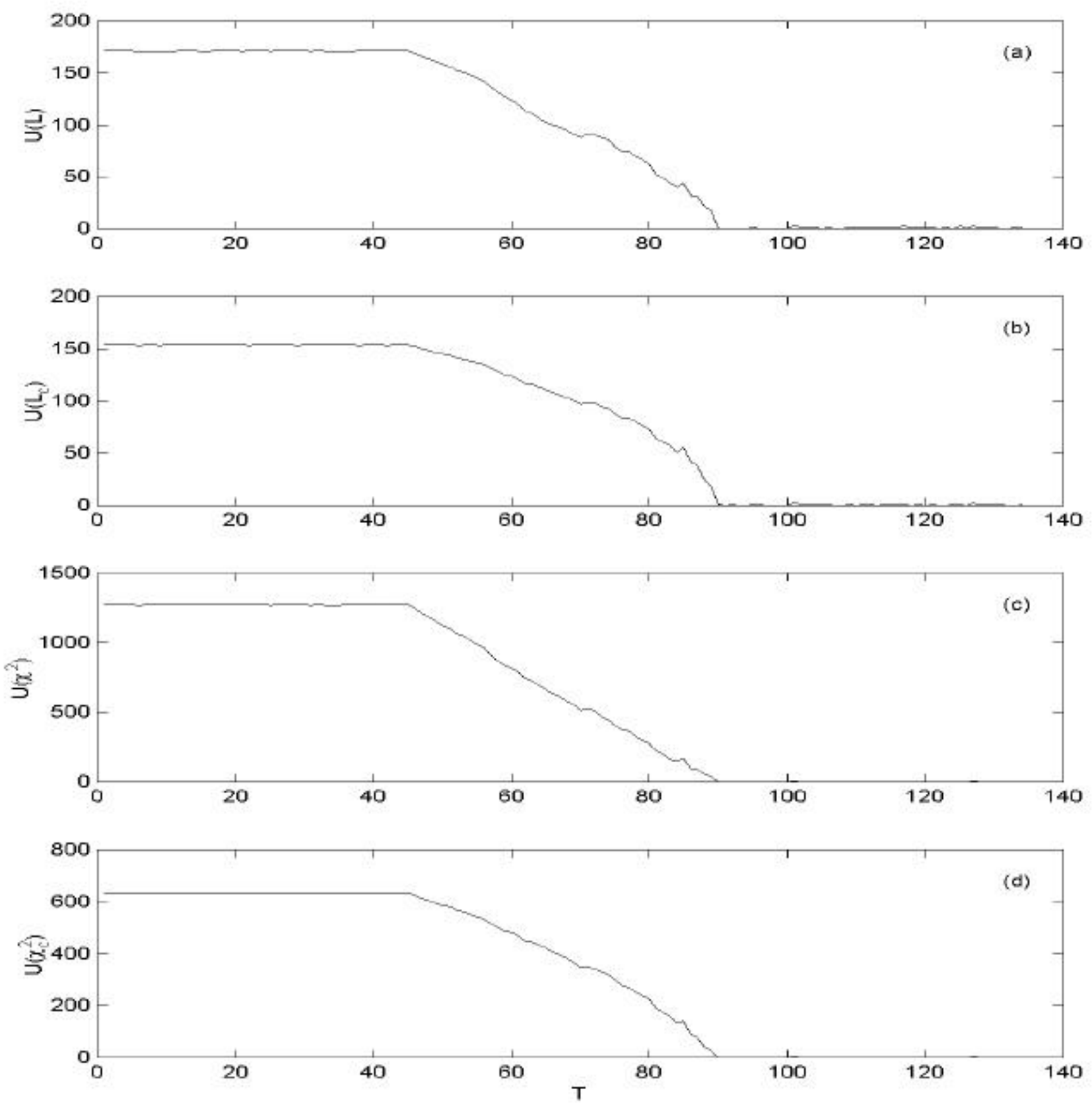

Fig. 4. Renormalized nonlinear measures versus $r$ for the y coordinate of the Lorenz system with the basecase over the first 10 cutsets of $r=90$ : (a) non-connected $L_{1}$ dissimilarity, (b) connected $L_{1}$ dissimilarity, (c) non-connected connected $\chi^{2}$ dissimilarity, and (d) connected $\chi^{2}$ dissimilarity. The phasespace reconstruction parameters are: $S=12, d=3, N=50000$, and $\lambda=7$. The value of $r$ is as follows: $r=$ 45 for $0 \leq \mathrm{T} \leq 45, r=\mathrm{T}$ for $46 \leq \mathrm{T} \leq 89, r=90$ for $90 \leq \mathrm{T} \leq 134$. 

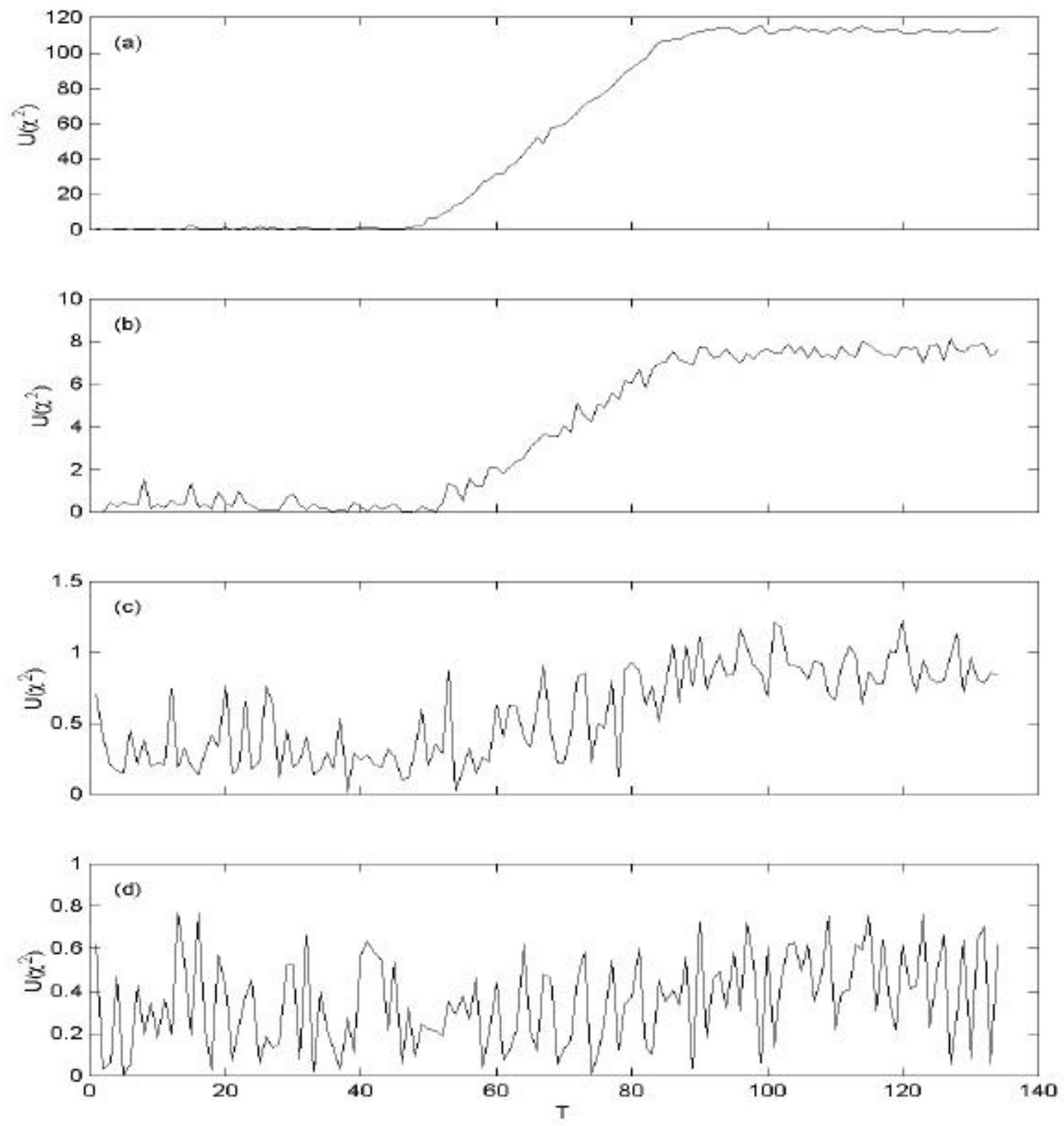

Fig. 5. Renormalized nonlinear measures versus $r$ for the y coordinate of the Lorenz system: (a) non-connected $\chi^{2}$ dissimilarity for $N=5000$, (b) non-connected $\chi^{2}$ dissimilarity for $N=500$, (c) non-connected $\chi^{2}$ dissimilarity for $N=50$, (d) non-connected $\chi^{2}$ dissimilarity for $N=25$. The phase-space reconstruction parameters are: $S=12, d=3$, and $\lambda=2$. The horizontal axis variable (T) is a surrogate for $r$ as follows: $r=45$ for $0 \leq \mathrm{T} \leq 45, r=\mathrm{T}$ for 46 $\leq \mathrm{T} \leq 89, r=90$ for $90 \leq \mathrm{T} \leq 134$. 


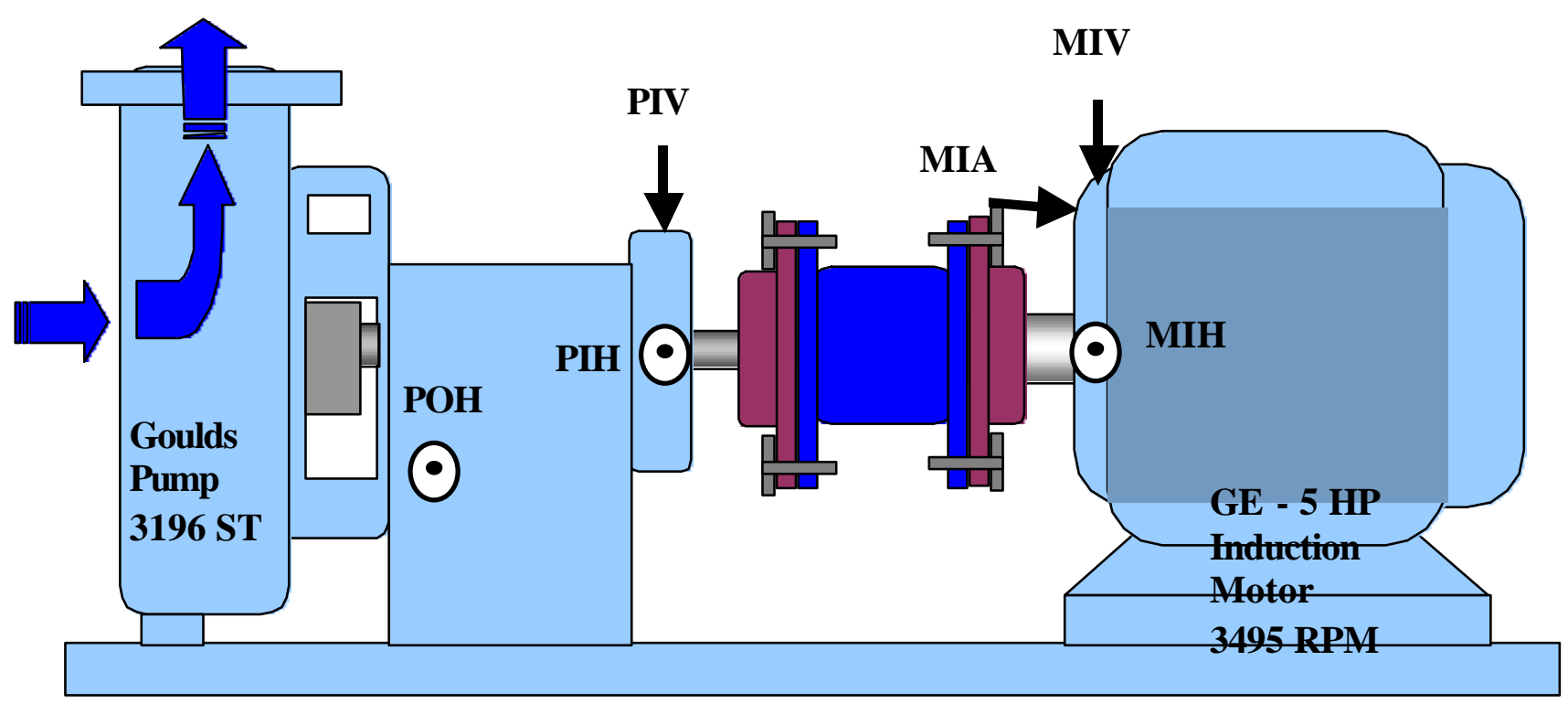

Fig. 6. Important features of the test equipment (5HP motor-driven pump) at the DE\&S testing facility in Mount Holly, North Carolina. DE\&S performed measurements of vibration on the motor inboard bearing casing velocity per ISO standards 2372 and 3945, as discussed in App. A, for correlation with the nonlinear analysis; see text for discussion. Vibration measurement points as indicated on the figure are:

$$
\begin{array}{ll}
\text { PIV }=\text { Pump Inboard Vertical } & \text { MIV }=\text { Motor Inboard Vertical } \\
\text { PIH = Pump Inboard Horizontal } & \text { MIH }=\text { Motor Inboard Horizontal } \\
\text { POH = Pump Outboard Horizontal } & \text { MIA }=\text { Motor Inboard Axial }
\end{array}
$$

MIV and MIH are the main indicators of motor vibration. 

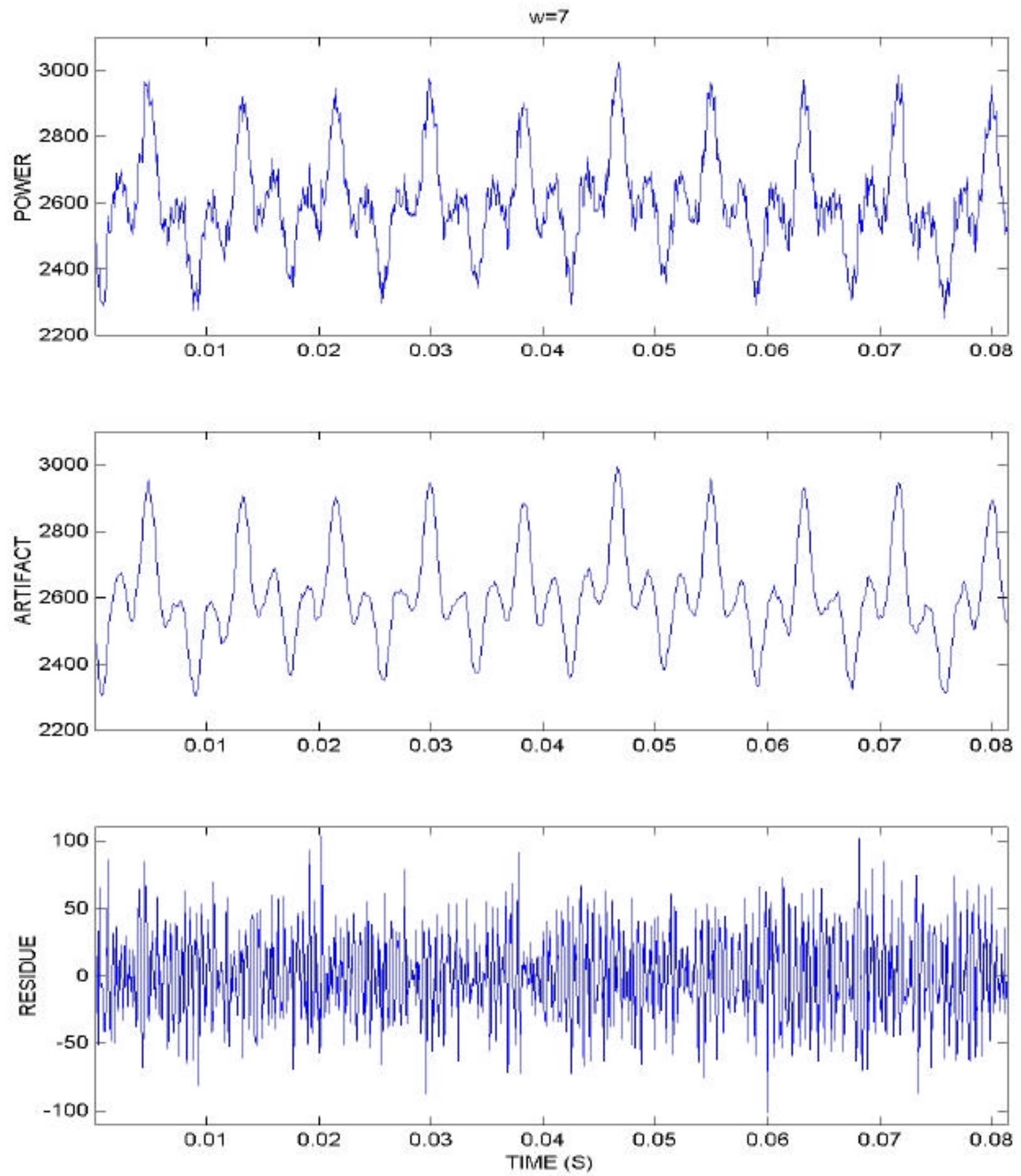

Fig. 7. Use of the zero-phase quadratic filter for removal of high-frequency noise from typical power data from the baseline unbalance test: (top) raw power data, (middle) extraction of the low-frequency component of the power data via the zero-phase quadratic filter, and (bottom) residual high-frequency "noise" after subtraction of the low-frequency power data from the raw data. 

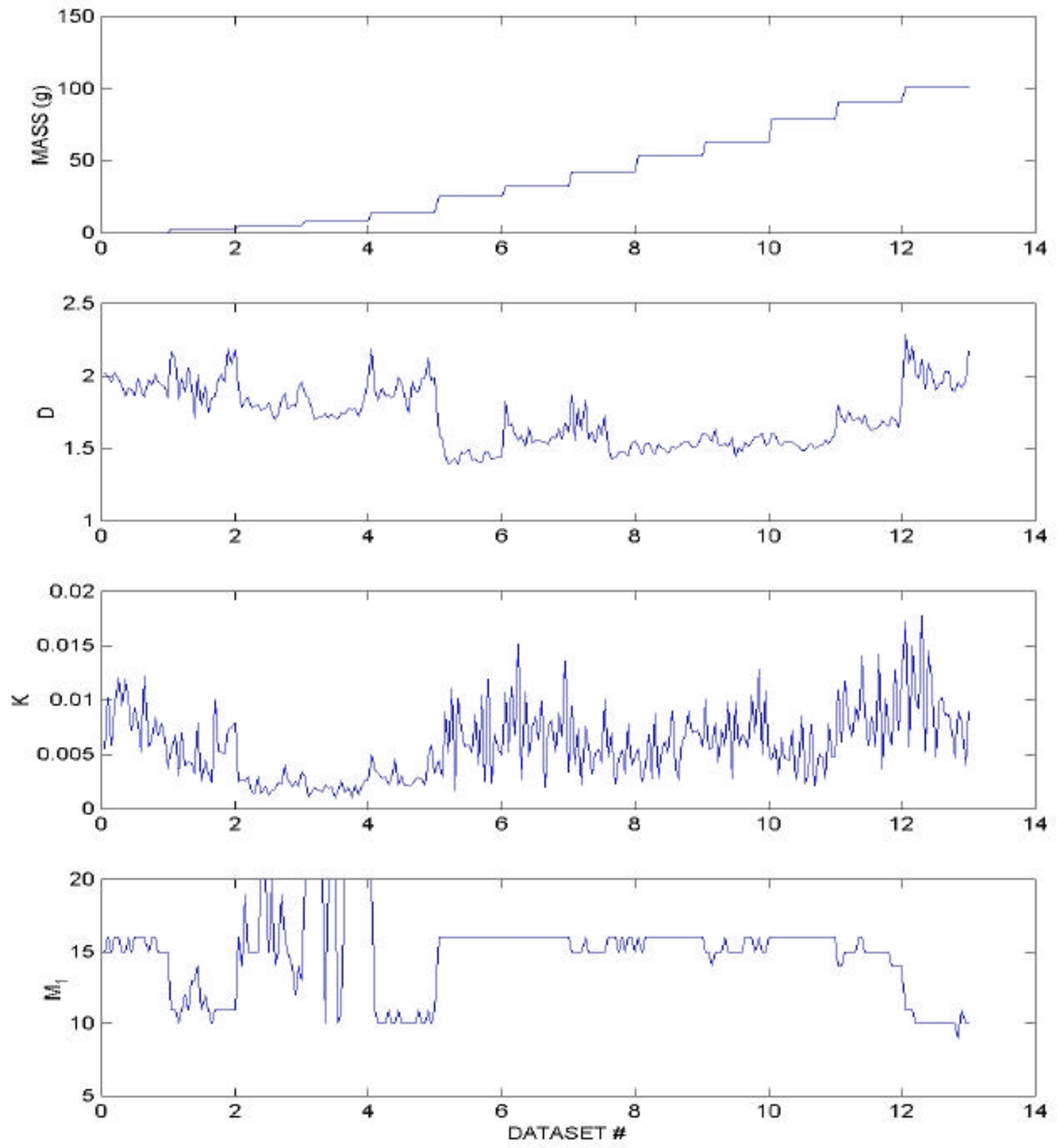

Fig. 8. Various linear measures of the unbalance power data as a function of the dataset number: (top) unbalance mass in grams; (second) minimum power $\left(\mathrm{P}_{\mathrm{n}}\right)$, maximum power $\left(\mathrm{P}_{\mathrm{x}}\right)$, and the average power \pm one standard deviation $(\sigma)$; (third) skewness (solid) and kurtosis (- -); (bottom) timesteps per cycle (TS/C). There is no correlation between these linear measures and the monotonically increasing amount of unbalance mass; see text for a detailed discussion. 

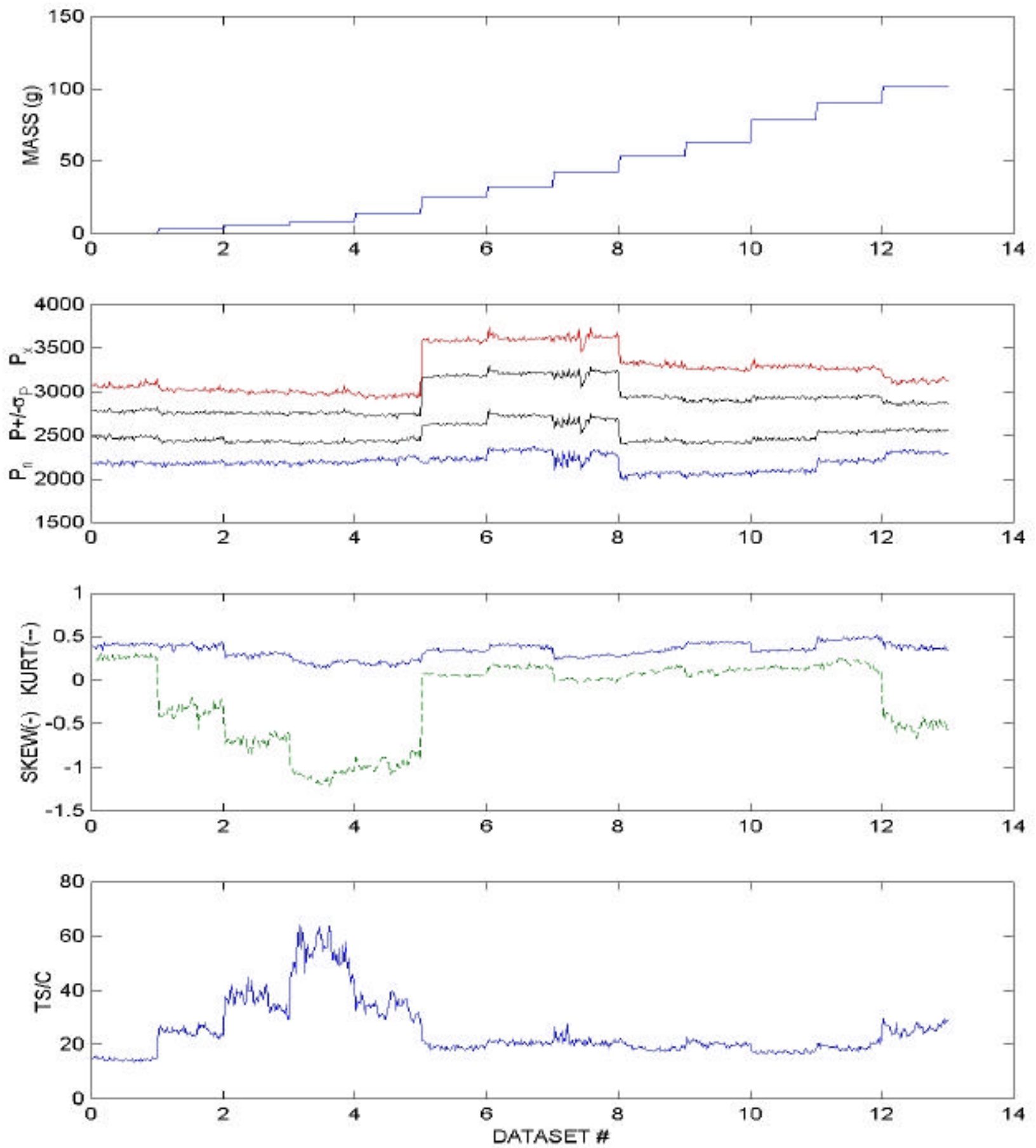

Fig. 9. Traditional nonlinear measures of the unbalance power data as a function of the dataset number. (top) unbalance mass (grams); (second) correlation dimension (D); (third) Kolmogorov entropy $(\mathrm{K})$; (bottom) first minimum in the mutual information function $\left(\mathrm{M}_{1}\right)$. No correlation exists between these traditional nonlinear measures and the monotonically increasing amount of unbalance mass; see text for further discussion. 


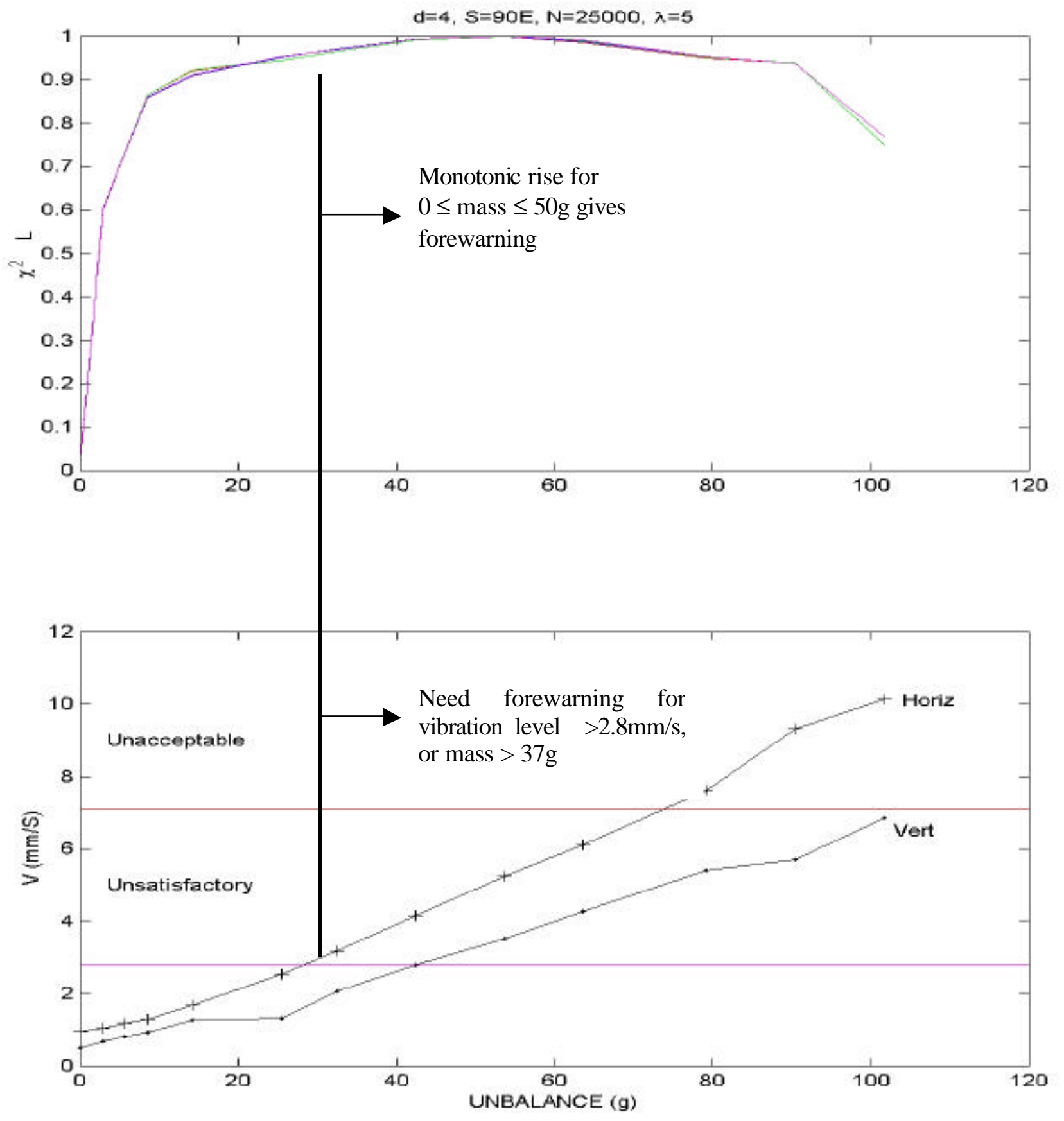

Fig. 10. Correlation of phase-space dissimilarity measure $s$ and vibration levels as a function of the unbalance mass: (top) (non)connected phase-space dissimilarity measures $\chi^{2}, \chi_{\mathrm{c}}{ }^{2}, \mathrm{~L}$ and $\mathrm{L}_{\mathrm{c}}$ ); (bottom) peak vibration levels in the horizontal direction (denoted as MIH in Fig. 6 and as 'horiz' in this figure) and the vertical direction (denoted as MIV in Fig. 6 and as 'vert' in this figure). The phase-space dissimilarity measures (top) rise monotonically and in unison for $0 \leq$ mass $\leq 50 \mathrm{~g}$, in direct correlation with the monotonic rise in peak vibration levels (bottom). The best condition change discrimination occurs for the following parameter values: $S=90$ (equiprobable symbols), $d=4, \lambda=5$, and $\mathrm{N}=25000$. Dissimilarity measures are scaled between 0 and 1 for ease of comparison. 


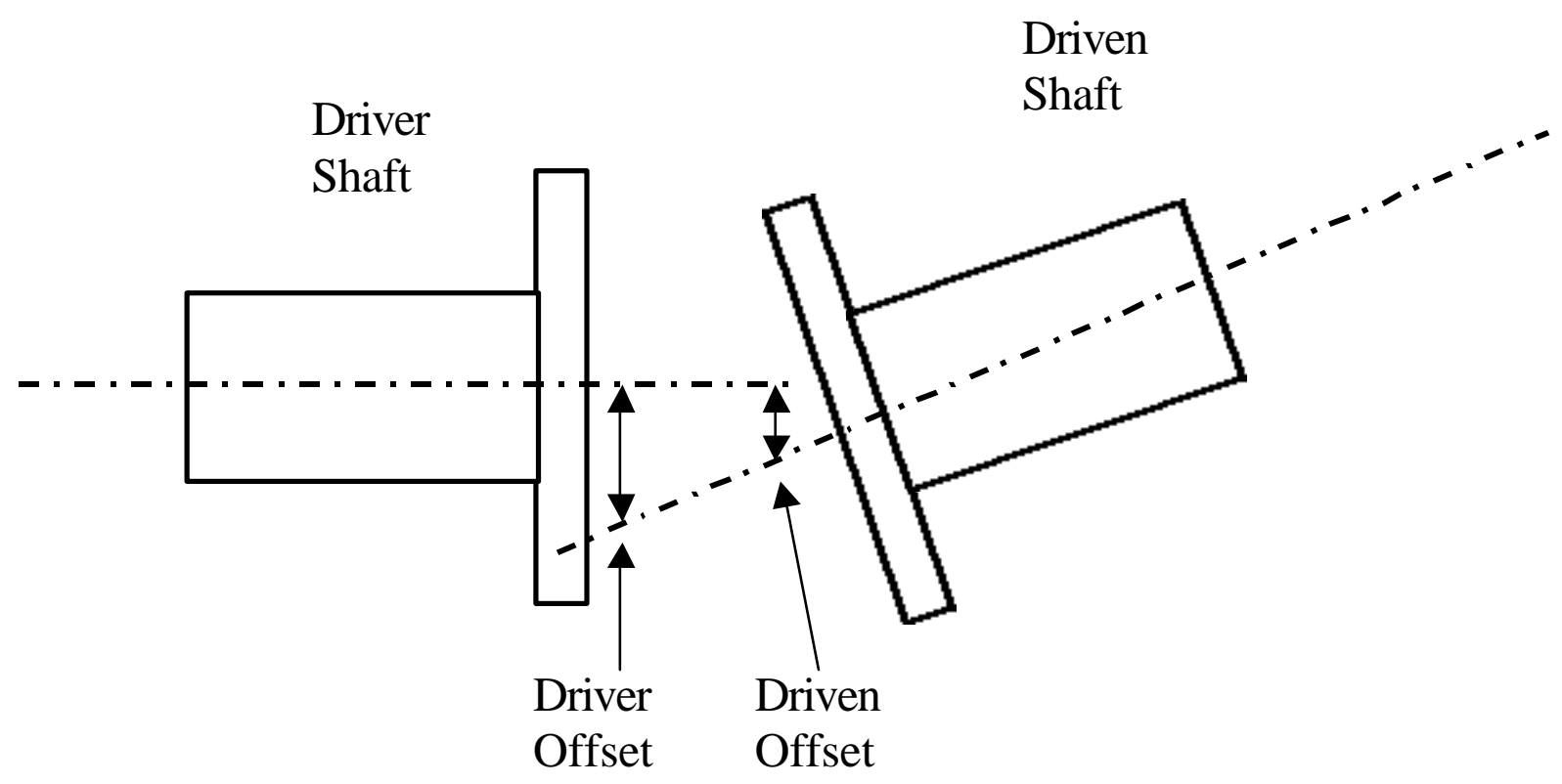

Fig. 11. Illustration of misalignment between motor and pump. Misalignment is typically expressed in mils/inch or an offset in mils for the angle made by the shaft centerlines. A parallel misalignment may be defined as the distance between two rotational centerlines in a given plane, often referred to as offset misalignment. DE\&S measured the misalignment via a laser alignment system with a resolution of $1 / 1000 \mathrm{~mm}$. DE\&S used shims at the motor-to-pump coupling and under motor mount to produce misalignment. 

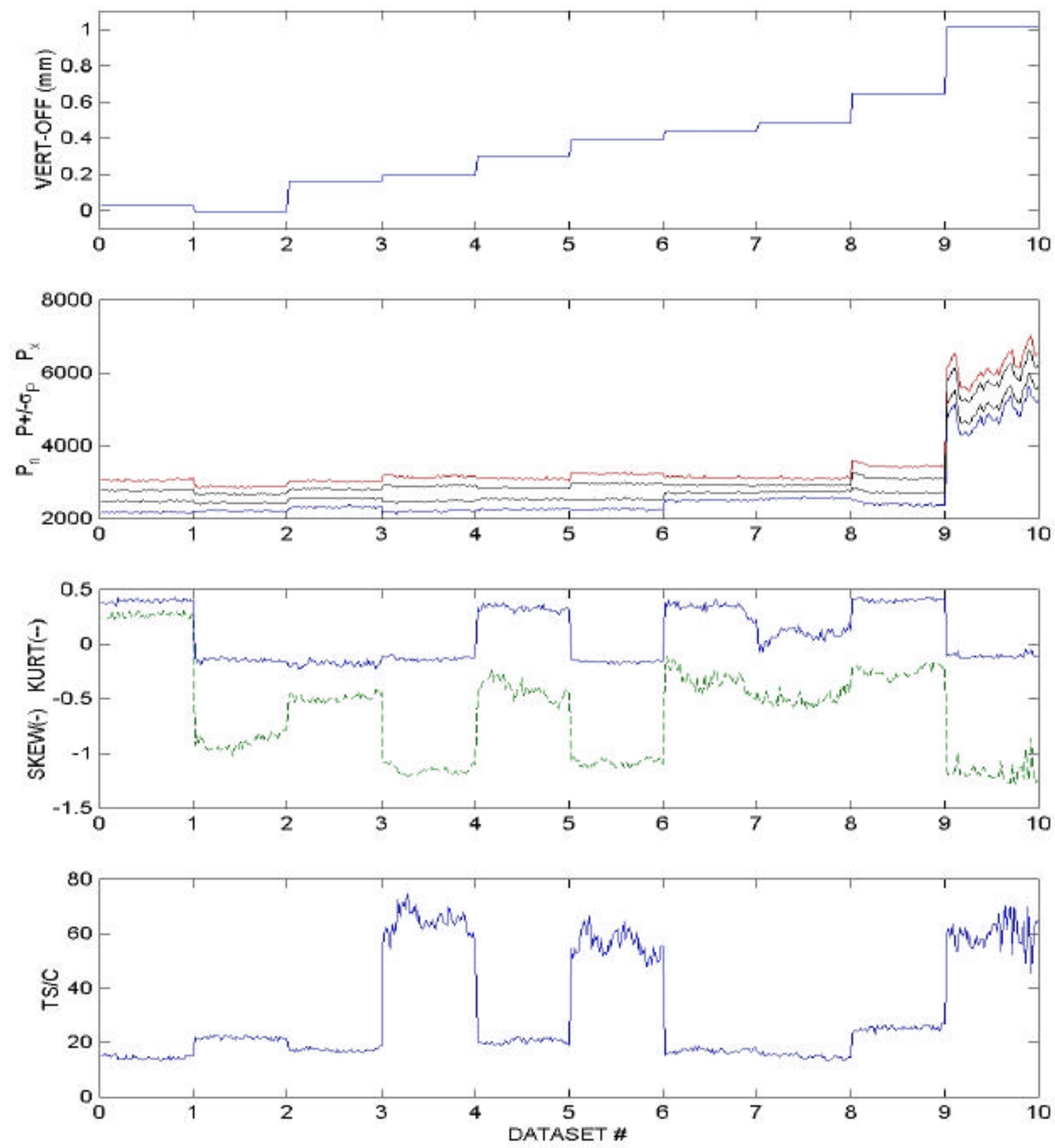

Fig. 12. Various linear measures of the misalignment power data as a function of the dataset number: (top) vertical angular misalignment (in millimeters as defined in Fig. 11); (second) minimum power $\left(\mathrm{P}_{\mathrm{n}}\right)$, maximum power $\left(\mathrm{P}_{\mathrm{x}}\right)$, and the average power \pm one standard deviation $(\sigma)$; (third) skewness (solid) and kurtosis (- -); (bottom) timesteps per cycle (TS/C). There is no correlation between these linear measures and the amount of misalignment; see text for a detailed discussion. 

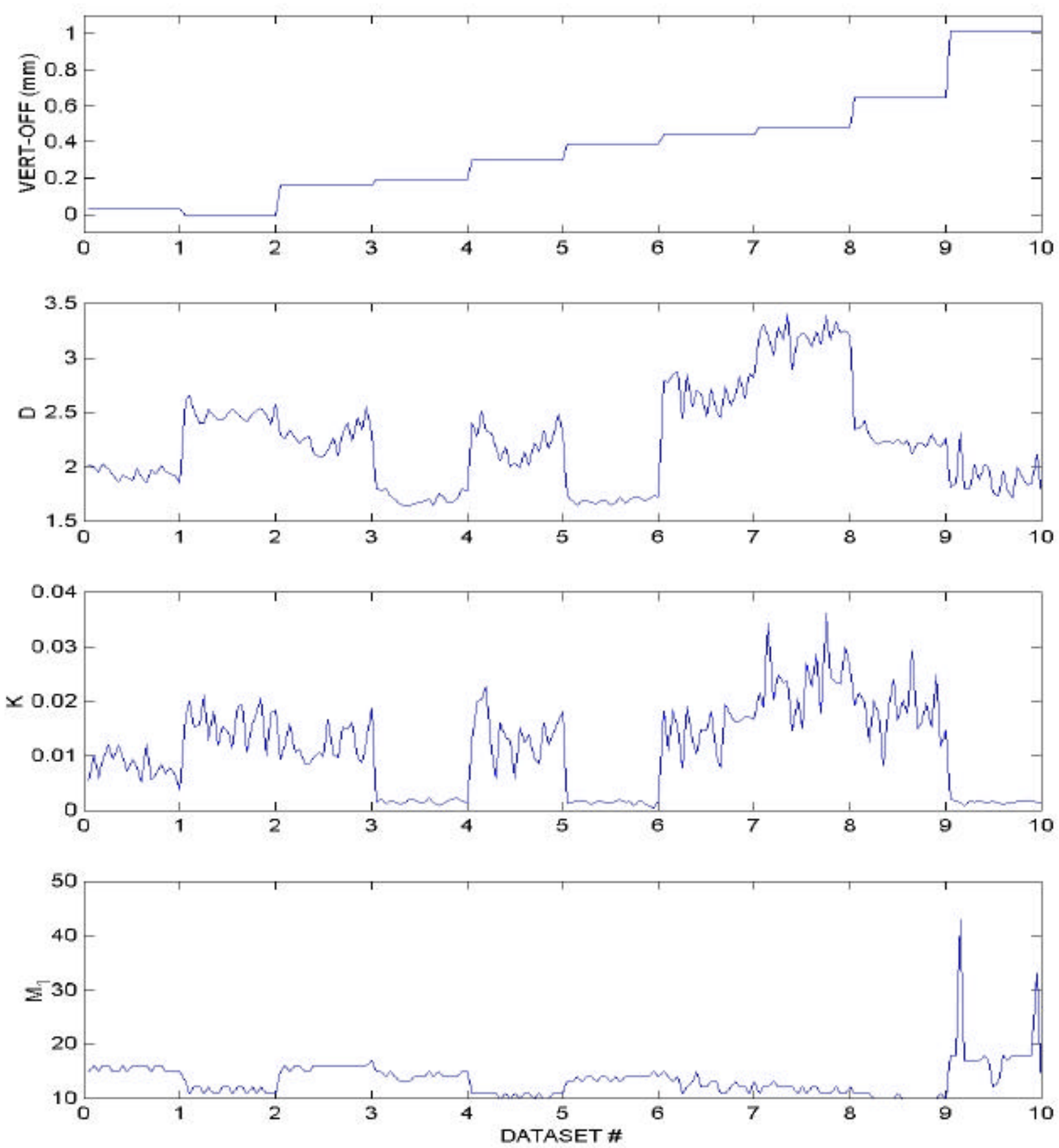

Fig. 13. Traditional nonlinear measures of the misalignment power data as a function of the dataset number: (top) vertical angular misalignment (in millimeters, as defined in Fig. 11); (second) correlation dimension $(D)$; (third) Kolmogorov entropy $(K)$; (bottom) first minimum in the mutual information function $\left(M_{1}\right)$. No correlation exists between these traditional nonlinear measures and the monotonically increasing amount of misalignment; see text for further discussion. 

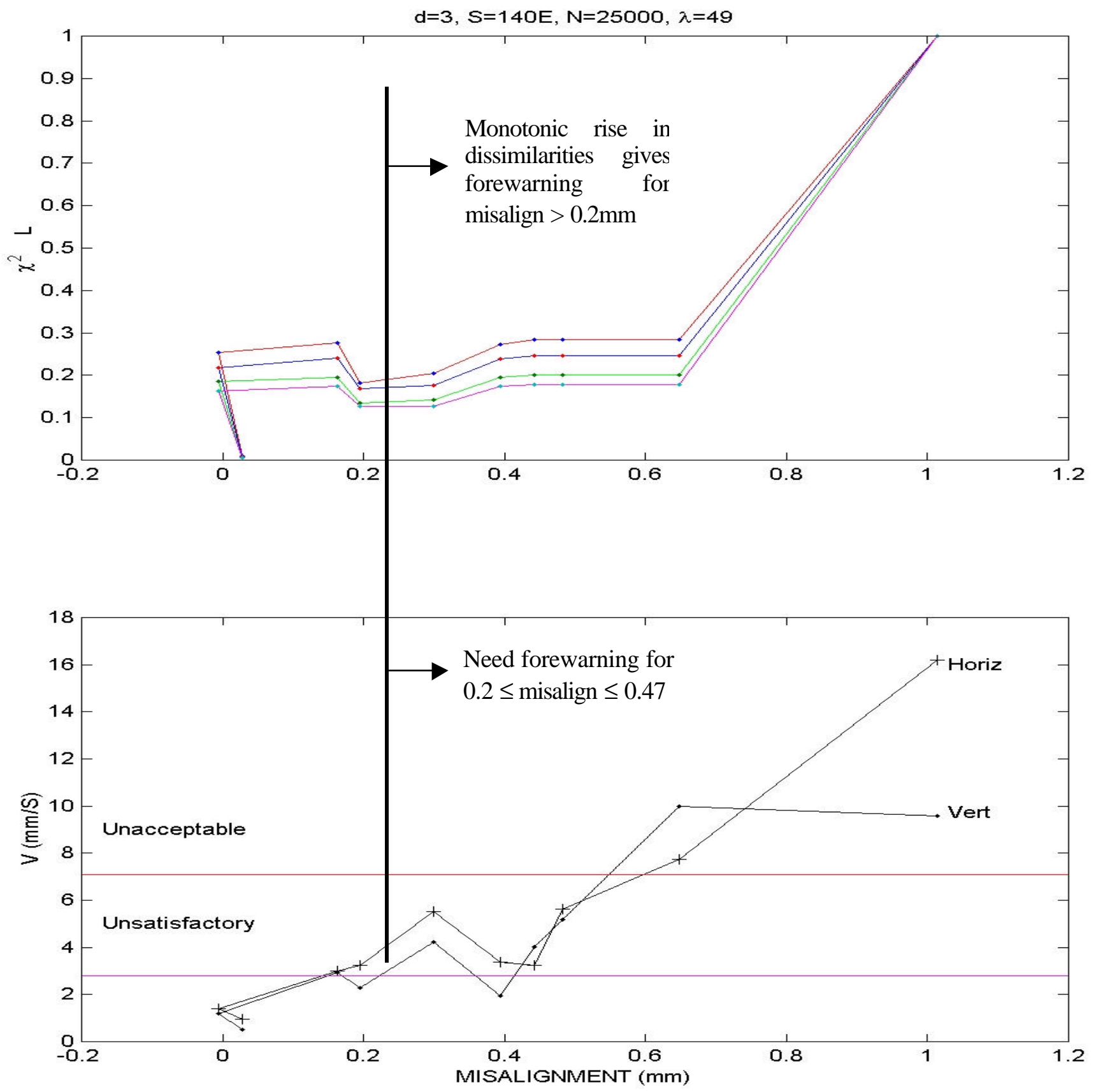

Fig. 14. Correlation of phase-space dissimilarity measures and vibration levels as a function of the unbalance mass: (top) (non) connected phase-space dissimilarity measures $\left(\chi^{2}, \chi_{c}{ }^{2}, L\right.$ and $L_{c}$ ); (bottom) peak vibration levels in the horizontal direction (denoted as MIH in Fig. 6 and as 'horiz' in this figure) and the vertical direction (denoted as MIV in Fig. 6 and as 'vert' in this figure). Note that the phase-space dissimilarity measures (top) rise monotonically and in unison for misalignment $>0.2 \mathrm{~mm}$, in correlation with the (erratic) rise in peak vibration levels (bottom). The best condition change discrimination occurs for the following parameter values: $S=140$ (equiprobable symbols), $d=3, \lambda=49$, and $\mathrm{N}=25$ 000. Dissimilarity measures are scaled between 0 and 1 for easy comparison. 
Table 1: Summary of Unbalance Test

\begin{tabular}{|c|c|c|c|c|c|c|c|}
\hline \multirow[b]{2}{*}{ Test \# } & \multirow{2}{*}{$\begin{array}{l}\text { Mass } \\
\text { (oz) }\end{array}$} & \multicolumn{6}{|c|}{ 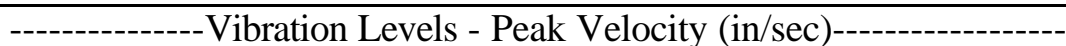 } \\
\hline & & MIV $^{*}$ & $\mathrm{MIH}^{*}$ & MIA & PIV & PIH & $\mathrm{POH}$ \\
\hline 1 & 0.00 & 0.0196 & $\mathbf{0 . 0 3 8 0}$ & 0.0445 & 0.0188 & 0.0182 & 0.0120 \\
\hline 2 & 0.10 & 0.0264 & 0.0414 & 0.0500 & 0.0200 & 0.0232 & 0.0116 \\
\hline 3 & 0.20 & 0.0321 & 0.0462 & 0.0555 & 0.0217 & 0.0226 & 0.0117 \\
\hline 4 & 0.30 & 0.0364 & 0.0514 & 0.0637 & 0.0216 & 0.0252 & 0.1172 \\
\hline 5 & 0.50 & 0.0497 & 0.0665 & 0.0843 & 0.0218 & 0.0293 & 0.0143 \\
\hline 6 & 0.90 & 0.0521 & 0.1000 & 0.1460 & 0.0264 & 0.0444 & 0.0261 \\
\hline 7 & 1.15 & 0.0817 & 0.1250 & 0.1770 & 0.0237 & 0.0511 & 0.0271 \\
\hline 8 & 1.50 & 0.1100 & 0.1640 & 0.2360 & 0.0255 & 0.0601 & 0.0356 \\
\hline 9 & 1.90 & 0.1390 & 0.2070 & 0.3120 & 0.0270 & 0.0741 & 0.0432 \\
\hline 10 & 2.25 & 0.1680 & 0.2410 & 0.3700 & 0.0277 & 0.0838 & 0.0537 \\
\hline 11 & 2.80 & 0.2130 & 0.3000 & 0.4600 & 0.0326 & 0.0979 & 0.0644 \\
\hline 12 & 3.20 & 0.2250 & 0.3670 & 0.5340 & 0.0439 & 0.1290 & 0.0859 \\
\hline 13 & 3.60 & 0.2700 & 0.3990 & 0.6060 & 0.0379 & 0.1400 & 0.0914 \\
\hline
\end{tabular}

* Vibration at the motor inboard bearing

Table 2: Summary of Data from Misalignment Test

\begin{tabular}{|c|c|c|c|c|c|c|c|c|c|c|c|}
\hline & $\begin{array}{l}\text { Shim. } \\
\text { Thick }\end{array}$ & $\begin{array}{l}\text { Horiz } \\
\text { Ang. }\end{array}$ & $\begin{array}{l}\text { Horiz } \\
\text { Off. }\end{array}$ & $\begin{array}{l}\text { Vert } \\
\text { Ang. }\end{array}$ & $\begin{array}{l}\text { Vert } \\
\text { Off. }\end{array}$ & & Vibration & vels - Pe & Velocity & in $/ \mathrm{sec}$ & \\
\hline \# & & Mils & Mils & Mils & Mils & MIV $^{*}$ & MIH $^{*}$ & MIA & PIV & PIH & $\mathrm{POH}$ \\
\hline$\overline{1}$ & 0 & 0.05 & 1 & 1.1 & 1.7 & 0.0196 & 0.0380 & 0.0445 & 0.0188 & 0.0182 & 0.0120 \\
\hline 2 & 0.000 & 0.5 & 0 & -0.2 & -0.1 & 0.0468 & 0.0556 & & 0.0474 & 0.0465 & 0.0301 \\
\hline 3 & $0.002^{\#}$ & 0.3 & 0.1 & 6.4 & 1.7 & 0.1160 & 0.1180 & & 0.0864 & 0.0906 & 0.0553 \\
\hline 4 & $0.005^{\#}$ & -1.9 & -0.2 & 7.7 & 2.4 & 0.0897 & 0.1280 & 0.1090 & 0.0331 & 0.0770 & 0.0569 \\
\hline 5 & $0.006^{\#}$ & -0.3 & -0.1 & 11.8 & 3.3 & 0.1670 & 0.2170 & 0.3120 & 0.1440 & 0.1460 & 0.0978 \\
\hline 6 & $0.010^{\#}$ & -3 & -0.1 & 15.5 & 5.1 & 0.0759 & 0.1330 & 0.1040 & 0.0435 & 0.0715 & 0.0519 \\
\hline 7 & $0.015^{\#}$ & 0.4 & 0.1 & 17.4 & 4.5 & 0.1580 & 0.1270 & 0.2330 & 0.0958 & 0.1030 & 0.0737 \\
\hline 8 & $0.005^{+}$ & 3.9 & 1.2 & 19.0 & 5.0 & 0.2040 & 0.2210 & 0.3560 & 0.1730 & 0.1910 & 0.1100 \\
\hline 9 & $0.010^{+}$ & 8.6 & 1.9 & 25.5 & 6.0 & 0.3930 & 0.3050 & 0.6580 & 0.2420 & 0.2090 & 0.1260 \\
\hline 10 & $0.020^{\#}$ & -2.3 & 0.7 & 39.9 & 12.6 & 0.3770 & 0.6370 & & & & \\
\hline$\underline{0}$ & $0.000^{\&}$ & -1.5 & -0.2 & 1.4 & 0.4 & 0.0558 & 0.1220 & 0.0810 & 0.0262 & 0.0594 & 0.0365 \\
\hline
\end{tabular}





\section{References}

H. D. I. Abarbanel, Analysis of Observed Chaotic Data (Springer pub., New York) 1996.

H. D. I. Abarbanel, R. Brown, J.J. Sidorowich, and L. S. Tsimring, "The analysis of observed chaotic data in physical systems," Rev. Mod. Phys. 65 (1993) 1331-1392.

H. D. I. Abarbanel and M. B. Kennel, "Local false nearest neighbors and dynamical dimensions from observed chaotic data," Phys. Rev. E 47 (1993) 3057-3068.

M. Abramowitz and I. A. Stegun (ed.), Handbook of Mathematical Functions, U. S. Government Printing Office, Washington, D.C. (1965).

O. N. Bjernstad and B. T. Grenfell, "Noisy Clockwork: Time Series Analysis of Population Fluctuations in Animals," Science 293 (2001) 638-643.

V. E. Bondarenko, "Analog neural network model produces chaos similar to the human EEG," Int. J. Bifurcation Chaos 7 (1997) 1133-40.

L. Cao, "Practical method for determining the minimum embedding dimension for a scalar time series," Physica D 110 (1997) 43-59.

M. Casdagli, "Nonlinear Prediction of Chaotic Time Series,” Physica D 35 (1989) 335.

J. M. Cushing, et al., J. Theor. Biol. 194 (1998) 1.

A. Cover, J. Reneke, S. Lenhart, and V. Protopopescu, "RKH space methods for low level monitoring and control of nonlinear systems. II A vector case example: the Lorenz system," Math. Models and Meth. in Appl. Sci. 7 (1997) 82345.

C. Diks, W. van Zwet, F. Takens, and J. DeGoede, "Detecting differences between delay vector distributions," Phys. Rev. E 53 (1996) 2169-76.

J. P. Eckmann and D. Ruelle, "Ergodic theory of chaos and strange attractors," Rev. Mod. Phys. 57 (1985) 617-55.

S. P. Ellner and Y. Seifu, J. Comput. Graph. Stat., in press.

M. A. Essawy, "Prediction of Machine Performance Using Artificial Intelligence Methods," Proc. Maintenance and Reliability Conf., Univ. of Tennessee publ., Knoxville, Tn. (2001).

J. D. Farmer and J. Sidorowich, "Predicting Chaotic Time Series," Phys. Rev. Lett. 59 (1987) 845.

A. M. Fraser and H. L. Swinney, "Independent coordinates for strange attractors from mutual information." Phys. Rev. A 33 (1986) 1134-40.

P. C. Gailey, L. M. Hively, and V. A. Protopopescu, "Robust detection of dynamical change in scalp EEG," in Proc. Fifth Experimental Chaos Conference, June 28 - July 1, 1999, Orlando, Florida (to be published). 
I. S. Gradshteyn and I. M. Ryzhik, Tables of Integrals, Series, and Products, Academic Press publ., New York ( $4^{\text {th }}$ ed., 1965).

C. Grebogi, E. Ott, and J. A. Yorke, "Unstable periodic orbits and the dimensions of multifractal chaotic attractors," Phys. Rev. A 37 (1988) 1711-24.

D. L. Harmon, J. E. Campbell, L. D. Chapman, M. W. Golay, K. P. Maynard, J. W. Spencer, "Developing 'Smart' Equipment and Systems through Collaborative NERI Research and Development: a First Year of Progress," Proc. Maint. Reliability Conf. (6-9 May 2001) Gatlinburg, TN (Univ. Tennessee, Knoxville).

L. M. Hively, N. E. Clapp, C. S. Daw, and W. F. Lawkins, "Nonlinear analysis of EEG for epileptic events," ORNL/TM-12961 (Oak Ridge National Laboratory, Oak Ridge, TN, 1995).

L. M. Hively, "Data-Driven Nonlinear Technique for Condition Monitoring," Proc. Maintenance and Reliability Conf. (Univ. of Tennessee, Knoxville, Tn) 1 (1997) 16.01-16.10.

L. M. Hively, P. C. Gailey, and V. A. Protopopescu, "Detecting dynamical change in nonlinear series time series," Phys. Lett. A 258 (1999) 103-114.

L. M. Hively, P. C. Gailey, and V. A. Protopopescu, "Sensitive Measures of Condition Change in EEG Data," in Proc. International Workshop: "Chaos in Brain?,'”(Bonn, Germany, 10-12 March, 1999), ed. K. Lehnertz et al. (World Scientific, Singapore, 2000), p. 333-336.

L. M. Hively, V. A. Protopopescu, and P. C. Gailey, "Timely detection of dynamical change in scalp EEG signals," Chaos 10 (2000a) 864-875.

E. A. Jackson, Perspectives of Nonlinear Dynamics, (Cambridge University Press) 1 (1989); 2 (1990).

H. Kantz and T. Schreiber, Nonlinear Time Series Analysis, (Cambridge University Press) 1997.

R. I. King, "Historical Background," Chapter 1 in Handbook of High-Speed Machining Technology, R. I. King ed., (Chapman and Hall publ., New York) 1985.

C. Letellier, J. Maquet, L. Le Sceller, G. Gouesbet, and L. A. Aguirre, "On the non-equivalence of observables in phase-space reconstructions from recorded time series," J. Phys. A. 31 (1998) 7913 - 7927.

E. N. Lorenz, "Deterministic nonperiodic flow,” J. Atmos. Sci. 20 (1963) 130-141.

R. Manuca, M. C. Casdagli, and R. S. Savit, "Nonstationarity in epileptic EEG and implications for neural dynamics," Math. Biosci. 147 (1998) 1-22.

R. Manuca and R. S. Savit, "Stationarity and nonstationarity in time series analysis," Physica D 99 (1996) 134-161.

B. R. Moeckel and B. Murray, "Measuring the distance between time series," Physica D 102 (1997) 187194.

NIST/ATP Workshop on Condition-Based Maintenance, http://www.nist.gov/www/cbm/cbm_wp1.htm>.

NRC (2000), http://www.nrc.gov/NRR/OVERSIGHT/ROP/description.html\#cornerstones. 
V. Protopopescu, L. M. Hively, and P. C. Gailey, "Robust forewarning of dynamical change from single channel scalp EEG data", Proc. $18^{\text {th }}$ Energy symposium on energy Sciences (May 15-16, 2000) Argonne, p. $137-45$.

V. Protopopescu, L. M. Hively, and P. C. Gailey, "Robust forewarning of dynamical change from single channel scalp EEG data," Proc. $18^{\text {th }}$ Energy Symp. on Energy Sci.(May 15-16, 2000) Argonne, p. 137-45.

V. A. Protopopescu, L. M. Hively, and P. C. Gailey "Epileptic event forewarning from scalp EEG," invited review paper in J. Clin. Neurophysiol. 18 (May 2001), 223-245.

L. Qu, A. Xie, and S. Li, "Study and Performance Evaluation of Some Nonlinear Diagnostic Methods for Large Rotating Machined," Mech. mach. Theory, 28, (1993), 699-713.

R. Quian Quiroga, J. Arnhold, K. Lehnertz, and P. Grassberger, "Kuhlback-Leibler and renormalized entropies: Applications to electroencephalograms of epilepsy patients," Phys. Rev. E. 62 (2000) 83808386.

A. Rezek and S. J. Roberts, "Stochastic complexity measures for physiological signal analysis," IEEE Trans. Biomedical Eng. 45 (1998) 1186-1191.

T. Sauer, J. Yorke, and M. Casdagli, “Embedology,” J. Stat. Phys. 65 (1991) 579-616.

J. C. Schouten, F. Takens, and C. M. van den Bleek, "Maximum likelihood estimation of the entropy of an attractor," Phys. Rev. E 49 (1994) 126-129.

J. C. Schouten, F. Takens, and C. M. van den Bleek, "Estimation of the dimension of a noisy attractor," Phys. Rev. E 50 (1994a) 1851-1861.

A. T. Schreiber, "Detecting and analyzing nonstationarity in a time series using nonlinear cross predictions," Phys. Rev. Lett. 78 (1997) 843-46.

A. T. Schreiber, "Interdisciplinary application of nonlinear time series methods," Phys. Rep. 308 (1999) $1-64$.

C. E. Shannon and W. Weaver, The Mathematical Theory of Communication (Univ. of Illinois Press, Urbana) 1949.

G. Sugihara and R. M. May, "Nonlinear Forecasting as a Way of Distinguishing Chaos from Measurement Error in Time Series," Nature 344 (1990) 734.

F. Takens, "Dynamical Systems and Turbulence," Lecture Notes in Mathematics 898 (1981) 366 (Springer publ., New York).

F. Takens, "On the numerical determination of the dimension of an attractor," Lecture Notes in Mathematics 1125 (1984) 99-106 (Springer publ., Berlin).

N. Thomasson, T. J. Hoeppner, C. L. Webber Jr., and J. P. Zbilut, "Recurrence quantification in epileptic EEGs," Phys. Lett. A 279 (2001) 94-101. 

APPENDIX A

FOREWARNING OF FAILURE IN CRITICAL EUIPMENT AT NEXT-GENERATION NUCLEAR POWER PLANTS

NERI LAB NE-2000-1

TEST PLAN 

Forewarning of Failure in Critical Equipment at Next-Generation Nuclear Power Plants

\author{
NERI Lab NE-2000-1 \\ Appendix A \\ Test Plan
}

To

Dr. Lee M. Hively

Oak Ridge National Laboratory

P.O. Box 2009

Oak Ridge, TN 37831-8066

865-574-7188 (office)

865-574-8481 (fax)

By

Dr. Mammar Maghraoui

Mr. Joe W. Spencer

Mr. Albert S. Kluttz

Duke Engineering \& Services

400 South Tryon Street, WC27A

Charlotte, NC 28201-1004 


\section{A.1 Introduction}

This Appendix addresses the various considerations for the test plan for this project.

Section A. 2 describes the important-to-safety equipment in a nuclear power plant.

Section A. 3 chooses two test modes, based on typical failure modes.

Section A.4 explains the choice of testing facility and methodology.

Section A.5 shows the detailed specifications of the equipment to be tested.

Section A.6 provides the detailed protocol for the accelerated failure testing.

Section A.7 lists the detailed specifications of the data acquisition equipment.

Section A.8 discusses the resulting test data for subsequent analysis by ORNL.

The choices for the Phase-1 test plan arise from the considerations in this Appendix.

\section{A.2 Important-to-Safety Equipment for Testing}

Nuclear power plants (NPPs) use a large variety of safety-related equipment. Table A.1 shows typical examples of such equipment. Table A.2 show typical failures in rotating components.

TABLE A.1: Typical safety-related equipment in a PWR nuclear power plant

\begin{tabular}{|l|c|l|}
\hline \multicolumn{1}{|c|}{ Component Type } & $\begin{array}{c}\text { Approximate } \\
\text { Number per Unit }\end{array}$ & Notes \\
\hline $\begin{array}{l}\text { Control rods and control element } \\
\text { assemblies }\end{array}$ & $\mathbf{5 0}$ to 60 & 160 in a BWR Unit \\
\hline $\begin{array}{l}\text { Heat exchangers, condensers, and steam } \\
\text { generators }\end{array}$ & $\mathbf{2 4}$ & \\
\hline Turbines (steam, gas) & $\mathbf{1}$ & \\
\hline Generators and inverters & $\mathbf{6}$ & \\
\hline $\begin{array}{l}\text { Blowers, compressors, fans, vacuum pumps, } \\
\text { and cooling units }\end{array}$ & $\mathbf{2 0}$ & \\
\hline Pumps & $\mathbf{2 0}$ & \\
\hline Electric Motors & $\mathbf{5 0 0}$ & \\
\hline Relays & $\mathbf{1 0 0 0}$ to 2000 & \\
\hline Circuit breakers, contactors, and controllers & $\mathbf{7 5 0 ~ t o ~ 1 0 0 0}$ & \\
\hline Governors and gear boxes & $\mathbf{1 5}$ & \\
\hline Valves & $\mathbf{6 5 0}$ & All types \\
\hline Valve operators & $\mathbf{1}$ & Motor operated valves \\
\hline Engines (gas, diesel) & & \\
\hline
\end{tabular}


TABLE A.2: Approximate Distribution of Some Critical Rotating Components Failures in Nuclear Power Plants

Prior to 1997 [2]

\begin{tabular}{|l|c|c|c|}
\hline \multirow{2}{*}{ Component Type } & \multicolumn{3}{|c|}{ Number of Failures that Resulted in: } \\
\cline { 2 - 4 } & $\begin{array}{c}\text { Reduced-Power } \\
\text { Operation }\end{array}$ & $\begin{array}{l}\text { Unit } \\
\text { Line }\end{array}$ & $\begin{array}{l}\text { Reactor } \\
\text { Trip }\end{array}$ \\
\hline $\begin{array}{l}\text { Blowers, compressors, fans, vacuum pumps, } \\
\text { cooling units }\end{array}$ & $\mathbf{2}$ & $\mathbf{1 7}$ & $\mathbf{0}$ \\
\hline Generators, inverters, motor generators & $\mathbf{7 9}$ & $\mathbf{7 9}$ & $\mathbf{1 3 1}$ \\
\hline Governors, couplings, gear boxes & $\mathbf{8 8}$ & $\mathbf{2 8}$ & $\mathbf{5 2}$ \\
\hline Motors (electric, hydraulic, pneumatic) & $\mathbf{7 6}$ & $\mathbf{9 0}$ & $\mathbf{5 3}$ \\
\hline Pumps, eductors & $\mathbf{2 7 2}$ & $\mathbf{2 5 2}$ & $\mathbf{6 2}$ \\
\hline Valve operators & $\mathbf{4 3 0}$ & $\mathbf{3 3 8}$ & $\mathbf{2 2 0}$ \\
\hline Turbines (steam, gas) & $\mathbf{8 8}$ & $\mathbf{4 1}$ & $\mathbf{4 8}$ \\
\hline
\end{tabular}

Failures of motors and motor driven equipment represent a big percentage of plant events that resulted in serious plant condition ranging from reactor trip to reduced-power operation.

INPO-EPIX database [1] shows that motor failures directly impact NPP operations, including reactor trips ( $25 \%$ of failures), unit off-line ( $40 \%$ of failures), and reduced power operation (35\% of failures). Motors are among the most common equipment in NPPs. Motor testing is a straight-forward matter of acquiring voltage and current. For all of these reasons, we choose to test electric motors for the first phase of this NERI project. DE\&S is well acquainted with motor testing, and has extensive facilities and experience in such testing, as described below.

A nuclear power plant utilizes a large number of electric motors ranging from fractional horsepower to many thousands of horsepower in almost every safety system. Most NPP motors are three-phase, alternating current (AC), induction type at 110-480 volts with anti-friction bearings. These motors drive small pumps for coolers, dampers, and similar components. Direct current (DC) motors usually provide backup in the case of AC power loss. In PWRs, safety systems contain small induction-type valve motors that are pipe mounted. Motors are used for both continuous and intermittent duty. Continuous duty motors drive pumps, fans, generators, dampers, chillers, and other components for long periods. Intermittent duty motors run for a short duration to actuate valves from open to closed position and viceversa. Table A.3 provides an approximate distribution of motors in a PWR plant [1]. 
TABLE A.3: Approximate Motor Population in a PWR Plant [1]

\begin{tabular}{|c|c|c|c|c|c|}
\hline \multirow{2}{*}{ HP } & \multicolumn{2}{|c|}{ SAFETY-RELATED MOTORS } & \multicolumn{2}{|c|}{$\begin{array}{c}\text { NONSAFETY-RELATED } \\
\text { MOTORS } \\
\end{array}$} & \multirow[b]{2}{*}{$\begin{array}{r}\text { TOTAL } \\
\text { MOTORS }\end{array}$} \\
\hline & $\begin{array}{c}\text { INSIDE } \\
\text { CONTAINMENT }\end{array}$ & $\begin{array}{c}\text { OUTSIDE } \\
\text { CONTAINMENT }\end{array}$ & $\begin{array}{c}\text { INSIDE } \\
\text { CONTAINMENT }\end{array}$ & $\begin{array}{c}\text { OUTSIDE } \\
\text { CONTAINMENT } \\
\end{array}$ & \\
\hline \multicolumn{6}{|c|}{ CONTINUOUS DUTY MOTORS } \\
\hline$<1 \mathrm{HP}$ & 0 & 15 & 0 & 20 & 35 \\
\hline $1-100 \mathrm{HP}$ & 10 & 150 & 10 & 270 & 440 \\
\hline $125-250 \mathrm{HP}$ & 10 & 0 & 0 & 20 & 30 \\
\hline$>300 \mathrm{HP}$ & 0 & 20 & 4 & 15 & 39 \\
\hline $\mathbf{D C}$ & 0 & 10 & 0 & 5 & 15 \\
\hline \multicolumn{5}{|r|}{ SUB - TOTAL 1} & 559 \\
\hline \multicolumn{6}{|c|}{ VALVE MOTORS (INTERMITTENT OPERATION) } \\
\hline AC Power & 30 & 250 & 0 & 260 & 540 \\
\hline DC Power & 0 & 10 & 0 & 0 & 10 \\
\hline \multicolumn{5}{|r|}{ SUB - TOTAL 2} & 550 \\
\hline & & & & TOTAL & 1109 \\
\hline
\end{tabular}

\section{A.3 Failure Modes of Equipment}

Component failure analysis identifies specific root cause(s), beginning with identification of the possible failure modes. The fault tree approach is often combined with one or more other techniques to reveal possible causes for the observed failure mode of the equipment. A failure cause may involve the investigation of health monitoring indicators, degradation mechanisms, direct degradation indicators, indirect degradation indicators, and use of various data sources. A functional failure mode is indicated when the component fails to perform its designed function. Some common failure modes associated with electric motor driven equipment are presented in Table A.4. 
TABLE A.4: Representative electrical motor driven equipment faults

\begin{tabular}{|l|l|}
\hline General category & Brief description of specific deterioration modes \\
\hline Mass unbalance & $\begin{array}{l}\text { Force unbalance, couple unbalance, dynamic unbalance, overhung. } \\
\text { rotor unbalance }\end{array}$ \\
\hline Misalignment & Angular, parallel, misaligned bearing cocked on shaft \\
\hline Journal bearings & Wear/cle arance problems, oil whirl instability, oil whip instability \\
\hline Gears & $\begin{array}{l}\text { Tooth wear, tooth load, gear eccentricity and backlash, gear misalignment, } \\
\text { cracked/broken tooth, gear assembly phase problems, hunting tooth problems, } \\
\text { loose bearing fit }\end{array}$ \\
\hline AC induction motors & $\begin{array}{l}\text { Stator eccentricity shorted lamination or loose iron, eccentric rotor, rotor } \\
\text { problems, phasing problems }\end{array}$ \\
\hline $\begin{array}{l}\text { DC motors and } \\
\text { controls }\end{array}$ & $\begin{array}{l}\text { Broken armature windings, grounding problems, or faulty system tuning, } \\
\text { faulty firing card or blown fuse, faulty SRC, shorted control card, loose } \\
\text { connection and/or blown fuse, faulty comparator card, electrical current } \\
\text { passage through bearings }\end{array}$ \\
\hline Belt drive problems & $\begin{array}{l}\text { Worn/loose/mismatched belts, belt/pulley misalignment, eccentric pulleys, } \\
\text { belt resonance }\end{array}$ \\
\hline $\begin{array}{l}\text { Hydraulic/aerodynami } \\
\text { c force }\end{array}$ & Blade pass, vane pass, flow turbulence, cavitation \\
\hline Foot problems & Soft foot, sprung foot, foot-related resonance \\
\hline
\end{tabular}

The motor components most likely to result in failures are bearings and stator windings (including connections) [3], as shown in Table A.5. Analysis [3] shows that $60 \%$ of failures are of mechanical origin and that $30 \%$ are of electrical origin, as summarized in Table A.6. An example of mechanical failure is the overheating due to overloading, blocked ventilation, or phase unbalance. The effect may not be drastic enough to trip the overload relay or fuses, but may cause the motor bearing lubrication degradation leading to bearing failure. Alternatively, overheating may result in premature aging and failure of the winding insulation. 
TABLE A.5. Motor Component Failures [3]

\begin{tabular}{|c|c|c|}
\hline Cause & IEEE Survey & EPRI Survey \\
\hline Bearing Related & $44 \%$ & $41 \%$ \\
\hline Stator Related & $26 \%$ & $36 \%$ \\
\hline Rotor Related & $8 \%$ & $9 \%$ \\
\hline Other & $22 \%$ & $14 \%$ \\
\hline
\end{tabular}

TABLE A.6. Failure Mechanisms [3]

\begin{tabular}{|c|c|c|}
\hline Cause of Failure & Bearings & Windings \\
\hline Overheating & $12 \%$ & $21 \%$ \\
\hline Insulation Breakdown & $2 \%$ & $37 \%$ \\
\hline Mechanical Damage & $50 \%$ & $10 \%$ \\
\hline Electrical Fault & $4 \%$ & $11 \%$ \\
\hline
\end{tabular}

Motors frequently fail due to excessive vibration, resulting from mechanical, as well as electrical excitations. Mechanical imbalance and misalignment are the most common mechanical conditions that produce excessive vibration in rotating machinery. Changes in vibration arise from bearing deterioration, misalignment, damaged parts, electrical imbalance, and wear. Unbalance is the most common cause of vibration in rotating machinery, occurring when the actual center of the rotating mass is not exactly at its geometric center. This eccentricity causes a heavy side of the rotating component, creating a synchronous rotating force vector. For linear systems, unbalance produces a vibration directly proportional to the unbalance amount, and has a frequency equal to the running speed of the machine. Mechanical unbalance in rotating machinery is usually caused by unavoidable errors in design, manufacture, assembly, initial balancing, or impeller damage. Unbalance can lead to excessive vibration, bearing wear, and seal leakage. Impellers should be statically and dynamically balanced so that the maximum residual unbalance is less than $1 \mathrm{xW} / \mathrm{rpm}$, where $\mathrm{W}=$ impeller weight. An unbalance condition may involve different modes of the rotor bearing system. For rigid rotor modes, the condition may be static, coupled, or dynamic. Flexible rotors are more complex; unbalance correction requires several balancing planes and may require knowledge of the mode shapes involved. Hydraulic unbalance in pumps is induced by the fluid flow and is usually caused by poor suction piping arrangements and design. A flow restriction or an elbow too close to the pump suction causes fluid to assume different velocities within the pipe. If these velocities do not equalize before reaching the impeller, the hydraulic unbalance will impose a high radial vibration at the running frequency of the machine.

Misalignment is considered the second most prevalent vibration source, and is due to non-coincidence of rotating axis of coupled components. Misalignment results in a high axial vibration at multiples of running speed, mainly the two-times $(2 \mathrm{X})$ component. The axial reading may be as high as twice the vertical reading. Misalignment causes pump vibration resulting in seal leakage, bearings overheating, and coupling wear. Soft foot and pipe stresses contribute a great deal to misalignment.

Based on these considerations, the two failure modes for our testing are unbalance and misalignment. As discussed below, DE\&S can induce these failures on Duke Training Center Test Cell by replacing the actual flexible springtype coupling with a more rigid coupling. 


\section{A.4 Testing Options}

DE\&S Electric Motor Testing Services provide both on-line and off-line electric motor testing. A DE\&S technician typically visits the client's site, acquires the data, performs the analysis, and then delivers a written report with recommendations. Three facilities can be used for this motor testing: DE\&S Toddville Complex Facility (Charlotte, NC); Duke Power Mount Holly Training Center (Charlotte, NC); Advanced Energy (NC State University, Raleigh, NC).

DE\&S keeps most testing equipment and instrumentation at the Toddville Complex facility. This facility can be used for the purpose of this project, but we would have to build a test setup using our existing motors. This option has been ruled out due to the time and budget constraints.

DE\&S has a closed-loop pumping system with three similar pump motors at the Mount Holly Training Facility. This system belonged to an ex-NPP; DE\&S uses the system for training. As discussed below, this option is the best for this phase of the project due to its proximity (half an hour drive) and to the flexibility we have in terms $\boldsymbol{f}$ scheduling. It is also much cheaper to rent the Mount Holly Training Facility than the Advanced Energy facility since there are negligible expenses associated with its use.

Advanced Energy Motor Services is the only independent motors testing facility of its kind in the nation. Advanced Energy can test motors for their efficiency and/or operating characteristics, and motor test data are used to help industries develop motor repair and replacement policies that reduce operating costs. The Motor Test Lab can perform a wide variety of tests on new and repaired motors at full and partial loads in the range of 3 - 150 horsepower. The lab is equipped to perform dynamometer load tests on 3-phase AC induction motors per IEEE 112B, NEMA MG-1 and CSA C-390 test standards. Foot Mount and Face Mount "C" flange and "D" flange motors can be tested. In-field motor testing is also available with the IEL's In-Situ Motor Analyzer, which can determine efficiency, operating load, and temperature rise. This capability is particularly beneficial when the configuration of the motor prevents it from being tested at the IEL motor lab.

Table A.7 summarizes the considerations for choice of a testing facility. Pricing is a major consideration. Use of the UNC facility for three weeks would require more than $\$ 20 \mathrm{~K}$, in addition to DE\&S expenses and labor using our own motors. Another important issue is scheduling. The NC State Facility is used extensively by many testers, and has very tight advanced scheduling. DE\&S facilities allow the freedom of setting a less stringent schedule. The best test facility option is the Duke Mount Holly Training Center. 
TABLE A.7. Benchmarking of the three options

\begin{tabular}{|l|l|l|l|}
\hline & $\begin{array}{l}\text { Toddville } \\
\text { Complex } \\
\text { Charlotte, NC }\end{array}$ & $\begin{array}{l}\text { Duke's Training Center } \\
\text { Charlotte, NC }\end{array}$ & $\begin{array}{l}\text { NC State Lab } \\
\text { Rale igh, NC }\end{array}$ \\
\hline Testing Equipment & $\begin{array}{l}\text { Only Motors } \\
\text { Available }\end{array}$ & $\begin{array}{l}\text { Closed Loop Water } \\
\text { System with Three } \\
\text { Pump/Motor used in NPP }\end{array}$ & $\begin{array}{l}\text { Motor with } \\
\text { Dynamometers for } \\
\text { load variations }\end{array}$ \\
\hline $\begin{array}{l}\text { Travel/Lodging } \\
\text { Expenses }\end{array}$ & None & Very Low & $\begin{array}{l}\text { Mileage from DE\&S } \\
\text { Charlotte to Raleigh + } \\
\text { Expenses }\end{array}$ \\
\hline $\begin{array}{l}\text { Cost of testing } \\
\text { equipment }\end{array}$ & Very High & Low & None \\
\hline $\begin{array}{l}\text { Cost of Testing (labor, } \\
\text { Rent) }\end{array}$ & Very Low & Low & Very High \\
\hline Scheduling Constraints & None & Negligible & Tight Scheduling \\
\hline Access Restrictions & None & Weekdays & Controlled \\
\hline Data format & As required & As required & No idea \\
\hline
\end{tabular}

Electric motor testing involves both "on-line" and "off-line" methods. ORNL has found that subtle faults in electric motor-driven elements are detectable via nonlinear analysis of "on-line" motor current or motor power data, and can capture the rich array of process dynamics in the entire motor-driven train. DE\&S uses a motor/circuit evaluator produced by PdMA Corporation called MCE/Emax. MCE is a lightweight, static tester that provides a detailed analysis of motor and circuit condition. This portable unit features diagnostic results that evaluate all five of the motor's fault zones including the power circuit, insulation, stator, rotor and air gap. MCE tests all major types of motors: induction, synchronous, wound rotor, DC, servo and spindle. Emax is a dynamic tester that simultaneously collects all three phases of current and voltage to provide spectral and digital data in the areas of power, motor current signature analysis, crest factor, total harmonic distortion, power factor, and impedance. This information can be used to evaluate incoming power quality and motor efficiency, as well as rotor, stator, air gap and power circuit conditions. DE\&S has used the MCE/Emax throughout Duke Energy, as well as other industrial customers. Common faults include loose or corroded connections between cabling and motor leads, broken or cracked rotor bars, eccentricity, and poor stator and/or cable insulation. DE\&S will use the PdMA MCE/Emax to acquire voltage and current from each of the three motor phases during accelerated failure testing.

In electrical machines in general, faults can be detected by measuring the currents or voltages in the machine windings. The magnetic field created near an electrical machine, changes when faults occur. Therefore, using induction loops to measure flux can aid in condition monitoring and diagnostics of the machine.

Operating electric motor current signatures ("on-line") contain information not only related to the motor itself but also that related to the driven component mechanical condition. Therefore, driven devices, such as fans, pumps, or motor-operated valves, can be monitored using a simple current loop on a lead that can be remote from hostile or inaccessible environments. 


\section{A.5 Test site and equipment to be tested}

The testing facility of choice for this project is the Duke Power Mount Holly Training Center located in Charlotte, NC. The Mount Holly Training Facility contains of a closed loop pumping system with three similar pump motors. This system belonged to an ex-NPP and is used for training. This system is shown in Figures A.1 to A.5.

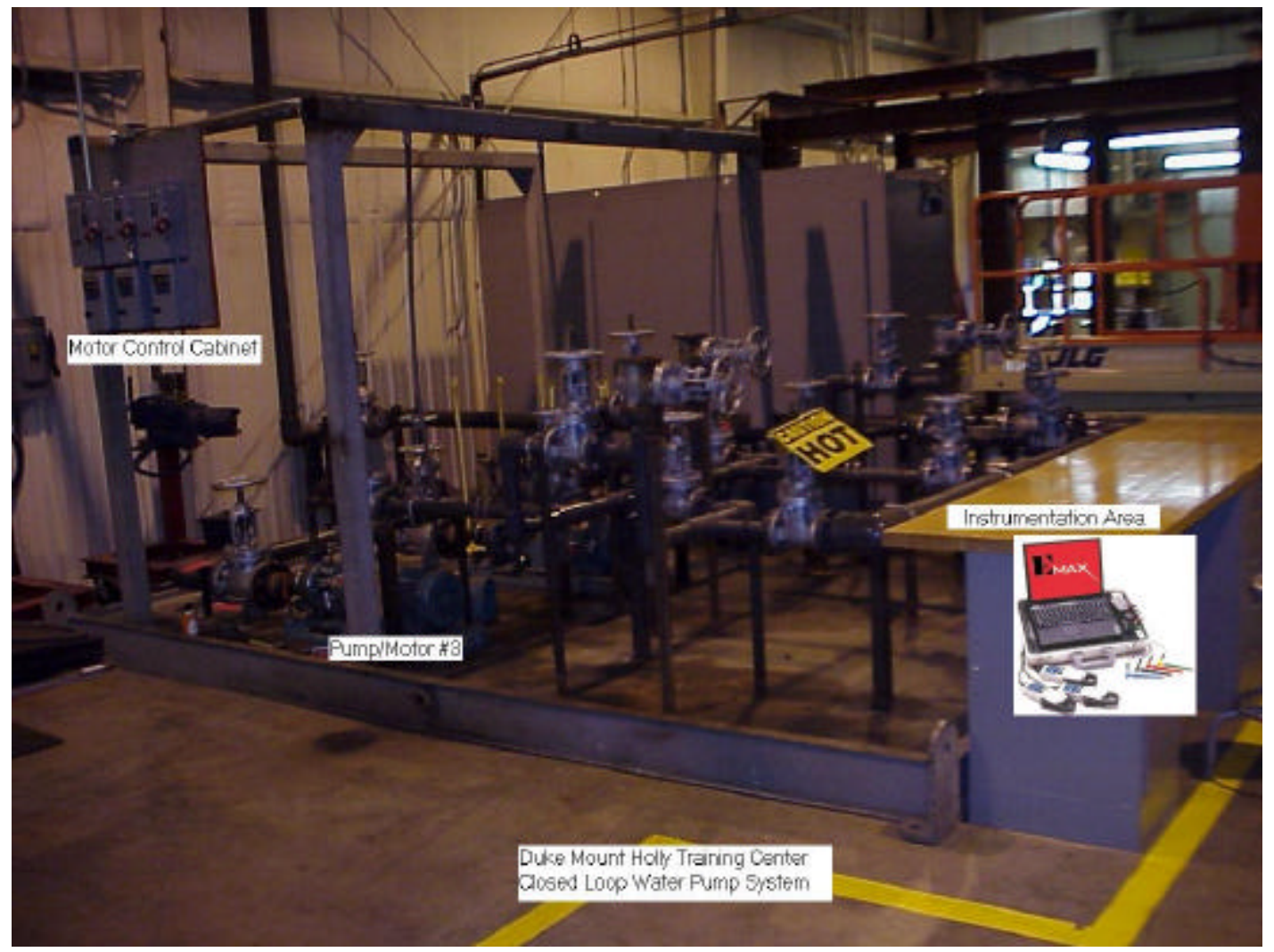

Figure A.1: Closed Loop Pumping System at Duke Mount Holly Training Center 


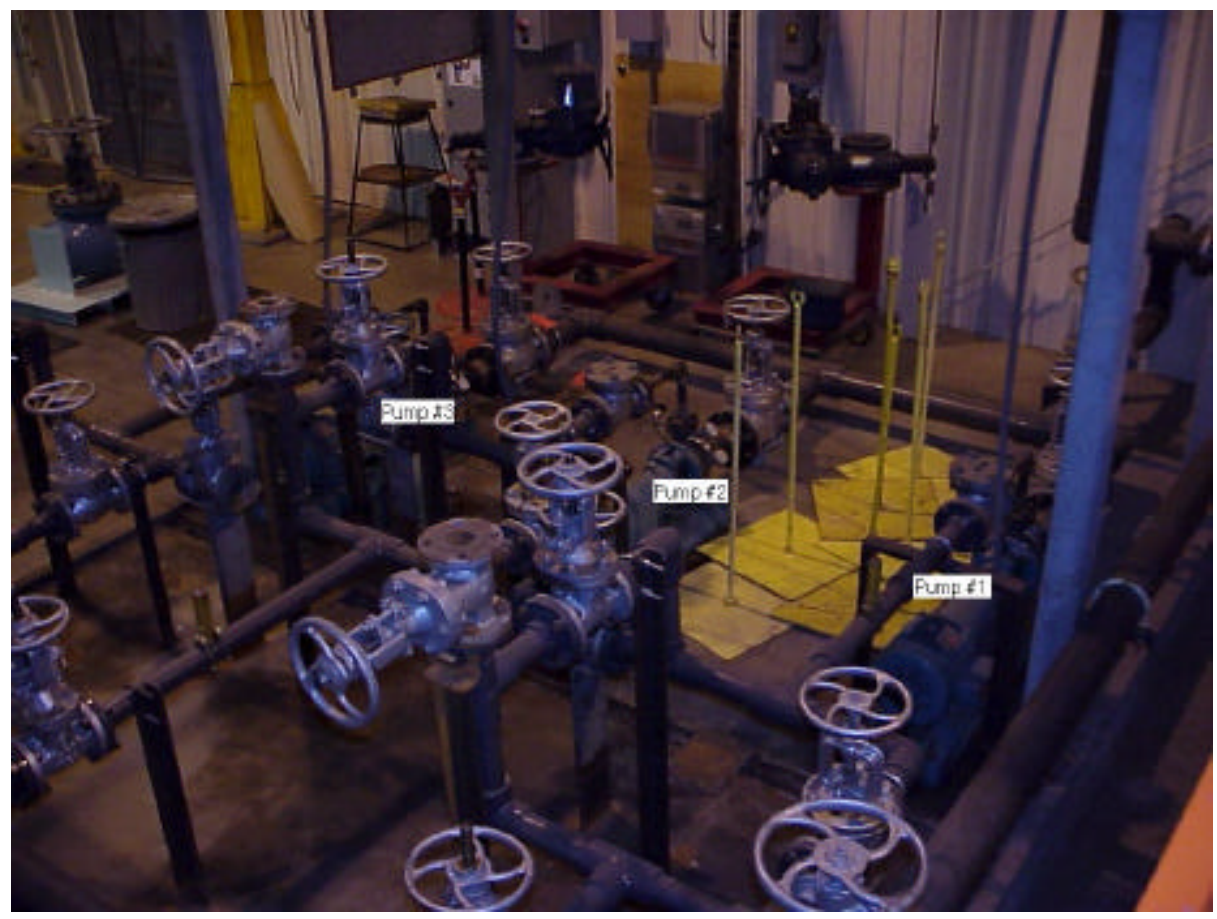

Figure A.2: Three Pumps in Parallel can be used in any combination

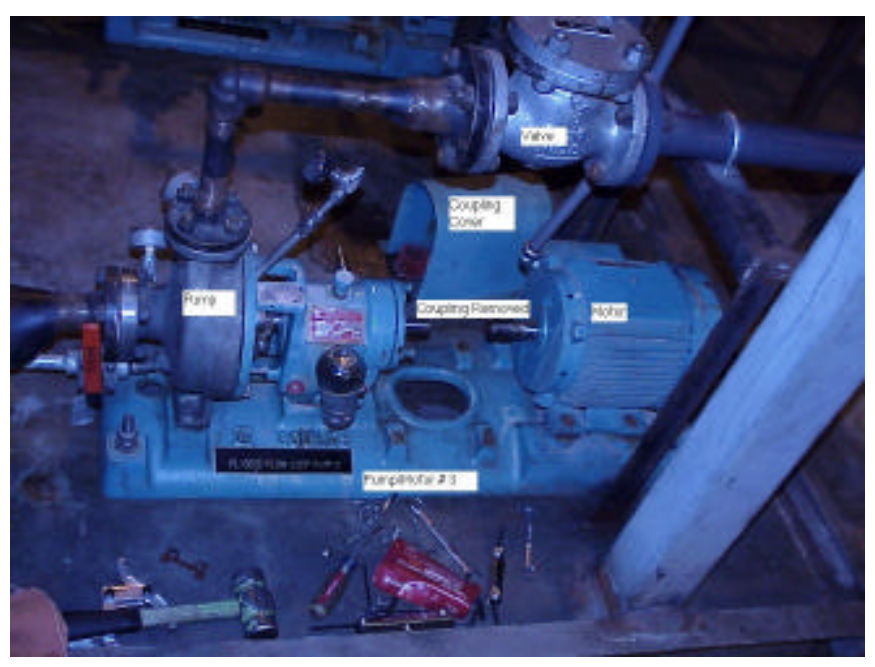

Figure A.3: A closer view of the pump/motor assembly - Coupling Removed 


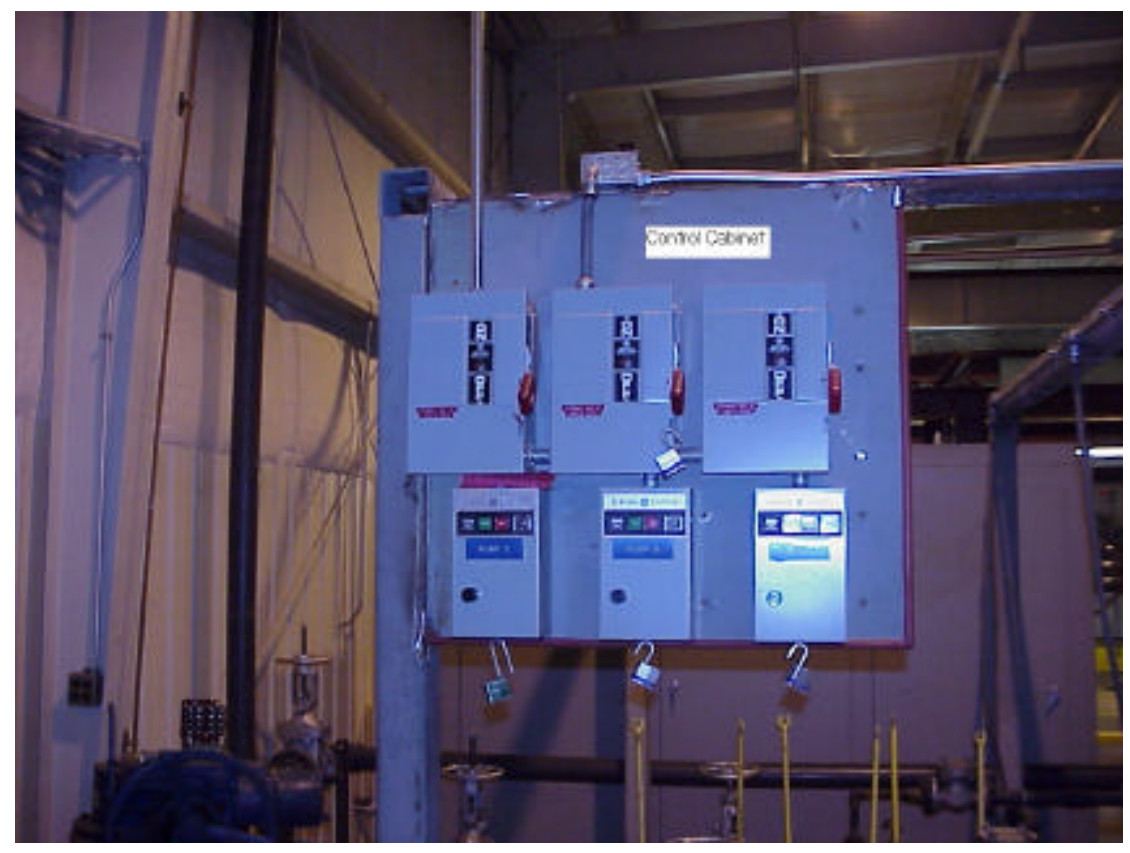

Figure A.4: Motor Control Panel Closed

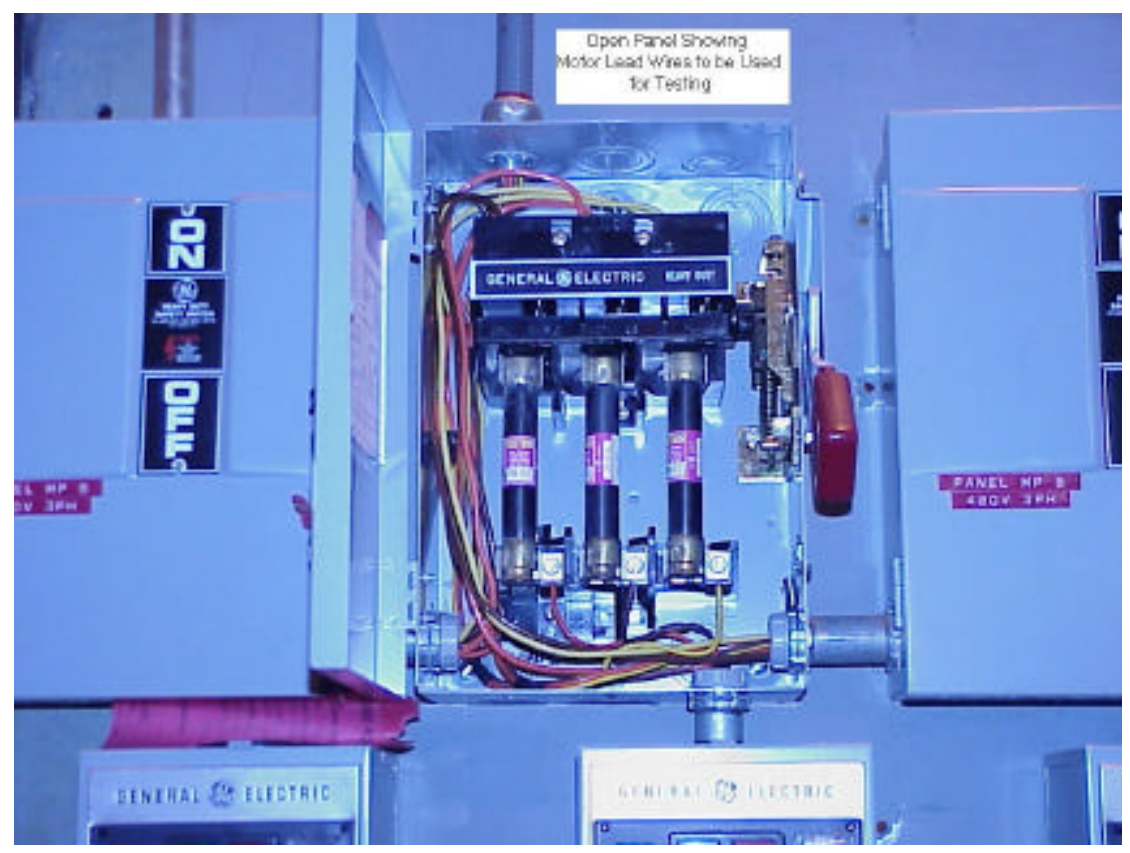

Figure A.5: Motor Control Panel Open - Provides Connection to Emax Testing

The picture of the testing facility is shown in Figure A.1. The equipment to be tested consists of a closed loop pumping station made of three groups of pump/motor. The motor and pump nameplate data is provided in Table A.8. Figure A.6 shows the pump head versus flow curve. 
Table A.8. Test Equipment Characteristics

\begin{tabular}{|l|l|l|}
\hline & Motor & Pump \\
\hline Manufacturer & & Gould \\
\hline Model & 5K182AL1963 & 3196 ST \\
\hline HP & 5 & - \\
\hline Speed (rpm) & 3495 & 3500 \\
\hline Volts & $230 / 460$ & - \\
\hline Amps & $12.6 / 6.3$ & - \\
\hline Phases & 3 & - \\
\hline Capacity (GPM) & - & 30 \\
\hline Head (feet) & - & 135 \\
\hline Weight (lbs) & 80 & 84 \\
\hline Max. Filtered Bearing Casing Vibration (Mils p-p) & 1.3 & 1.3 \\
\hline Max. Filtered Bearing Casing Vibration (in/s peak) & 0.3 & 0.3 \\
\hline Notes & No.-KRF & Size 1X1X-6 \\
\hline
\end{tabular}

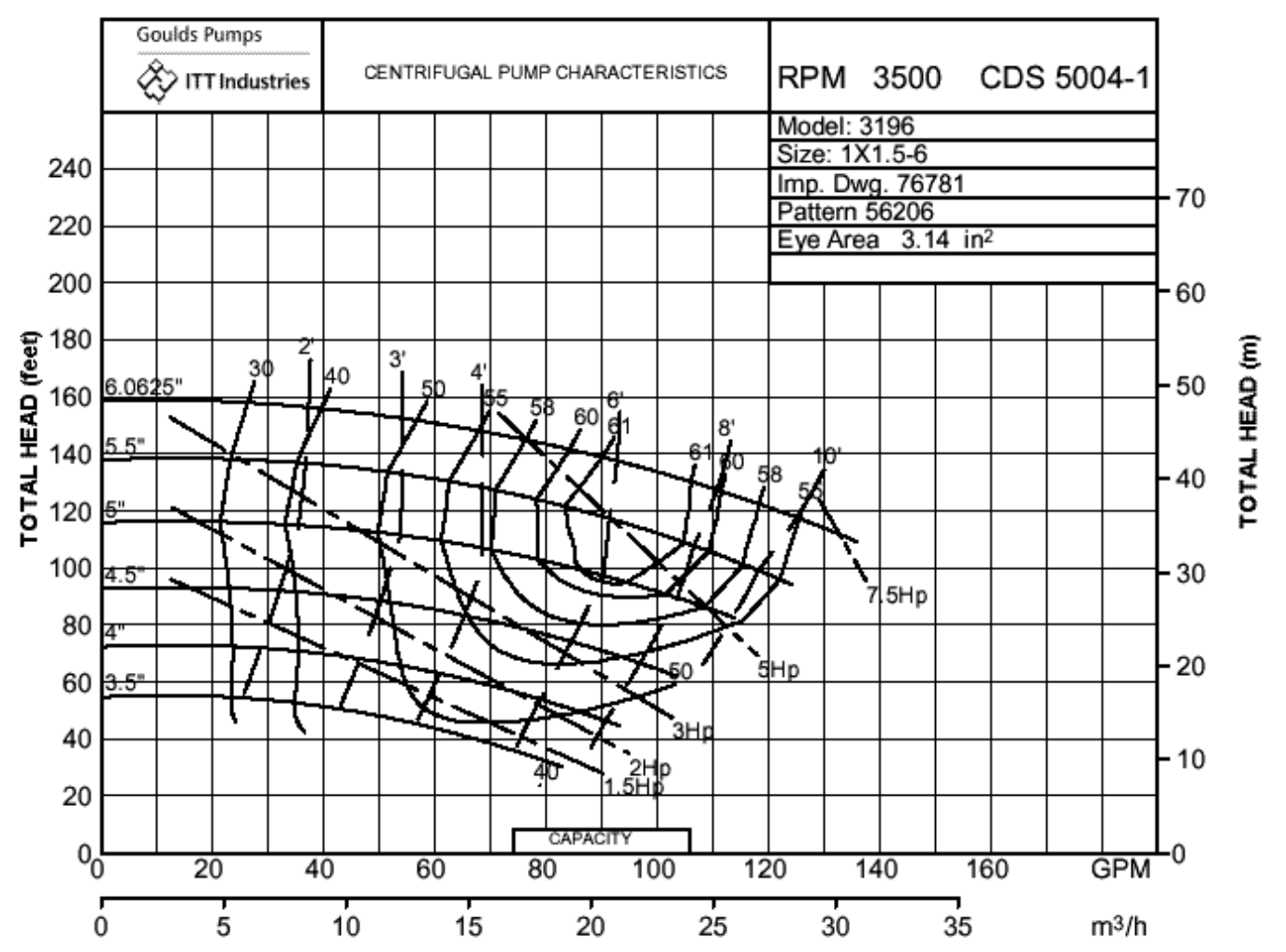

Figure A.6: Pump Characteristics

\section{A.6 Detailed Protocol for the Accelerated Failure Testing}

During operation, an electric motor's components such as rolling bearings and rotor bars produce distinctive vibrations that can be used for motor condition assessment and help identify problems. Consequently, vibration monitoring and analysis has become a widely accepted part of power plant motor predictive maintenance programs. 
Vibration analysis has a wide scope of application to nuclear power plant rotating equipment. Vibration sources include common structural vibrations from the interaction of rotating and non-rotating parts, as well as fluid-flow noise such as cavitation in pumps. The following sources of vibration are documented in the literature:

- Imbalance problems

- Alignment problems

- Bearing wear

- Wear of geared pump/motor couplings

- Cracked and/or worn shaft

- Mechanical looseness (bearings, pedestals, base)

- Improper internal pump clearances (design, mounting)

- Impeller wear (especially that caused by off-Best Efficiency Point (BEP) operation)

- Degradation of wear rings, diffusers, volutes, channel rings, balancing device, and interstage seals

- Erosion, corrosion of pump casing and/or rotor internal flow paths

Vibration transducers and monitoring instrumentation will be used to access the mechanical condition of the equipment. Duke Engineering \& Services (DE\&S) will provide the motor current and vibration data to the ORNL team. DE\&S collects and analyzes thousands of data points on a monthly basis using the latest available condition monitoring hardware and software across several industries. DE\&S owns industry standard instrumentation including CSI, SKF, Bently Nevada and various laboratory type analyzers. Typical transducers and instrumentation are depicted in Figures A.7 to A.9.

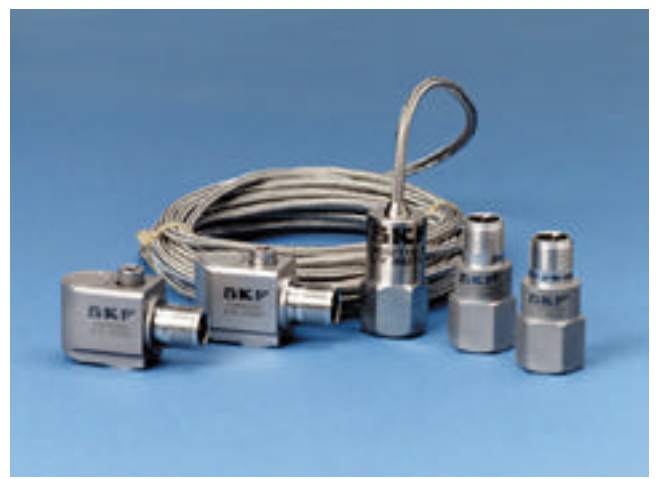

Figure A.7: Typical Vibration Sensors (SKF)

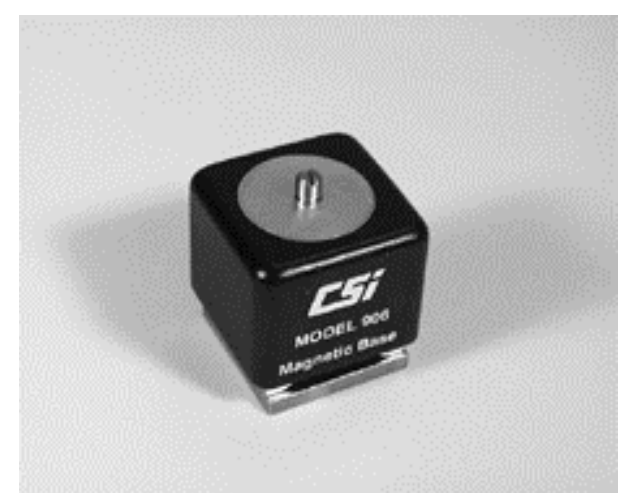

Figure A.8: Sensor Mounting Magnet (CSI) 


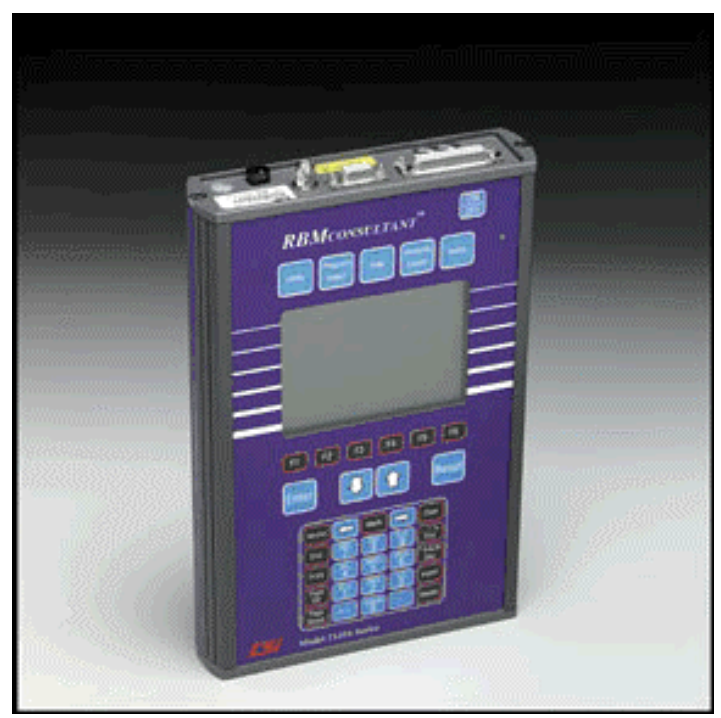

\section{Figure A.9: CSI 2120 Dual Channel Portable Vibration Analyzer (Courtesy CSI Inc.)}

\section{A.6.1 Electric Motor Failures}

Conditions of excessive temperature and vibration are the most common symptoms of electric motor failures.

Temperature is a good indicator of electric motor problems. Higher than normal temperature can result from electrical as well as mechanical problems. For example, the first indication of bearing trouble may be high bearing temperature. Temperature increase can be caused by such conditions as high ambient temperature, voltage imbalance, excessive load, dirty windings or blocked air intakes.

Vibration can be caused by electrical as well as mechanical faulty conditions. When an open bar develops in the rotor winding or a short happens in the stator winding, the effect on motor operation may show up as a higher vibration reading. The cause of vibration can be due to imbalance, misalignment, or bearing wear/defect. Motors can also have initial damaged due to handling and storage or have a manufacturing defect, which will appear as a vibration problem over time because of residual stresses.

Failures seemingly not related to vibration can develop because of vibration in an electric motor. Bearing damage, insulation abrasion, excessive brush-wear, commutator or collector ring burning, and winding fatigue can all result from excessive vibration.

In general, motor failures can be induced mechanically, electrically, or some combination of the two source areas.

\section{A.6.1.1 Mechanical Faults}

Some of the more common mechanical faults include rotor mass imbalance, coupling misalignment and bearing defects. These three are considered the most common conditions encountered in the majority of rotating machinery faults.

Rotor mass imbalance may be caused by dirt accumulation, loss of rotating parts, or possibly a loss of balance weights. Coupling misalignment can be due to coupling wear, temperature growth of the driver 
or driven component; and an improper alignment during installation. Bearing defects or degradation may be due to manufacturing flaws, improper mounting, excessive loads or inadequate lubrication.

\section{A.6.1.2 Electrical Faults}

In addition to mechanical faults, motors can also show indications of electromechanical abnormalities. Although electrical faults are diagnosed less often than their mechanical counterparts, they do exist. The difficulty is in determining that the fault is electrical in nature instead of mechanical.

\section{A.6.1.3 Additional causes of failures are:}

Ambient Temperature: Motor components such as stator windings, armature windings, field windings, bearings and lubricants have maximum temperature limitations. If these limitations are exceeded, the useful life of these components may be shortened. High ambient temperature, when added to the rated temperature rise of the component, can cause the temperature limit to be exceeded leading to motor failure.

Moisture: Excessive moisture causes failures in motor winding insulation and in motor leads. It can also cause loss of lubrication capability in bearing oil systems and deterioration of both electrical and mechanical motor parts.

Corrosion: Corrosion can cause serious damage to motor parts. Conduit boxes, motor feet, bearing fits, air deflectors, screens, and assembly bolts can be destroyed. Oil cooling coils can develop pitting and holes from corrosion.

Motor Starts: Large squirrel cage induction and synchronous motors have limited capability for repetitive starts defined by the motor manufacturer. Exceeding these repetitive starting limitations can lead to failure of rotor bars, rotor short circuiting ring, or stator winding.

Lubrication: Both oil-based and greased-based systems degrade due to contamination or lack of adequate lubrication. Dirt in lubrication systems will lead to eventual bearing failure. Oil analysis is one of the predictive maintenance technologies used widely in the industry to assess the condition of lubricating oils through trending of their physical properties in addition to providing diagnostic data for bearing health monitoring.

Misapplication: Excessive loading results in high temperature and deterioration of electrical insulation. Bearings and shaft materials are carefully selected for the loading demands of the shaft system (i.e. side loaded VS direct coupled).

Repair/Design Related: Motor failures can result from improper repair/design procedures and techniques. Defects can result from, but are not limited to, poor rewind techniques, stator core damage from burn-out oven procedures, improper installation of new bearings, damage from dropping major components, and inadequate efforts to exclude foreign material.

Shaft Currents: Large motors have one or two insulated bearings to prevent the flow of current from motor frame to motor shaft through the bearing. If allowed to flow, these currents can damage the bearings. The integrity of the insulation can be assessed by a check of the resistance path between the oil reservoir and the bearing housing 
Ventilation: Motor cooling can be adversely affected by foreign material in the ventilation path including oil, dirt, paper, and rags. Also, structural columns, pipes, building walls, and low ceilings can restrict airflow to or from motors.

Contaminants: Oil and dirt have a detrimental effect on insulated stator and rotor windings. Oil tends to dissolve insulation systems and makes them more susceptible to the deteriorating effects of moisture. Oil attracts dirt, which reduces heat transfer from the winding surface and plugs ventilating passages causing overheating.

\section{A.6.2 Vibration Measurements}

Vibrations can be measured by attaching displacement, velocity, or acceleration transducers to different parts of the machine in different orientations (see Figure A.10). Noise is measured by microphones and treated the same way as vibrations, except that noise levels are expressed in decibels $(\mathrm{dB})$ and generally referenced to human ear characteristics. Vibration measurements can be divided into two major types:

- Direct shaft motion by displacement probes which is often accompanied by a tachometer pulse attachment (a sensor generates a pulse with every shaft revolution used as a reference for phase measurements)

- Casing vibration by velocity probes or accelerometers

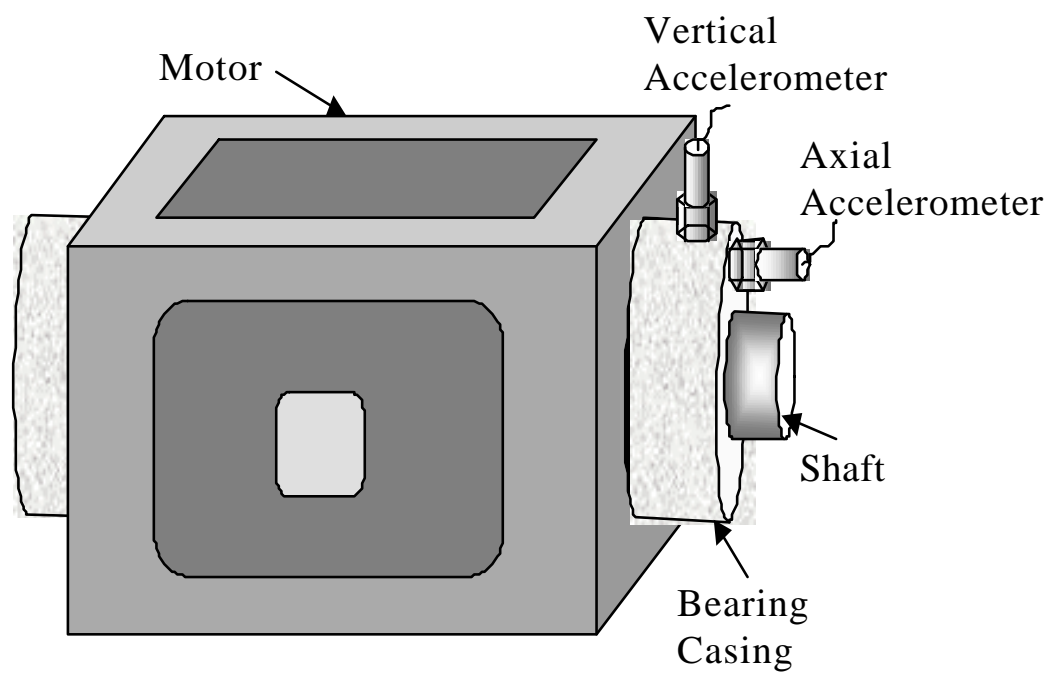

Figure A.10: Vibration Measurements Using Displacement Probes and Accelerometers

\section{A.6.3. Vibration Characteristics of Pump/Motor Systems}

\section{A.6.3.1 Electrically Induced Faults}

Frequency domain analysis indicates some electrical faults by peaks at multiples of the line frequency $(50 \mathrm{~Hz} / 60 \mathrm{~Hz}$ and $100 \mathrm{~Hz} / 120 \mathrm{~Hz})$, as summarized in Table A.9. In certain cases, it is possible to differentiate between mechanical and electrical faults by removing power from the motor and allowing a coast down. If the indication is electrical in origin it will usually disappear when power is removed. If the fault is mechanically induced, it will still be evident, although it may diminish in severity as the speed decreases. 
Table A.9: Typical Electrical Fault Diagnoses Chart

\begin{tabular}{|l|l|l|}
\hline \multicolumn{1}{|c|}{ Problem } & \multicolumn{1}{c|}{ Symptom } & \multicolumn{1}{c|}{ Comments } \\
\hline Uneven Air Gap & 2X Line Frequency & Always 120Hz \\
\hline Eccentric Rotor & 1X Running Speed & Beat frequency present \\
\hline Broken Rotor Bar & 1X Running Speed & Beat frequency present \\
\hline
\end{tabular}

\section{A.6.3.2 Mechanical Imbalance}

Imbalance, the most common cause of vibration in rotating machinery, occurs when the actual center of the rotating mass is not exactly at its geometric center. This eccentricity causes a heavy side of the rotating component, creating a synchronous rotating force vector. For linear systems, imbalance produces a vibration directly proportional to the imbalance amount, and has a frequency equal to the running speed of the machine (Figure A.11).

Mechanical imbalance in rotating machinery is usually caused by unavoidable errors in design, manufacture, assembly, initial balancing, or impeller damage. Imbalance can lead to excessive vibration, bearing wear, and seal leakage. Impellers should be statically and dynamically balanced so that the maximum residual imbalance is less than $1 \mathrm{xW} / \mathrm{rpm}$, where $\mathrm{W}=$ impeller weight.

An imbalance condition may involve different modes of the rotor bearing system. For rigid rotor modes, the condition may be static, coupled, or dynamic. Flexible rotors are more complex; imbalance correction requires several balancing planes and may require knowledge of the mode shapes involved. 

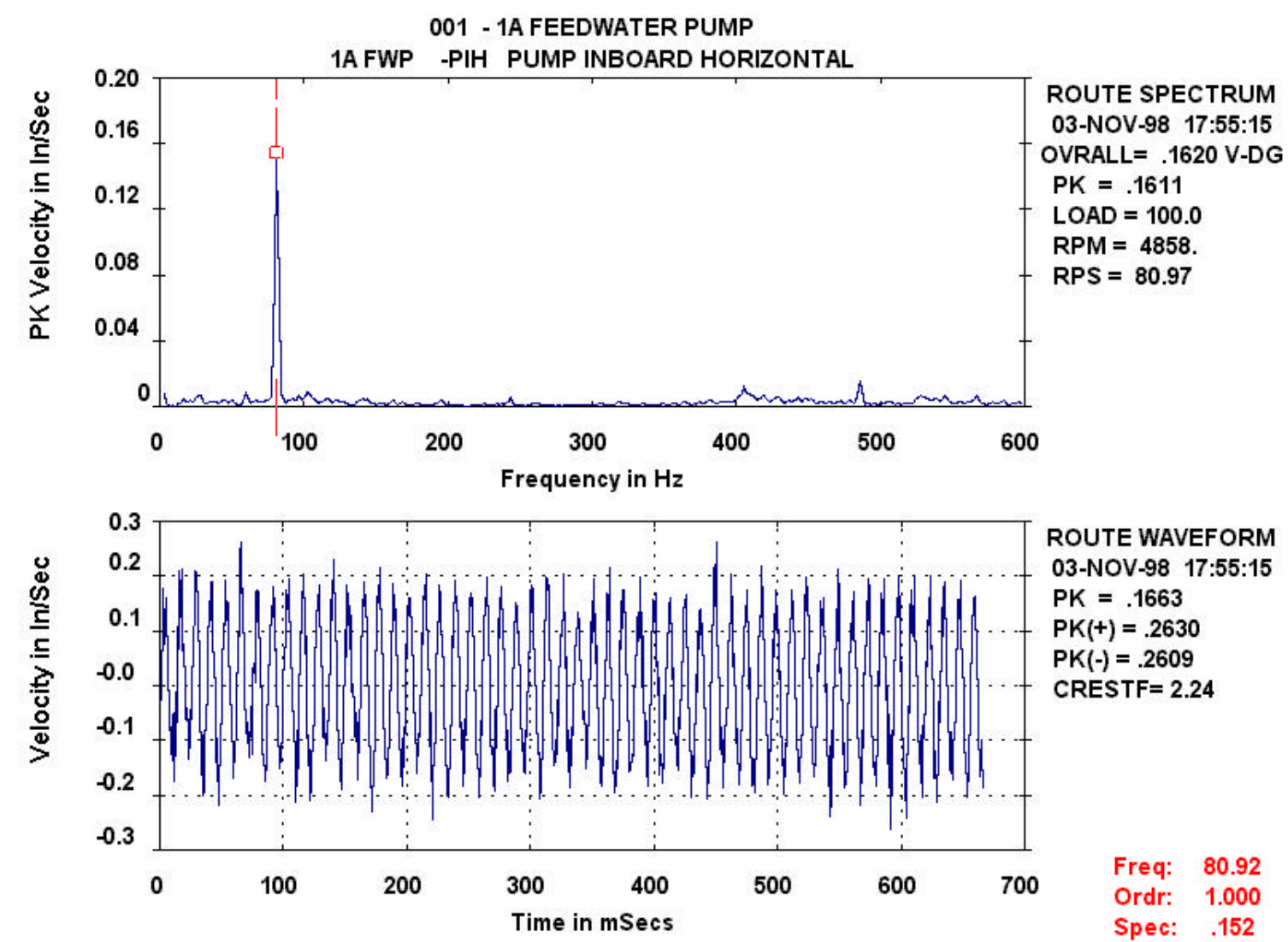

ROUTE WAVEFORM 03-NOV-98 17:55:15 $\mathrm{PK}=.1663$ $\mathrm{PK}(+)=.2630$ $\mathrm{PK}(-)=.2609$ CRESTF $=2.24$

Figure A.11: Vibration Spectrum Indicating a Mechanical Imbalance Condition

\section{A.6.3.3 Hydraulic Imbalance}

Hydraulic imbalance in fluid flow is usually caused by poor suction piping arrangements and design. Velocity inhomogeneities can arise from a flow restriction or an elbow too close to the pump suction. If these velocities do not equalize before reaching the impeller, the hydraulic imbalance will impose a high radial vibration at the running frequency of the machine.

\section{A.6.3.4 Misalignment}

Misalignment is considered the second most prevalent vibration source. It is due to non-coincidence of rotating axis of coupled components. Misalignment results in a high axial vibration reading, in addition to multiples of running speed, mainly the two-times (2X) component (Figure A.12). The axial reading may be as high as twice the vertical reading. Misalignment causes pump vibration resulting in seal leakage, bearings overheating, and coupling wear. Soft foot and pipe stresses contribute a great deal to misalignment. 


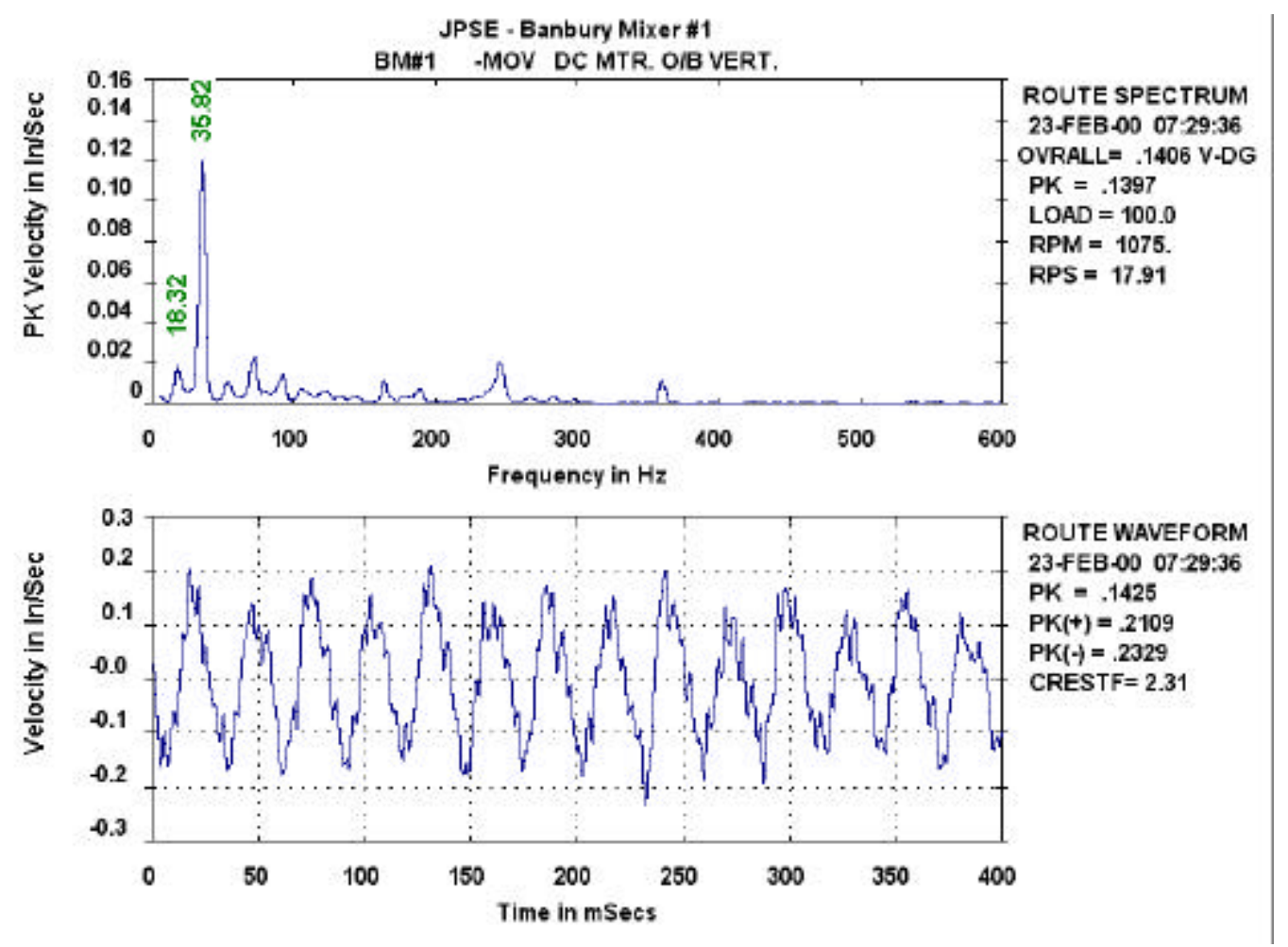

Figure A.12: Vibration Spectrum Indicating a Misalignment

\section{A.6.3.5 Bent Shaft}

A bent shaft will appear as an imbalance condition (see Figure A.11), accompanied by high axial vibration due to the contortion of the rotor configuration. A twice-per-revolution harmonic will also appear in the spectrum. Phase readings are usually taken to distinguish between imbalanced and bent shaft. Phase readings at both bearings in the same direction indicate an in-phase relationship, whereas in the axial direction they indicate an out-of-phase condition. 


\section{A.6.3.6 Looseness}

Mechanical looseness produces running speed harmonics with generally decreasing magnitudes (Figure A.13), depending upon the degree of looseness and the machine design. Rotating forces occur twice per revolution in horizontal machines due to excessive clearances or lack of tightness. The vibration response reflects this double impact. A strobe light synchronized to the frequency of the rotating machine is typically used to investigate looseness of assembled parts.

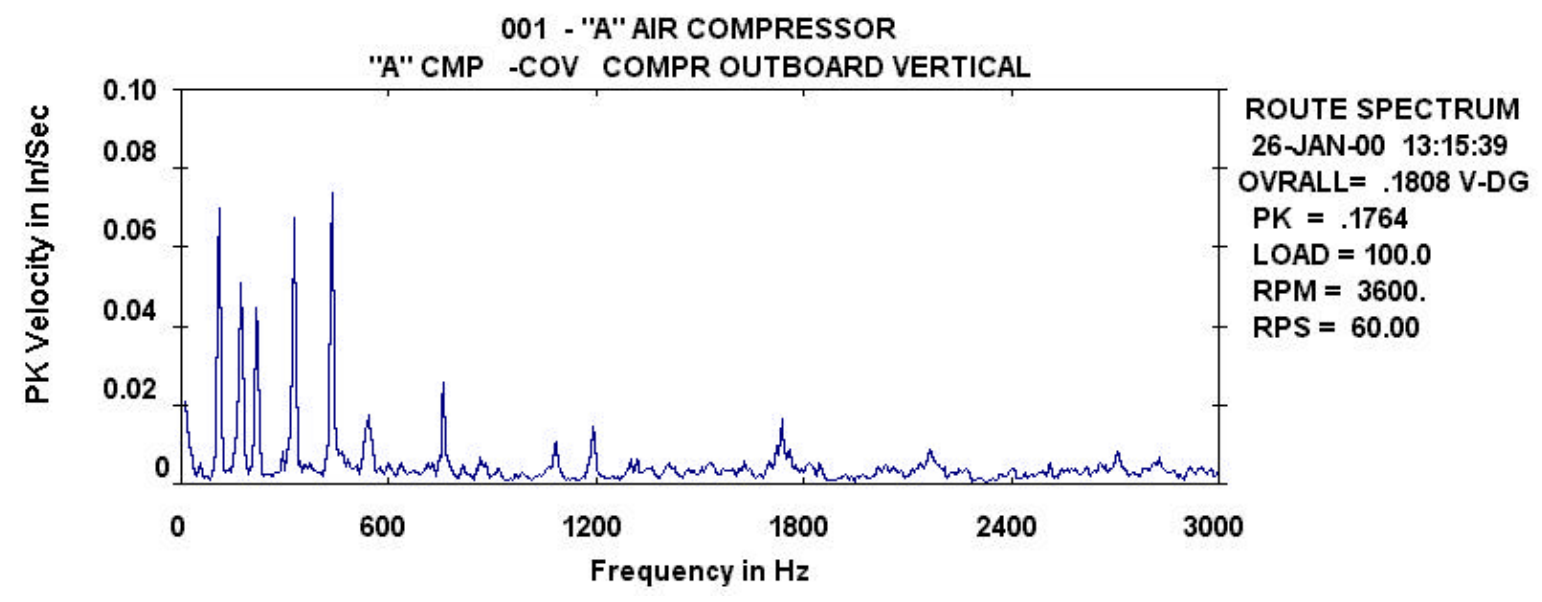

Figure A.13: Vibration Spectrum Indicating Looseness

\section{A.6.3.7 Impeller/Diffuser Interaction}

Turbulence occurs when the fluid interacts with the diffuser at less than the rated flow rate. Inappropriate clearances between the impeller and casing are the main cause for sub-synchronous and random vibrations. Further evidence of impeller/diffuser interaction is acoustic resonance in the discharge piping caused by pressure pulsations. The piping resonates at the vane-pass frequency (Figure A.14), regardless of the number of fixed vanes. 

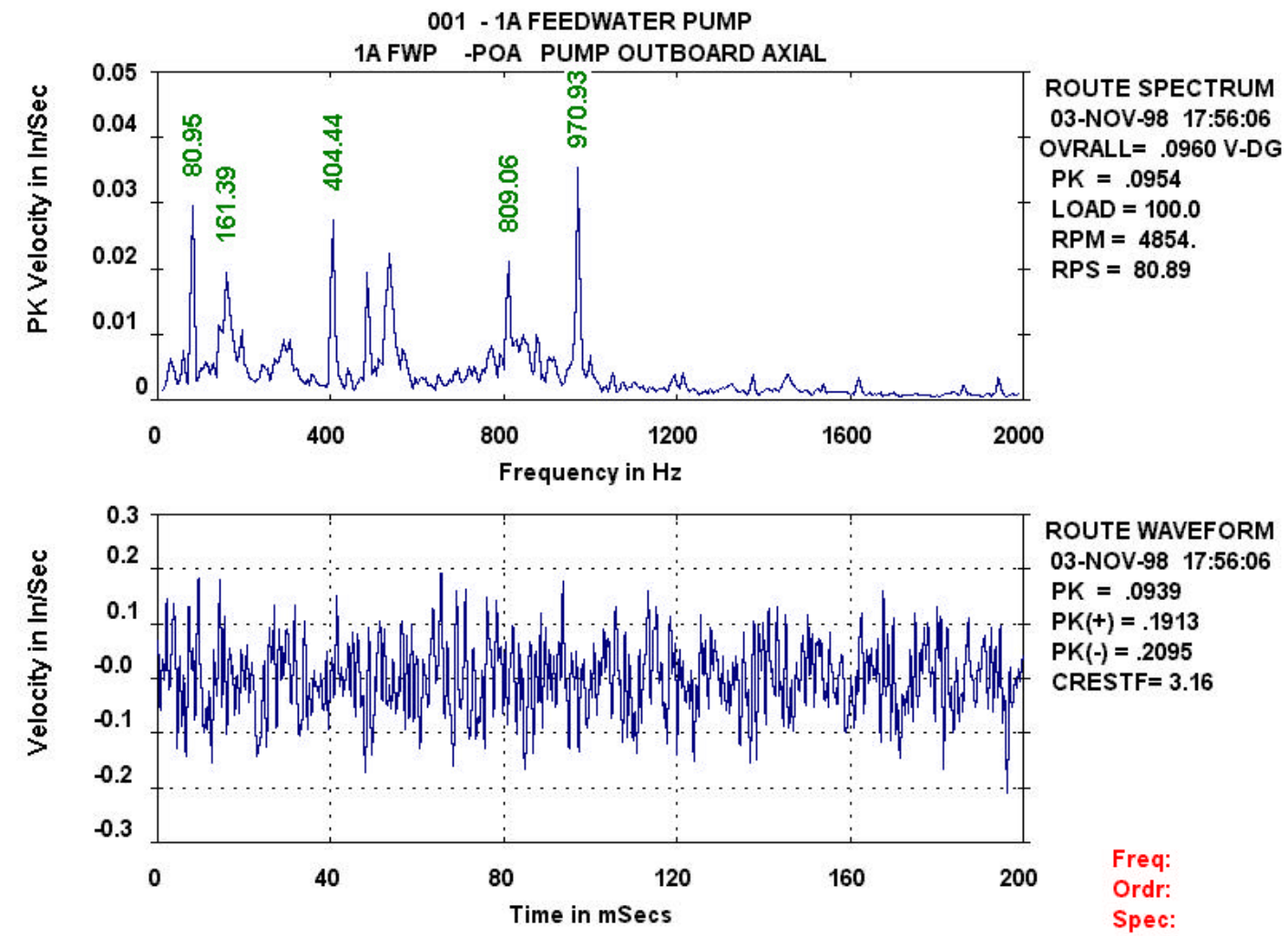

ROUTE WAVEFORM 03-NOV-98 17:56:06 $\mathrm{PK}=.0939$ $\mathrm{PK}(+)=.1913$ $\mathrm{PK}(-)=.2095$ CRESTF $=3.16$

Figure A.14: Vibration Spectrum Indicating a Vane-Pass Excitation (5X) with Sum and Difference Frequencies

\section{A.6.3.8 Pump and Motor Bearings}

Water or other contamination in the lube oil can cause bearing failures. Coupling alignment is another high contributor to bearing failures. One cause is thermal expansion of the pump as it heats up during operation. This thermal growth must be considered when the pump is aligned cold so that the hot condition alignment with the driver is correct. Most manufacturers will provide the amount of thermal growth expected. However, their calculations include assumptions that may not exist in the power plant. For example, some equipment manufacturers provide the amount of thermal growth based on the assumption that the pedestal reaches full operating temperature of the fluid. However, in the plant the pedestal may never reach this temperature since it is not insulated. In this example, the thermal growth provided would be more than the pump exhibits in the plant and the pump would be misaligned in its operating condition. The thermal growth should be measured in the power plant to verify the manufacturer recommendations.

High suction pressures in pumps can cause unusual axial thrust loads on a thrust bearing that may cause the bearing to fail. Also, some pumps have balancing lines installed to reduce the axial loads and the size of the thrust bearing. If this line becomes blocked, the thrust loads would be increased and the bearing may fail. Also, for the same reason, valves are never installed in a balancing line.

In anti-friction bearings, structural deformation due to metalto-metal contact of the balls or rollers and/or races produces a high frequency, low amplitude vibration (Figure A.15). 
The useful life of a rolling element bearing depends on two basic sets of variables:

- The application set of variables, such as load, speed, temperature, mounting, lubrication, etc.

- The configuration of the bearing itself, including the design, material and method of fabrication

Literature has shown that it is possible for a superior quality bearing to fail to achieve rated life predictions. Many such bearing failures are caused by improper mounting and lubrication, as well as contamination, high temperature and load. Manufacturing defects also play an important role in bearing failures. As many as $10 \%$ of new bearings are reported to have manufacturing defects. Bad storage practic es may also reduce the life of a bearing.

Typical defects include those found in the inner or outer race, the balls or rollers, and the retainers (sometimes referred to as ball separators or cages). Other failure causes include improper internal clearances and the imposition of either thrust or radial loads.

Most anti-friction bearing failures have characteristic frequencies that are readily discernible from the fundamental running frequency of the rotating equipment.

\section{Anti-friction Bearing Frequencies}

The predominant frequencies generated by anti-friction type bearings can be classified as:

- Ball Pass Frequency of the Outer race (BPFO) - This frequency is associated to localized defects occurring on the outer race

- Ball Pass Frequency of the Inner race (BPFI) - This frequency is associated to localized defects occurring on the inner race

- Ball Spin Frequency (BSF) - This frequency is associated to defects occurring on the ball or roller

- Fault on the Train Frequency (FTF) - This frequency occurs when there are faults on the cage of the bearing (Train of Rolling Elements)

Race Frequencies (BPFO and BPFI) are produced as the balls or rollers pass over a defect in the raceway. As a ball or roller strikes the raceway, it produces a particular response at BSF. The defect can impact both races during each revolution; thus, the response can be two times the operating speed. Rotation of the cage and ball or roller assembly or train produces FTF. Also, when particular faults occur, harmonics are generated with unique characteristic frequencies. 

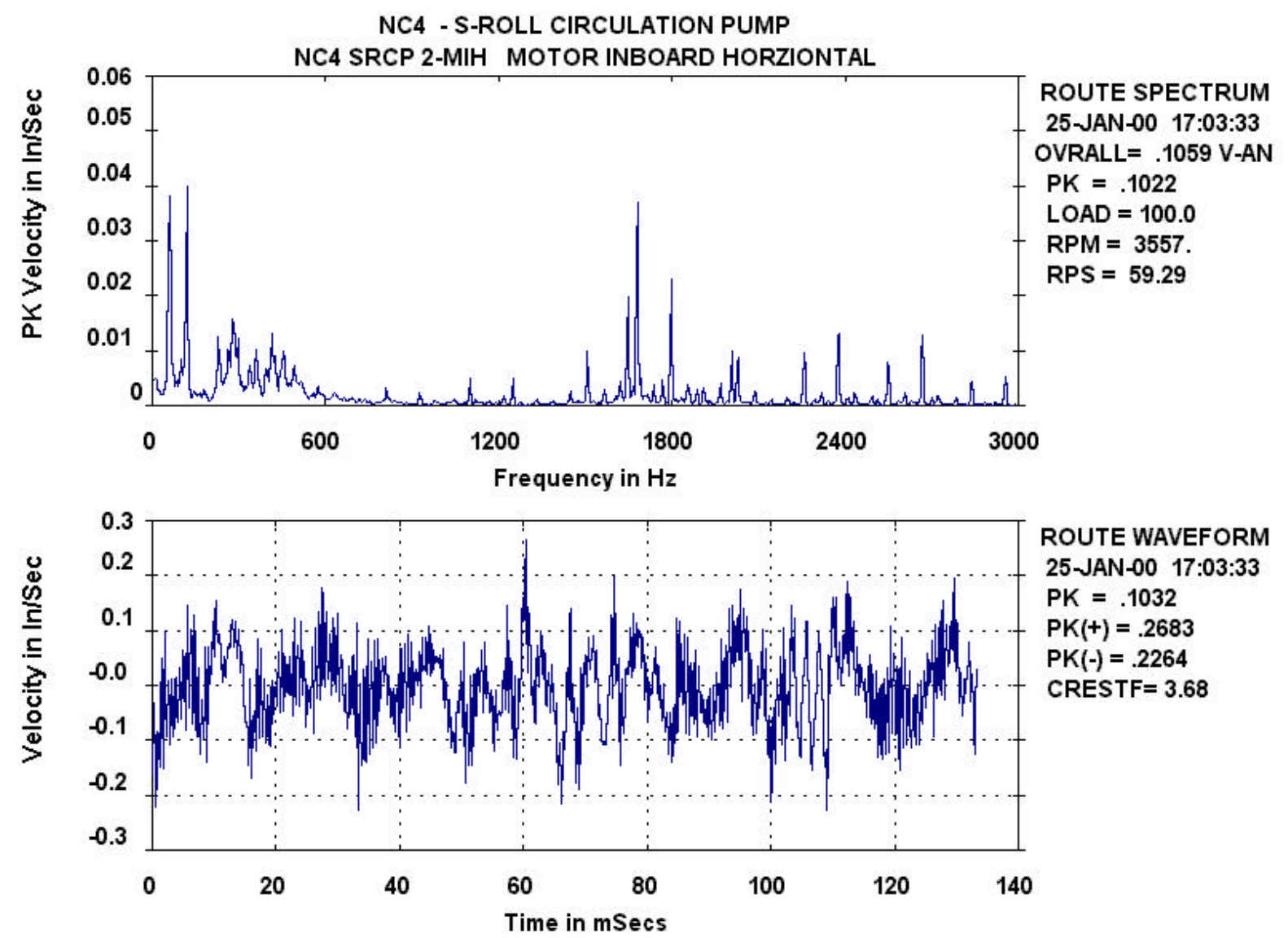

Figure A.15: Vibration Spectrum Showing a Bearing Fault (BSF)

\section{Spectrum Analysis of Rolling Element Bearings}

Formulas have been developed to calculate bearing characteristic frequencies associated with a ball or roller bearing given the following:

- $\quad$ Rotating speed

- Number of balls or rollers

- Diameter of ball or roller

- $\quad$ Pitch diameter

- Contact angle

In general, there is no set rule to determine when a critical condition has been reached. However, experience has shown that trends in the spectrum, such as the following, may indicate a developing bearing fault:

- $\quad$ Shifting from single peaks to a broad spectrum with the running speed superimposed

- An increase in amplitude

- The presence of any bearing frequency related peaks

- The appearance of single peaks at characteristic frequencies that were not present during startup 
- A combination frequency caused by the sum and/or difference of several characteristic frequencies

\section{A.6.3.9 Foundation/Structural Problems}

Foundation failure can cause erratic changes in vibration amplitude and phase, especially during transient regime operations of high-speed rotating machinery. Bases, bedplates or baseplates, machine feet, and mounting bolts are often overlooked as potential sources of vibration problems.

Soft foot is a term loosely applied to several mounting related faulty conditions. Soft foot can include structural looseness, deformation of the machine feet due to static or dynamic loading, weakness of the baseplate, and a degraded foundation. Soft foot is a structural problem, although it is frequently considered an alignment-related problem.

Attached structural components such as piping, seismic restraints and hangers might be poorly installed or adjusted, resulting in unwanted loads on the pump casing causing excessive vibration.

\section{A.6.3.10 Resonance}

Resonance occurs when a forcing frequency falls within the range of the natural frequency of the excited system (Figure A.16). Resonance conditions can amplify the vibration to dangerous levels, depending largely on the amount of damping present in the excited mode of vibration.

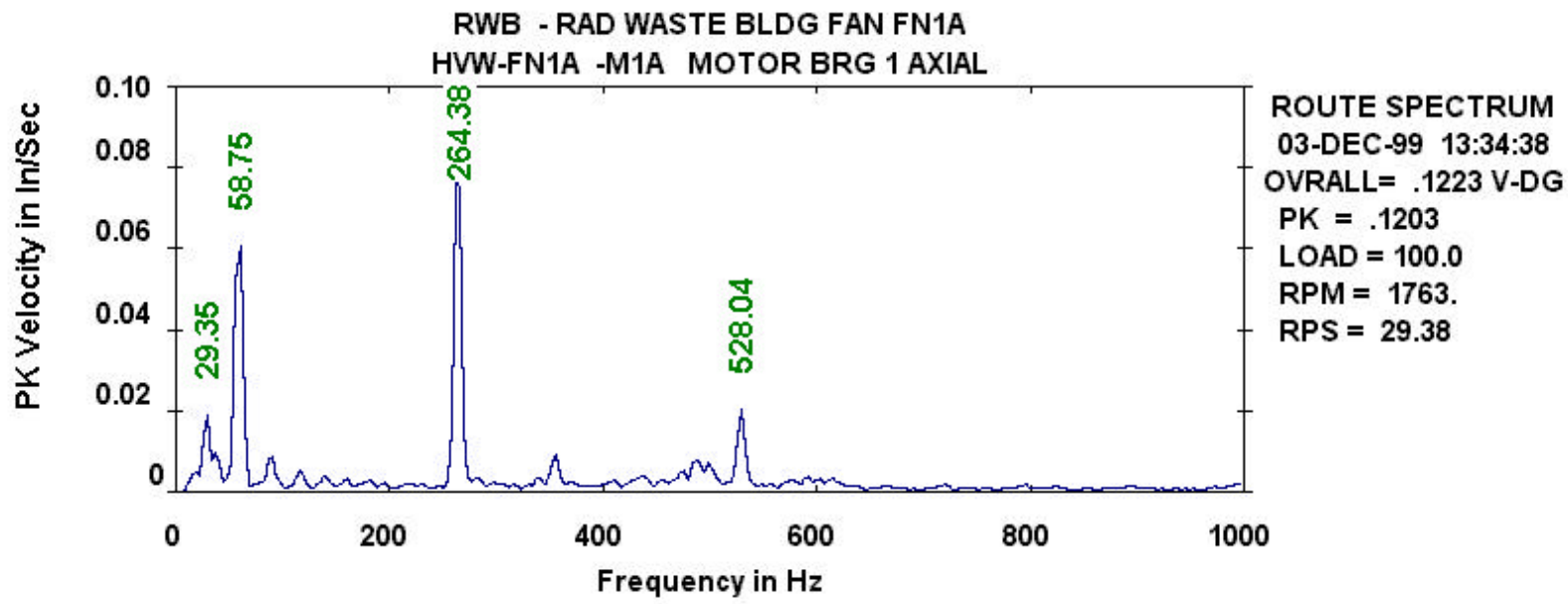

Figure A.16: Vibration Spectrum Indicating a Resonance Condition Excited by Fan $9 X$ Blade Pass In the Presence of Misalignment

Rotating machinery critical speeds present a special case of resonance conditions during run-up or coastdown operations. They involve the synchronizing the rotating frequency with the rotor natural frequency.

\section{A.6.4. Diagnostic Aids}

Years of diagnostic experience with vibration analysis has been captured and documented in table-like vibration diagnostic charts to aid professionals in their day-to-day vibration diagnostic work. Table A.10 is a typical example.

Table A.10: Diagnostic Table Using Vibration Analysis 


\begin{tabular}{|c|c|c|c|c|}
\hline Cause & Frequency & Amplitude & Phase & Notes \\
\hline Imbalance & $1 \times$ xPM & $\begin{array}{l}\text { Proportional to } \\
\text { imbalance Radial } \\
\text { - steady }\end{array}$ & $\begin{array}{l}1 \text { Reference } \\
\text { mark - steady }\end{array}$ & $\begin{array}{l}\text { Most common cause of vibration, no phase } \\
\text { change }\end{array}$ \\
\hline Eccentricity & $1 \times \mathrm{RPM}$ & Varies & $\begin{array}{l}0 \text { or } 180^{\circ} \\
\text { between } \\
\text { Horizontal } \\
\text { and Vertical }\end{array}$ & $\begin{array}{l}\text { Balancing may reduce vibration in one } \\
\text { direction but increase it in the other }\end{array}$ \\
\hline Bent shaft & $\begin{array}{l}(1 \text { to } 2) \\
\text { RPM }\end{array}$ & Axial - high & $\begin{array}{l}180^{\circ} \text { out of } \\
\text { phase axially }\end{array}$ & $\begin{array}{l}\text { Same radial phase on both bearings Orbit } \\
\text { and phase are good parameters to monitor }\end{array}$ \\
\hline $\begin{array}{l}\text { Thermal } \\
\text { bow }\end{array}$ & $1 \mathrm{x}$ RPM & Varies & $\begin{array}{l}1 \text { Reference } \\
\text { mark - steady }\end{array}$ & $\begin{array}{l}\text { Increasing vibration during load variations } \\
\text { and startup from a cold condition }\end{array}$ \\
\hline $\begin{array}{c}\text { Misalign- } \\
\text { ment }\end{array}$ & $\begin{array}{l}(1,2,3, \ldots) \times \\
\text { RPM }\end{array}$ & Axial- high & $\begin{array}{l}1,2 \text { or } 3 \\
\text { reference } \\
\text { marks }\end{array}$ & $\begin{array}{l}\text { Axial amplitude may be twice the vertical or } \\
\text { horizontal. }\end{array}$ \\
\hline Looseness & $\begin{array}{l}(1,1.5,2,2.5 \\
3, \ldots) \times \text { RPM }\end{array}$ & $\begin{array}{l}\text { Proportional to } \\
\text { load }\end{array}$ & $\begin{array}{l}2 \text { reference } \\
\text { marks, } \\
\text { slightly } \\
\text { erratic }\end{array}$ & $\begin{array}{l}\text { Frequently coupled with misalignment } \\
\text { Strobe may help. Amplitude depends on } \\
\text { load }\end{array}$ \\
\hline Soft foot & 1 to $2 \times$ RPM & $\begin{array}{l}\text { Proportional to } \\
\text { load }\end{array}$ & & Check mountings for variations in amplitude \\
\hline Electrical & $\begin{array}{l}1 \times \mathrm{RPM} \text { or } 1 \\
\text { to } 2 \times \mathrm{x} \text { line } \\
\text { frequency }\end{array}$ & Large & Erratic & $\begin{array}{l}\text { When power is turned off vibrations } \\
\text { disappears instantly }\end{array}$ \\
\hline $\begin{array}{l}\text { Sleeve } \\
\text { bearings } \\
\text { wear and } \\
\text { clearance }\end{array}$ & $\begin{array}{l}(1,2,3,4, \ldots) \\
\text { x RPM }\end{array}$ & $\begin{array}{l}\text { May be higher in } \\
\text { Vertical than } \\
\text { Horizontal }\end{array}$ & Erratic & $\begin{array}{l}\text { Compare shaft to bearing displacement } \\
\text { readings. Oil analysis best monitor for wear }\end{array}$ \\
\hline Oil whip & $.5 \times \mathrm{RPM}$ & $\begin{array}{l}\text { Radial } \\
\text { unsteady, } \\
\text { excessive }\end{array}$ & Erratic & $\begin{array}{l}\text { Frequency is near one-half running speed } \\
\text { (machine speed is nearly } 2 x \text { critical speed) } \\
\text { Oil temperature is a good indicator }\end{array}$ \\
\hline Oil whirl & $\begin{array}{l}\text { (.42 to .48) } \mathrm{x} \\
\text { RPM }\end{array}$ & $\begin{array}{l}\text { Radial } \\
\text { unsteady, } \\
\text { sometimes } \\
\text { severe }\end{array}$ & Erratic & $\begin{array}{l}\text { Caused by unloading of bearing. Tangential } \\
\text { destabilizing force due to lube film in the } \\
\text { direction of rotation adds energy to vibration }\end{array}$ \\
\hline
\end{tabular}


Table A.10: (Continued) Diagnostic Table Using Vibration Analysis

\begin{tabular}{|c|c|c|c|c|}
\hline \multirow{2}{*}{$\begin{array}{c}\begin{array}{c}\text { Anti-friction } \\
\text { bearings }\end{array} \\
\text { Rubbing }\end{array}$} & \multirow{2}{*}{$\begin{array}{l}\text { BPFI, BPFO, } \\
\text { BSF, FTF } \\
\text { and } \\
\text { Harmonics } \\
(0-0.5) x, 1 x, \\
\text { and higher } \\
\text { harmonics } \\
\end{array}$} & Radial - low & Erratic & \multirow[t]{2}{*}{ Use velocity, acceleration or spike energy } \\
\hline & & Erratic & atic & \\
\hline Gears & \begin{tabular}{l|l} 
GMF $=Z$ \\
RPM
\end{tabular} & Radial - low & Erratic & $\begin{array}{l}\text { Use velocity or acceleration. Tooth wear is } \\
\text { better indicated by side-bands around GMF } \\
\text { and excitation of tooth natural frequency. } \\
\text { Higher tooth load will increase amplitude at } \\
\text { GMF. Backlash is characterized by } \\
\text { decreasing amplitude at GMF when load is } \\
\text { increased. Gear misalignment shows with } \\
\text { higher } 2 x \text { and } 3 x \text { GMF. A cracked or broken } \\
\text { tooth is best seen on the time signal. A } \\
\text { hunting tooth problem shows at very low } \\
\text { frequencies }\end{array}$ \\
\hline Foundation & Unsteady & Erratic & $\begin{array}{l}\text { Unstable } \\
\text { reference }\end{array}$ & Strobe may help \\
\hline Resonance & $\begin{array}{l}\text { System } \\
\text { specific }\end{array}$ & High & Erratic & $\begin{array}{l}\text { Increased levels at resonant frequency. } \\
\text { Often appears on old machines pedestals }\end{array}$ \\
\hline Cracks & 1x, 2x RPM, & $\begin{array}{l}\text { Variable } \text { during } \\
\text { transients. Drop } \\
\text { in } \quad \text { higher } \\
\text { harmonics }\end{array}$ & Phase shift & $\begin{array}{l}\text { Increased levels at resonant frequency } \\
\text { Phase is a good indicator. 2x RPM } \\
\text { excitation of critical speed during coast } \\
\text { down. }\end{array}$ \\
\hline $\begin{array}{l}\text { Hydraulic } \\
\text { Forces }\end{array}$ & $\begin{array}{l}\text { Vane Pass = } \\
\mathrm{Z} \times \mathrm{RPM} \text { and } \\
\text { harmonics }\end{array}$ & $\begin{array}{l}\text { High radial and } \\
\text { axial }\end{array}$ & NA & $\begin{array}{l}\text { Use velocity or acceleration. Due to uneven } \\
\text { internal gap between rotating vanes and } \\
\text { diffuser. May excite natural frequencies. } \\
\text { Flow obstructions are common causes. }\end{array}$ \\
\hline Cavitation & $\begin{array}{l}\text { Random high } \\
\text { frequency }+ \\
\text { Vane Pass }\end{array}$ & $\begin{array}{l}\text { High radial and } \\
\text { axial }\end{array}$ & NA & $\begin{array}{l}\text { Due mainly to insufficient suction pressure } \\
\text { and the presence of vapor and air in the } \\
\text { liquid. }\end{array}$ \\
\hline
\end{tabular}

\section{A.6.4 Acceptance Criteria}

Acceptance criteria are necessary to translate a measurement into a mechanical condition. There are two types of guidelines:

- Physical constraints, such as clearances supplied by the original equipment manufacturer (OEM)

- Established limits, determined from experience and dependent on the type of machine, measurement location, etc.

Standards for vibration limits are published by industry groups, and by national and international standards organizations including:

- the American Petroleum Institute (API),

- the American Gear Manufacturer Association (AGMA),

- the National Electrical Manufacturers Association (NEMA), the American National Standards Institute (ANSI), 
- $\quad$ and the International Standards Organization (ISO)

The rotating equipment OEM and vibration instrumentation vendors are good sources of vibration limits.

\section{A.6.4.1 OEM Limits}

Radial and axial clearances between rotating and stationary surfaces are important physical parameters. They are usually expressed as "maximum allowable," and should not be exceeded. Other types of OEM criteria may include limits on pressure, balance piston differential pressure, speed, temperature, etc.

\section{A.6.4.2 Published Severity Criteria}

Vibration limits are also established per the following:

- Independent testing organizations

- Severity charts from PdMA vendors

- Inspection results

- OEM recommendations

\section{A.6.4.3 Casing Vibration}

Limits for casing vibration for typical machines are based on measurements made under similar operating conditions (measurement type, location, etc.) in a controlled environment. ISO standards 2372 and 3945 are widely used.

- ISO 2372 is a general standard and is used primarily for shop acceptance testing.

- ISO 3945 is a more specific standard and is designed for evaluating the vibration of larger machinery in the field

Both standards contain criteria for judging machine condition from casing velocity measured at specific bearing locations. These standards apply to machines operating at 10 to $200 \mathrm{~Hz}$ (600 to $12,000 \mathrm{rpm}$ ). Both standards require a true root mean square (RMS) amplitude measurement, make a distinction between flexibly supported and rigidly supported machines, and recognize that a support system may be rigid in one direction and flexible in the other. Both standards are now withdrawn and replaced by a more current standard (ISO 10816).

There is generally good agreement on the various limits among experts. In general, a level below 0.1 $\mathrm{in} / \mathrm{sec}$ peak is considered acceptable, and a level above $0.6 \mathrm{in} / \mathrm{sec}$ peak is considered unacceptable. The advantage of velocity measurements, which are limited to casings, is that frequency is included in the measurement.

Acceleration measurements are not generally used for trending, but rather for diagnostic work. Acceleration signals accentuate the low amplitude, high frequency signals for diagnostics. 
To monitor conditions for operating gears, the AGMA specification recommends a conservative guideline limit of a constant $10 \mathrm{Gs}$ of casing acceleration above $600 \mathrm{~Hz}$.

Table A.11 summarizes the recommended limits for overall unfiltered casing velocities. Table A.12 gives the vibration severity per ISO criteria.

Table A.11: Recommended Limits for Overall Casing Velocity

\begin{tabular}{||l|l|}
\hline \multicolumn{1}{|c||}{ Peak Velocity } & \multicolumn{1}{c|}{ Classification } \\
\hline \hline Less than $0.15 \mathrm{ips}(3.8 \mathrm{~mm} / \mathrm{sec})$ & Acceptable \\
\hline 0.15 to $0.25 \mathrm{ips}(3.8-6.3 \mathrm{~mm} / \mathrm{sec})$ & Tolerable \\
\hline 0.25 to $0.4 \mathrm{ips}(6.3-10 \mathrm{~mm} / \mathrm{sec})$ & $\begin{array}{l}\text { May be tolerable for moderate periods of time } \\
\text { Monitor closely to warn of changes }\end{array}$ \\
\hline 0.4 to 0.6 ips $(10-15 \mathrm{~mm} / \mathrm{sec})$ & $\begin{array}{l}\text { Impending failure; watch closely for changes and } \\
\text { be prepared to shut down for repairs }\end{array}$ \\
\hline Above 0.6 ips $(15 \mathrm{~mm} / \mathrm{sec})$ & Danger of immediate failure \\
\hline
\end{tabular}


Table A.12: Vibration Severity Criteria per ISO 2372 and 3945

\begin{tabular}{|c|c|c|c|c|c|}
\hline \multirow{2}{*}{\multicolumn{2}{|c|}{$\begin{array}{c}\text { Ranges of Radial Vibration } \\
\text { Severity } \\
\text { RMS Velocity measured } \\
\text { in the } 10-1000 \mathrm{~Hz} \text { frequency band } \\
\end{array}$}} & \multicolumn{4}{|c|}{ Quality Judgment for Separate Classes of Machines } \\
\hline & & \multirow{2}{*}{ Class I } & \multirow{2}{*}{ Class II } & \multirow{2}{*}{ Class III } & \multirow{2}{*}{ Class IV } \\
\hline $\mathrm{mm} / \mathrm{sec}$ & in $/ \mathrm{sec}$ & & & & \\
\hline 0.71 & 0.028 & A & \multirow{2}{*}{ A } & \multirow{3}{*}{ A } & \multirow{4}{*}{ A } \\
\hline 1.12 & 0.044 & \multirow{2}{*}{ B } & & & \\
\hline 1.8 & 0.071 & & \multirow{2}{*}{ B } & & \\
\hline 2.8 & 0.11 & \multirow{2}{*}{ C } & & \multirow{2}{*}{ B } & \\
\hline 4.5 & 0.18 & & \multirow[t]{2}{*}{ C } & & \multirow[t]{2}{*}{ B } \\
\hline 7.1 & 0.28 & & & \multirow{2}{*}{ C } & \\
\hline 11.2 & 0.44 & & \multirow{3}{*}{ D } & & \multirow{2}{*}{ C } \\
\hline 18 & 0.71 & & & \multirow{2}{*}{ D } & \\
\hline 45 & 1.8 & & & & D \\
\hline \multicolumn{6}{|c|}{ MACHINE CLASSES } \\
\hline \multicolumn{6}{|c|}{$\begin{array}{l}\text { CLASS I Small Machines to } 20 \mathrm{HP} \\
\text { CLASS II Medium Machines } 20 \text { to } 100 \mathrm{HP} \\
\text { CLASS III Large Machines } 10-200 \mathrm{rev} / \mathrm{sec}, 400 \mathrm{HP} \text { and Larger Mounted on Rigid } \\
\text { Supports } \\
\text { CLASS IV Large Machines } 10-200 \mathrm{rev} / \mathrm{sec}, 400 \mathrm{HP} \text { and Larger Mounted on Flexible } \\
\text { Supports }\end{array}$} \\
\hline $\begin{array}{l}\text { A = GOOD } \\
\text { UNACCEPT }\end{array}$ & \multicolumn{2}{|c|}{ B = SATISFACTORY } & \multicolumn{3}{|c|}{$\mathrm{C}=$ UNSATISFACTORY } \\
\hline
\end{tabular}

\section{A.6.5 Accelerated Test Plan}

The accelerated testing will involve creating mechanical conditions of imbalance and misalignment that would lead to unacceptable vibration levels based on above criteria tables. 
Initially (Test \#1), the machine will be aligned to acceptable levels then balanced to (CLASS I per Table A.12). The second step will be to determine the amount of imbalance in oz-in necessary to bring the machine to a degraded level based on bearing casing vibration (Test \#10). Test \# 2 to Test \# 9 will be an approximate succession of trends from motor good operating condition to motor degraded condition based on bearing vibration. An imbalance condition will be created by adding calculated weights at a specific machine location. Resulting vibration levels will be monitored. Imbalance weights will be interpolations based on the force-response linear relationship. Angular misalignment is easier to control than parallel misalignment and will be implemented during these tests. An acceptable shaft alignment for the system will be determined (Test \#1). Then, an unacceptable misalignment (maximum degraded condition) for the pump/motor will be determined (Test \#10). The shaft angle (offset) will be incremented from alignment condition (Test \#1) to misalignment condition (Test \# 10), to produce eight more tests (from \#2 to \#9). Overall vibration levels and non-synchronous harmonic components of the vibration signal will be monitored for alignment condition.

The following table summarizes the various tests that would be conducted along with the necessary vibration monitoring data (Trend Plots and Spectra).

Table A.13: Test Plan

\begin{tabular}{|c|c|c|c|c|c|c|c|c|c|c|}
\hline Test \# & 1 & 2 & 3 & 4 & 5 & 6 & 7 & 8 & 9 & 10 \\
\hline Imbalance (oz-in) & 0.0 & & & & & & & & & \\
\hline Vibration (in/sec) & & & & & & & & & & \\
\hline Acceptance Class & A & & & & & & & & & D \\
\hline Emax File (CD) & 001 & 002 & 003 & 004 & 005 & 006 & 007 & 008 & 009 & 010 \\
\hline Misalignment (deg) & 0.0 & & & & & & & & & \\
\hline Vibration (in/sec) & & & & & & & & & & \\
\hline Acceptance Class & A & & & & & & & & & D \\
\hline Vibration Spectra \# & & & & & & & & & & \\
\hline Emax File (CD) & 101 & 102 & 103 & 104 & 105 & 106 & 107 & 108 & 109 & 110 \\
\hline
\end{tabular}




\section{A.7 Detailed Specifications of the Data Acquisition Equipment}

Emax is a dynamic tester (see Figure A.17) that utilizes state of the art technology to collect data while the motor is operating. This information can be used to evaluate incoming power quality and motor efficiency, as well as rotor, stator, air gap and power circuit conditions. The data can be analyzed immediately or recalled later for trend analysis.

Static testing can also be done with Emax providing a detailed analysis of motor and circuit condition. This feature allows diagnostic and evaluation of all five of the motor's fault zones including the power circuit, insulation, stator, rotor and air gap. Emax allows testing of all major types of motors: induction, synchronous, wound rotor, DC, servo and spindle.

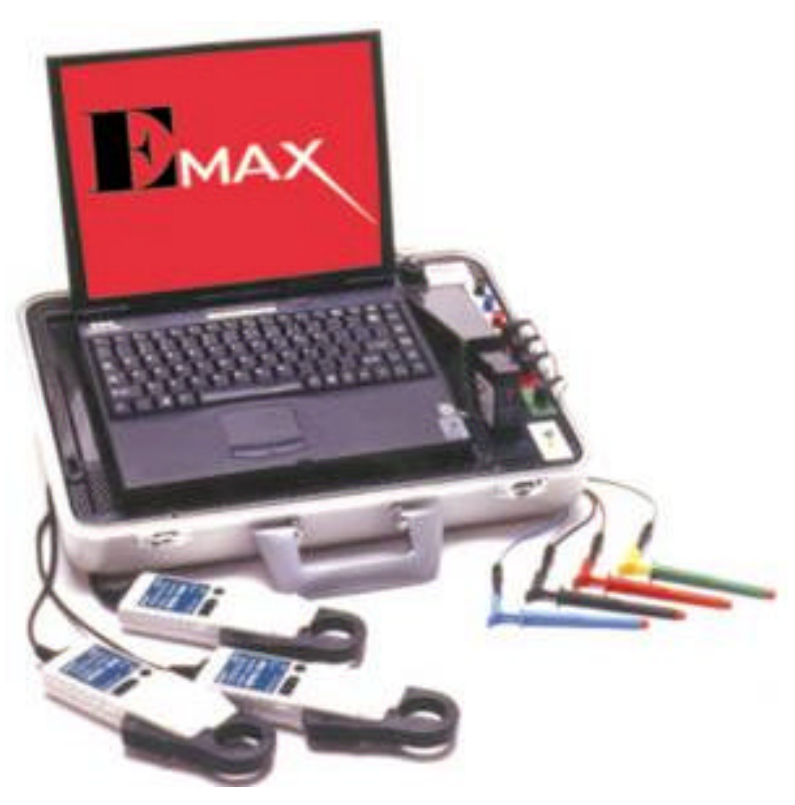

Figure A.17: Motor Testing Instrument - Emax (Courtesy PdMA)

The Emax system is portable (13" x 18" x 3.5 " in size), lightweight (17 lbs.), and operates in typical plant conditions $\left(5-35^{\circ} \mathrm{C}\right.$ at $20-80 \%$ humidity). The Emax system simultaneously collects all three phases of current and voltage to provide spectral and digital data in the areas of:

- Power

- Motor Current Signature Analysis

- Efficiency

- Crest factor

- Total Harmonic Distortion (THD)

- Sequence Data

- Power Factor

- Impedance 
- Current

- Voltage

\section{A.8 Test Data for Subsequent Analysis by ORNL}

The specific data that will be acquired during these tests involves six channels of data: three voltages and three currents from each from each of the three phases for the pump motor, as shown in the Figure A.18.

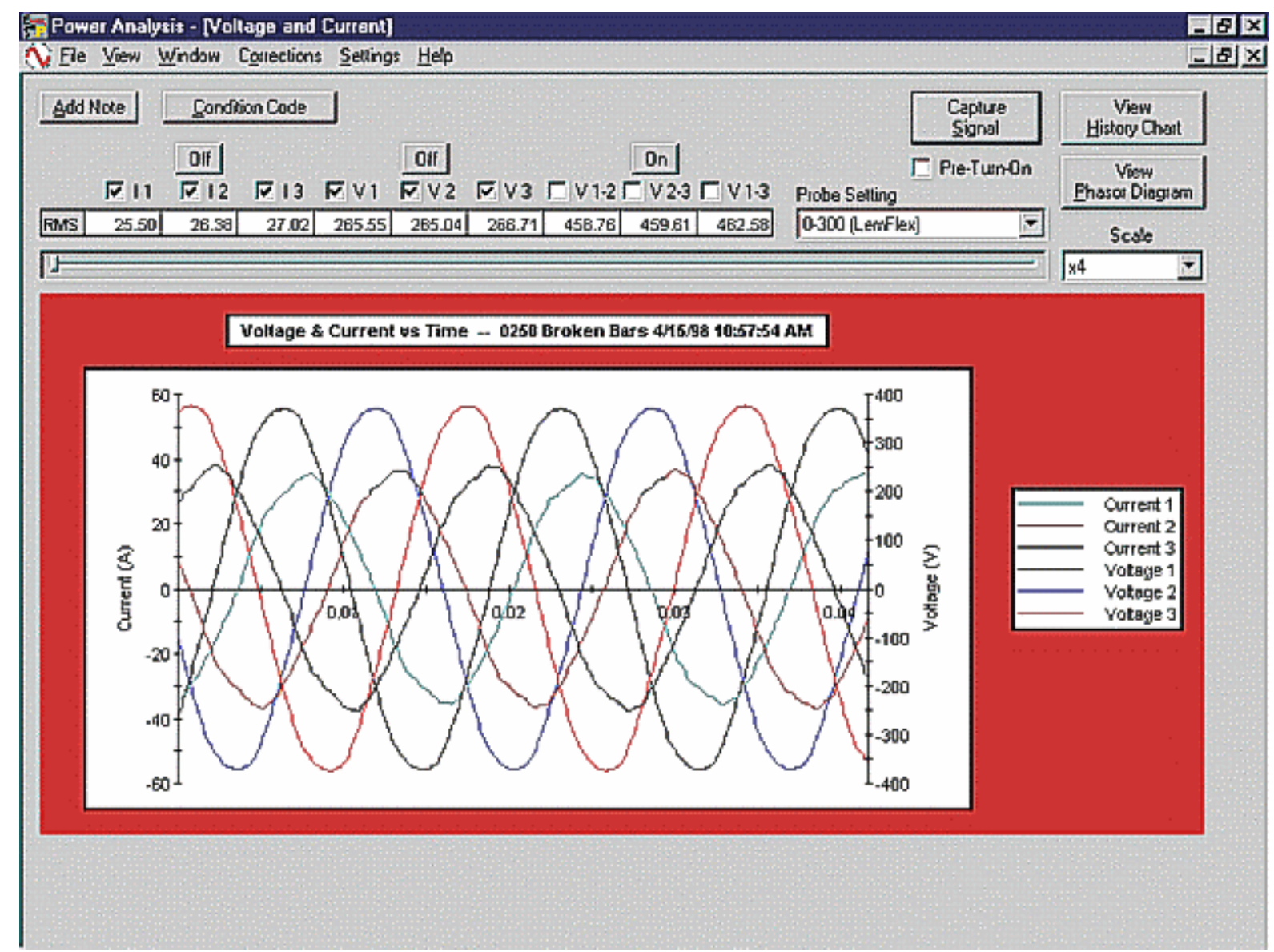

Figure A.18: Motor Signatures (Courtesy PdMA) 
The Emax system is battery powered and uses a PCMIA card to measure and acquire data the three-phase voltages and currents, as shown summarized below.

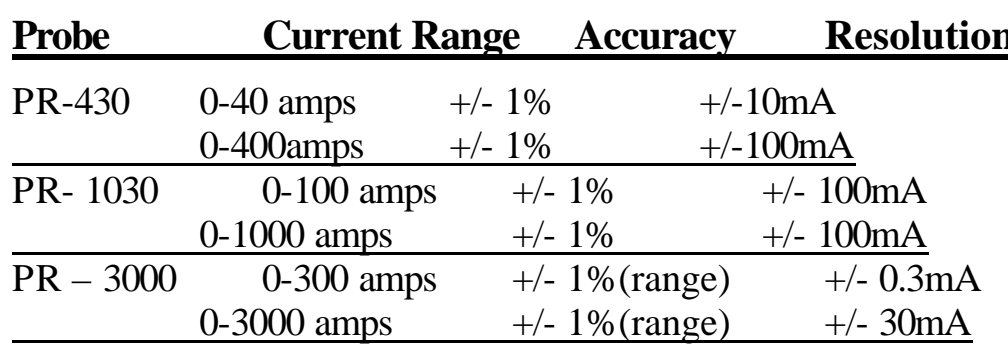

Location Voltage Range Accuracy

Direct Line $\quad 0-600 \mathrm{v} \quad+/-.6 \%$

Secondary No Limit $\quad+/-.6 \%+$ PT error

Test Sampling Rate Max Frequency Resolution

High Resolution $480 / \mathrm{sec} \quad 0-240 \mathrm{~Hz} \quad 8000$ lines

Low Resolution $960 / \mathrm{sec} \quad 0-480 \mathrm{~Hz} \quad 8000$ lines

Eccentricity $\quad 12,288 / \mathrm{sec} \quad 0-6000 \mathrm{~Hz} \quad 8000$ lines

PdMA Corp. (5909-C Hampton Oaks Parkway, Tampa, FL 33610 www.pdma.com) provided DE\&S with a modified software package for the Emax system to do these experiments. This modified system can measure and acquire six simultaneous channels at $12,288 \mathrm{~Hz}$ per channel over at total time of 85.3 seconds for a total of 1048576 samples for each channel. The test capabilities under the Advanced Insulation System include AC standard, DC standard, rotor influence check, polarization index, dielectric absorption ratio, step voltage tests. Acquisition capabilities are summarized in the Table below. 


\begin{tabular}{|c|c|c|c|c|c|}
\hline RANGE & RESOLUTION & \begin{tabular}{|c|} 
ACCURAC \\
$Y$
\end{tabular} & RANGE & RESOLUTION & $\begin{array}{c}\text { ACCURAC } \\
Y\end{array}$ \\
\hline \multicolumn{3}{|c|}{ CAPACITANCE } & \multicolumn{3}{|c|}{ GROUND RESISTANCE (Standard Test) } \\
\hline \multirow[t]{4}{*}{$1000-999,750$} & \multirow[t]{4}{*}{$250 \mathrm{pF}$} & \multirow[t]{4}{*}{$+/-1 \%$} & 0 - $100 \mathrm{Mohm}$ & \multirow[t]{4}{*}{$.1 \mathrm{Mohm}$} & $+/-1 \%$ \\
\hline & & & $100-500 \mathrm{Mohm}$ & & $+/-2.5 \%$ \\
\hline & & & 500 - 1000 Mohm & & $+/-5 \%$ \\
\hline & & & 1000 - 2000 Mohm & & $+/-5 \%$ \\
\hline \multicolumn{3}{|c|}{ DC RESISTANCE } & \multicolumn{3}{|c|}{ INDUCTANCE (300 Hz) } \\
\hline $0-.018 \mathrm{Ohm}$ & $.00001 \mathrm{Ohm}$ & \multirow[t]{7}{*}{$+/-1 \%$} & $100-250 \mathrm{mH}$ & $.1 \mathrm{mH}$ & $+/-1 \%$ \\
\hline $.018-1.8 \mathrm{Ohm}$ & $.0005 \mathrm{Ohm}$ & & $250-500 \mathrm{mH}$ & $.5 \mathrm{mH}$ & \\
\hline $1.8-50 \mathrm{Ohm}$ & $.005 \mathrm{Ohm}$ & & $500-1000 \mathrm{mH}$ & $1 \mathrm{mH}$ & \\
\hline $50-1000$ Ohm & $.01 \mathrm{Ohm}$ & & $1000-1500 \mathrm{mH}$ & $2.5 \mathrm{mH}$ & $+/-2 \%$ \\
\hline \multirow[t]{3}{*}{$1000-2000$ Ohm } & \multirow[t]{3}{*}{$.1 \mathrm{Ohm}$} & & $1500-2500 \mathrm{mH}$ & $5 \mathrm{mH}$ & \\
\hline & & & $2500-3500 \mathrm{mH}$ & $10 \mathrm{mH}$ & \multirow[t]{2}{*}{$+/-5 \%$} \\
\hline & & & $3500-5000 \mathrm{mH}$ & $25 \mathrm{mH}$ & \\
\hline \multicolumn{3}{|c|}{ GROUND RESISTANCE (All Tests)** } & \multicolumn{3}{|c|}{ INDUCTANCE $(1200 \mathrm{~Hz})$} \\
\hline \multirow[t]{4}{*}{$40 \mathrm{~K}-200 \mathrm{Gohm}$} & \multirow[t]{4}{*}{$5 \%$ of range } & \multirow[t]{4}{*}{$+/-1 \%$} & $0-10 \mathrm{mH}$ & $.005 \mathrm{mH}$ & \multirow[t]{10}{*}{$+/-1 \%$} \\
\hline & & & $10-50 \mathrm{mH}$ & $.01 \mathrm{mH}$ & \\
\hline & & & $50-100 \mathrm{mH}$ & $.05 \mathrm{mH}$ & \\
\hline & & & \multirow[t]{7}{*}{$100-250 \mathrm{mH}$} & \multirow[t]{7}{*}{$.1 \mathrm{mH}$} & \\
\hline \multicolumn{3}{|c|}{ GROUND RESISTANCE (PI/DA Testing) } & & & \\
\hline $0-100 \mathrm{Mohm}$ & \begin{tabular}{r|}
$1 \mathrm{Mohm}$ \\
\end{tabular} & $+/-5 \%$ & & & \\
\hline $100-500$ Mohm & 1 Mohm & $+/-5 \%$ & & & \\
\hline $500-1000 \mathrm{Mohm}$ & $10 \mathrm{Mohm}$ & $+/-10 \%$ & & & \\
\hline 1000 - $2000 \mathrm{Mohm}$ & $100 \mathrm{Mohm}$ & $+/-10 \%$ & & & \\
\hline $2000-3500$ Mohm & 100 Mohm & $+/-20 \%$ & & & \\
\hline
\end{tabular}




\section{References}

[1.] "Nuclear Power Reliability Data System”, INPO - EPIX (ex. NPRDS).

[2.] M. Subudhi,W.E. Gunther, and J.H. Taylor, "Improving Motor Reliability in Nuclear Power Plants. V.1: Performance Evaluation and Maintenance Practices", NUREG CR-4939, 1987.

[3.] "Electric Motor Predictive and Preventive Maintenance 1992

NMAC report NP-7502, 
ORNL/TM-2001/195

\title{
INTERNAL DISTRIBUTION
}

\author{
1. J. Barhen \\ 2. E. C. Fox \\ 3. D. M. Hetrick \\ 4-7. L. M. Hively \\ 9. R. F. Holdaway \\ 10. J. K. Mattingly \\ 11. G. T. Mays \\ 12. G. E. Michaels \\ 13. D. L. Moses \\ 14. V. A. Protopopescu \\ 15. B. A. Worley \\ 16. T. Zacharia \\ 17. Central Research Library \\ 18. ORNL Laboratory Records - RC \\ 19-20. ORNL Laboratory Records - OSTI
}

\section{EXTERNAL DISTRIBUTION}

21. M. Maghraoui, Duke Engineering and Services Inc., 400 Tryon Street, Charlotte, NC 28105

22. S. R. Martin, DOE, Oak Ridge Operations, P. O. Box 2008, Oak Ridge, TN 37831-6269

23. T. P. Miller, U. S. Department of Energy, ND-20, 19901 Germantown Road, Germantown, MD, 20874-1290

24. F. A. Ross, U. S. Department of Energy, NE-20, 19901 Germantown Road, Germantown, MD, 20874-1290

25. J. W. Spencer, Duke Engineering and Services, Inc., 499 Tryon Street, Charlotte, NC 28105

26. P. Wong, Oakland Operations Office, 1201 Clay Street, Oakland, CA 94612-5208 